\title{
II. Von der DJV zum MdJ: Personelle und strukturelle Veränderungen (1948-1953)
}

\section{Das Ausmaß der Abhängigkeit von SMAD/SKK und SED}

Die SMAD-Rechtsabteilung blieb auch nach der Zäsur von 1948 als die für die DJV zuständige Fachabteilung der Militärverwaltung bestehen, und ohne ihre Eingriffe und ihre Rückendeckung wären die weitgehenden Umstellungen im Justizwesen nicht denkbar gewesen. Ihr Leiter Karassjow geriet seit 1947 jedoch zunehmend unter Beschuß. Anfang 1948 strebten Semjonow und Andrej Andrejewitsch Smirnow vom sowjetischen Außenministerium die Entlassung des Abteilungsleiters an, dem sie geringe fachliche und politische Fähigkeiten attestierten. Im Juni 1948 wurde ihm im Zuge einer Kaderüberprüfung zudem Führungsschwäche und Prinzipienlosigkeit vorgeworfen'. Trotz Bemühungen des Justizministeriums, ihn zu ersetzen, wurde erst Anfang 1949 ein Nachfolger ernannt, der im Juli in Berlin-Karlshorst eintraf. An Karassjows Stelle trat der 34jährige Oberstleutnant Fjodor Dmitrijewitsch Titow, der seit 1943 im sowjetischen Justizministerium gearbeitet hatte und 1946 zum Abteilungsleiter befördert worden war ${ }^{2}$. Eine institutionelle Änderung ergab sich aus der Gründung der DDR im Oktober 1949. Denn mit der Gewährung begrenzter Souveränität an den neuen deutschen Teilstaat war die Aufrechterhaltung einer Militärverwaltung nicht mehr vereinbar. Der Oberste Chef der SMAD, General Tschujkow, verkündete am 10. Oktober 1949 Ministerpräsident Otto Grotewohl und Volkskammerpräsident Johannes Dieckmann die Entscheidung der sowjetischen Regierung, der Provisorischen Regierung der DDR „die Verwaltungsfunktionen zu übergeben, die bis-

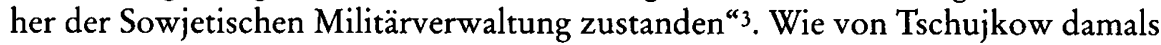
bereits angekündigt, trat an die Stelle der SMAD mit Regierungsbeschluß vom 5. November 1949 die Sowjetische Kontrollkommission in Deutschland (SKK)4. Ihre gegenüber der SMAD eingeschränkten Funktionen führten zu einem erheblichen Personalabbau und einer Straffung der inneren Organisation. Justizfragen wurden nun in der Abteilung für Verwaltungsfragen behandelt. Diese verfügte über 73 Stellen und war aus dem Zusammenschluß der SMAD-Verwaltung für Innere Angelegenheiten und den Abteilungen für Gesundheitswesen, für Rechtswesen sowie für Zivilverwaltung hervorgegangen. Sie unterstand zunächst dem

1 Vgl. Bordjugov, Rechtsabteilung, S. $64 \mathrm{f}$., der aber irrtümlicherweise behauptet, Karassjow sei bis Oktober 1949 Leiter der Rechtsabteilung geblieben.

2 Vgl. Titow, Sowjetische Juristen. Noch am 5.7. 1949 hatte Fechner ein Schreiben an Karassjow übersandt, BAB, DP1 SE Nr. 3360, Bl. 603.

3 Zit. nach DzD II/2, S. 178.

4 Siehe Scherstjanoi, Einleitung, in: SKK-Statut, S. 11. 
ehemaligen stellvertretenden SMAD-Chef für Zivilverwaltung, Oberst Alexandr Fjodorowitsch Kabanow, und bestand aus den Unterabteilungen für Polizei, Justiz, Arbeit, Gesundheitswesen und leitendes Personal im Staatsapparat. Weitgehende personelle Kontinuitäten zur SMAD lassen sich nicht nur an der Spitze und bei den Abteilungsleitern feststellen, sondern - im Falle der Unterabteilung Justiz - auch auf einer Ebene darunter ${ }^{5}$. Oberstleutnant (seit 1951 Oberst) Titow als der zuständige Leiter verkörperte diese Kontinuität ebenso wie seine Mitarbeiter Jakupow und Korobow ${ }^{6}$. Nach dem Bericht eines Flüchtlings aus dem DDRJustizministerium für das SPD-Ostbüro war Jakupow kommissarischer Leiter der Unterabteilung, Korobow für die Gesetzgebung und ein nicht weiter bekannter Major Iwanow für Rechtsprechung und Kontrolle zuständig, während Basmanow als Adjutant von Titow fungierte. Alle waren, ungeachtet ihrer militärischen Ränge, nach dem Wissen des Ostbüro-Informanten „durchweg ausgezeichnete Juristen ", die 1953 ihre Funktionen bereits mehrere Jahre bekleidet hatten". Letzteres gilt auch für Titow, der im Unterschied zu seinen Vorgesetzten, den Leitern der Verwaltungsabteilung, bis 1953 durchgehend im Amt blieb ${ }^{8}$. Er wurde zunächst noch Leiter der Rechtsabteilung bei der Sowjetischen Hohen Kommission, die ab Juni 1953 an die Stelle der SKK trat; ab Ende August/Anfang September 1953 ist deren Leitung von dem zum Oberst beförderten Jakupow nachweisbar?.

Mit der Schaffung der SKK wurde de jure auch ein neues Verhältnis zwischen den zentralen DDR-Organen und den sowjetischen Besatzern begründet. Denn beim Regierungsapparat der DDR handelte es sich nicht mehr um die Auftragsverwaltung einer Militäradministration, sondern um Einrichtungen eines teilweise souveränen Staatswesens. Das tatsächliche Ausmaß der Abhängigkeit der DDRRegierungsinstanzen von der SKK läßt sich zwar nur am Einzelfall klären und bedarf zudem einer genauen zeitlichen Differenzierung; generell kann jedoch davon ausgegangen werden, daß die SKK Ende 1949/Anfang 1950 versuchte, „sich von rigiden besatzungsdiktatorischen Methoden dort zu verabschieden, wo Sicherheitsinteressen im engeren Sinn des Wortes und Wiedergutmachung nicht tangiert waren“. Da die SED als Staatspartei seit 1948/49 relativ fest etabliert war, mußte die SKK in die Transformationsprozesse nicht mehr so oft eingreifen, wie dies noch die SMAD getan hatte. Sie besaß freilich zahlreiche Möglichkeiten der Intervention und behielt sich prinzipiell das letzte Wort vor ${ }^{10}$.

Die Justiz spielte für die sowjetischen Herrschaftsträger gegenüber anderen Bereichen des öffentlichen Lebens eine eher untergeordnete Rolle. Denn in der SKK wurde die Justiz nur noch in einer Unterabteilung bearbeitet. Der Gesamtentwurf für das SKK-Statut vom Dezember 1949 führte zudem lediglich eine einzige ju-

5 Ebenda, S. 16f., 19, $21 \mathrm{f}$. Trotz Unterstellung unter die Verwaltungsabteilung firmierte die Unterabteilung für Justiz im Schriftverkehr als Justizabteilung der SKK.

6 Titow selbst nennt diese Mitarbeiter in seinem Artikel, Sowjetische Juristen, S. 186, neben G. P. Schischow, J. M. Glaschkin, M. I. Basmanow und E. N. Rudakow.

7 Bericht, 19.11. 1953, AdsD, Ostbüro Nr. 0048a. Berichterstatter war der am 24. 10. 1953 geflohene Abteilungsleiter Rudolf Reinartz.

8 Zum Wechsel der Leiter der Verwaltungsabteilung vgl. Scherstjanoi, Einleitung, in: SKK-Statut, S. 57, 59 f., 86.

9 Vgl. dazu Benjamin an Grotewohl, 16. 9. 1953, BAB, DP1 SE Nr. 3321.

10 Vgl. Scherstjanoi, Einleitung, in: SKK-Statut, S. 43 (Zitat), 50. 
stizrelevante Aufgabe der Abteilung für Verwaltungsfragen an: „Kontrolle über die Erfüllung der Potsdamer und der anderen gemeinsamen Beschlüsse der vier Mächte zur Reorganisation des deutschen Gerichtswesens gemäß den Prinzipien der Demokratie, zur Aufhebung der nazistischen Gesetzgebung sowie zur Heranziehung der Kriegs- und Naziverbrecher zur gerichtlichen Verantwortung". Die Aufgaben anderer Abteilungen, etwa der für Wirtschaftsfragen, wurden hingegen sehr viel ausführlicher und genauer umschrieben. Außerdem sollten nach dem Statutenentwurf nicht die Justizorgane der DDR, sondern die „Organe der staatlichen Kontrolle" - also die ZKK und die ihr unterstellten Landeskontrollkommissionen - „zur Stärkung der demokratischen Gesetzlichkeit“ vervollkommnet werden ${ }^{11}$.

Die Umsetzung dieser Vorgaben - die in der sehr viel knapperen, im April oder Mai 1950 vom sowjetischen Ministerrat schließlich verabschiedeten Fassung des SKK-Statuts nicht mehr enthalten waren - wurde weitgehend der Praxis überlassen. Das DDR-Justizministerium wollte in den Wochen nach der Staatsgründung die Berichtspflichten gegenüber der SKK deutlich einschränken ${ }^{12}$, war aber durchaus bereit, den sowjetischen Interventionsansprüchen Rechnung zu tragen. Denn in einer Unterredung mit Titow am 29. November 1949 erklärte Fechner von sich aus, „daß ihm vorschwebe, in Zukunft die Rohentwürfe der zu erlassenden Gesetze der Rechtsabteilung [der SKK] zuzuleiten“, um dieser Gelegenheit zu geben, sich bis zur Fertigstellung der endgültigen Entwürfe dazu zu äußern ${ }^{13}$. Dieses Verfahren, das bei Titow auf Zustimmung stieß, ermöglichte einerseits sowjetische Eingriffe, diente jedoch andererseits dazu, den Anschein von Souveränität aufrechtzuerhalten.

Welche Rechte die SKK tatsächlich im Hinblick auf das Justizwesen für sich beanspruchte, läßt sich anhand der deutschen Überlieferung nur ansatzweise bestimmen. Vielfach belegt ist ein umfassendes Berichtswesen an die SKK-Justizabteilung, deren Leiter sich bereits bei der Unterredung vom 29. November 1949 nach "periodische[n] Rechenschaftsberichte[n] und statistische[n] Unterlagen“ von seiten des MdJ erkundigt hatte. Zahlreiche Berichte existieren sowohl zur „Kaderlage“ unter den Richtern und Staatsanwälten insgesamt als auch zur Besetzung des Justizministeriums ${ }^{14}$. Zudem erhielt die SKK Beurteilungen der Angestellten des MdJ, der Richter des Obersten Gerichts ${ }^{15}$ und vermutlich auch der Staatsanwälte der Obersten Staatsanwaltschaft. Im Zuge der Neuorganisation des Gerichtswesens 1952 wurde der SKK sogar „vereinbarungsgemäß“ die Liste der zu ernennenden Bezirksgerichtspräsidenten einschließlich der Personalunterlagen

11 SKK-Statut, S. 122.

12 Vermerk Brandts über eine Besprechung bei Fechner am 18. 10. 1949, BAB, DP1 VA Nr. 6220.

13 Vermerk über eine Unterredung Fechners mit Titow am 29.11. 1949, BAB, DP1 VA Nr. 11, Bl. $166 \mathrm{f}$. Vgl. dazu auch, mit etwas abweichender Interpretation, Scherstjanoi, Einleitung, in: SKK-Statut, S. 43.

14 Vgl. u.a. MdJ an SKK, 20. 7. 1950, BAB, DP1 SE Nr. 3560, sowie die Listen und Berichte aus den Jahren 1950, 1952 und 1953 in russischer Sprache in: BAB, DP1 VA Nr. 7621.

15 Siehe u.a. die Beurteilungen vom September 1950 in den Personalakten von Julie Ganske, Erich Liss, Fritz Niethammer, Kurt Pauli, BAB, DP1 SE Nr. 74, und Werner Gentz, BAB, DP1 VA Nr. 854. Hilde Benjamin übersandte am 22. 5. 1950 eine Charakteristik der Richter des Obersten Gerichts an die SKK, BAB, DP1 VA Nr. 7939. 
übersandt ${ }^{16}$. Darüber hinaus informierte das MdJ die SKK über die Schulung der Justizangestellten ${ }^{17}$, über Untersuchungshaft ${ }^{18}$ und Strafvollzug, über Gesetzgebungsvorhaben und über die politische Strafjustiz. Hierzu existiert einer der wenigen erhaltenen Berichtsaufträge der SKK, die in einer Besprechung am 16. Januar 1951 verlangt hatte: „Ab sofort muß von jeder politisch bedeutsamen Strafsache in jedem einzelnen Falle die SKK, Oberst Titow, unterrichtet werden" 19.

Die Mitarbeiter der SKK-Justizabteilung, die MdJ-intern auch als „übergeordnete Dienststelle in K[arlshorst] “ bezeichnet wurde ${ }^{20}$, konnten sich auch durch Teilnahme an zentralen Besprechungen ${ }^{21}$ sowie durch persönliche Revisionen über die für sie relevanten Vorgänge im DDR-Justizwesen informieren. Hinzu kamen anscheinend sehr enge Kontakte zwischen den zuständigen SKK-Offizieren und den Hauptabteilungen für Gesetzgebung sowie für Rechtsprechung und Kontrolle im Justizministerium, so daß Korobow und Iwanow „praktisch die Anleitung “ für die jeweilige Hauptabteilung übernahmen². Derartige „Anleitungen“ sind nur selten in den deutschen Akten überliefert. Eine Ausnahme bildeten die Vorbereitungen zu den Neukodifikationen der Strafprozeßordnung, des Gerichtsverfassungsgesetzes und des Strafgesetzbuches von 1952, bei denen eine enge Fühlungnahme einschließlich schriftlicher Stellungnahmen mit der Unterabteilung Justiz der SKK nachweisbar ist ${ }^{23}$. Diese Vorhaben, die in weiten Teilen auf eine Angleichung der deutschen an die sowjetischen Normen hinausliefen, wurden für so wichtig erachtet, daß - wie im Falle des Gerichtsverfassungsgesetzes überliefert - der Gesetzentwurf nicht nur der SKK-Leitung vorgetragen, sondern sogar dem damaligen Außenminister Andrej Wyschinski übermittelt wurde ${ }^{24}$. Sowjetische Eingriffe in das DDR-Justizwesen konnten darüber hinaus die Form von sogenannten „Merkblättern“ oder „Memoranden“ erhalten, deren Bedeutung allein daran erkennbar ist, daß sie vom SKK-Chef in der Regel an Ministerpräsident Grotewohl übermittelt wurden ${ }^{25}$. Der enge Zusammenhang von zwei dieser Ausarbeitungen mit dem "Justizbeschluß" des Politbüros vom Dezember $1951^{26}$ zeigt, welch weitreichende Wirkungen derartige Anweisungen der SKK besaßen. Neben einem weiteren „Merkblatt“ vom Mai 1953, das sich äußerst kritisch mit dem Entwurf des neuen Strafgesetzbuches auseinandersetzte und wohl letztlich

16 Fechner an Titow, 30. 7. 1952, BAB, DP1 VA Nr. 7842.

17 Siehe Dok. 24 in: Wentker, Volksrichter, S. 186-189.

18 Fechner an Titow, 7. 4. 1952, BAB, DP1 VA Nr. 6584, Bl. 330.

19 Auszug aus der Aktennotiz über die Besprechung bei der SKK am 16.1. 1951, BAB, DP1 VA Nr. 820, Bl. 1. Das MdJ hatte bereits zuvor über politisch bedeutsame Verfahren aus den Ländern berichtet, ebenda, Bl. 2-36.

20 Vermerk des Leiters der Personalabteilung, 25. 9. 1952, BAB, DP1 VA Nr. 7621.

21 So nahm etwa an der Besprechung des Studienplanes für die Zentrale Richterschule vom 31.3. 1950 Glaschkin von der SKK teil: Siehe Teilnehmerliste und Besprechungsprotokoll, BAB, DP1 VA Nr. 986, Bl. 119; DP1 SE Nr. 3556.

22 Bericht, 19. 11. 1953, AdsD, Ostbüro Nr. 0048a.

23 Siehe dazu Kap. B.IX.2.

24 So die Darstellung Benjamins gegenüber Spank, 13. 8. 1952, BAB, DP1 VA Nr. 8070.

25 Vgl. Scherstjanoi, Einleitung, in: SKK-Statut, S. 68-70.

26 Es handelt sich um die Memoranden vom November 1951, SAPMO, NY 4090/301, Bl. $76 \mathrm{f}$. (russisches Original), Bl. 73 f. (Übersetzung), und vom Mai 1952, NY 4090/440, Bl. $217 \mathrm{f}$. (russisches Original), Bl. $211 \mathrm{f}$. (Übersetzung). 
dazu führte, daß dieses nie in Kraft trat ${ }^{27}$, handelt es sich um die einzigen überlieferten justizrelevanten schriftlichen Anweisungen dieser Art von der SKK. Deren Nachfolger, die Sowjetische Hohe Kommission, ließ der DDR-Führung im August 1953 vier derartige „Empfehlungen“ zukommen, die der Umsetzung des auf Anordnung von Moskau verkündeten „Neuen Kurses“ in der Justiz dienen sollten ${ }^{28}$. „Merkblätter“ oder „Memoranden“, so die Schlußfolgerung aus diesen Fällen, wurden in Justizbelangen nur äußerst selten eingesetzt, berührten auch für die sowjetische Seite zentrale Vorhaben und waren daher von ihren Empfängern in der DDR umgehend umzusetzen.

Der Übergang von der SMAD zur SKK bedeutete für die sowjetischen Informations- und Interventionsmöglichkeiten im Hinblick auf das DDR-Justizwesen keinen grundsätzlichen Bruch. Im Vergleich zur Frühphase der Besatzungsherrschaft gingen die offenen justizrelevanten Anordnungen und Anweisungen von sowjetischer Seite jedoch zurück. Damit wurde eine bereits im Verlauf des Jahres 1947 erkennbare Tendenz verstärkt: Ungeachtet der tatsächlichen sowjetischen Eingriffe waren sowohl die SKK als auch die deutschen Justizorgane bestrebt, diese nach außen hin soweit wie möglich zu kaschieren. Von daher könnte sich auch erklären, warum so wenige Begegnungen zwischen SKK-Angehörigen und Vertretern der Ost-Berliner Justizbürokratie ihren Niederschlag in den Akten gefunden haben ${ }^{29}$. Dies erschwert eine Aussage über das Ausmaß der sowjetischen Einflußnahme auf die Tätigkeit der zentralen Justizorgane der DDR erheblich. Die schriftliche Hinterlassenschaft legt den Schluß nahe, daß die SKK vor allem dann eingriff, wenn es um zentrale Weichenstellungen im Justizwesen ging; unklar bleibt jedoch, welche mündlichen „Anleitungen“ auf einer unteren Ebene der zuständige SKK-Mitarbeiter seinem Gegenüber im DDR-Justizministerium gab.

Neben der Besatzungsmacht machte auch die SED nach 1948 ihren Einfluß gegenüber den Zentralinstanzen in Ost-Berlin in zunehmendem Maße geltend. Die zuständige Fachabteilung im zentralen Parteiapparat war zunächst noch die Abteilung Justiz. Im Vorfeld der DDR-Staatsgründung beschloß das Kleine Sekretariat, eine Kommission zu bilden, die diese Abteilung überprüfen und einen Vorschlag „für die Verbesserung der Arbeit der Abteilung“ ausarbeiten sollte. Dieser gehörten neben den SED-Juristinnen Hilde Neumann und Hilde Benjamin auch Walter Ulbricht, Paul Wessel und Anton Plenikowski an ${ }^{30}$. Am Ende der Kommissionstätigkeit entschied das Kleine Sekretariat am 17. Oktober 1949, die Abteilung Justiz als eine Unterabteilung der von Plenikowski geleiteten Abteilung Staatliche Verwaltung einzugliedern ${ }^{31}$. Wie bei der SKK wird dadurch der relative

27 Merkblatt vom Mai 1953, SAPMO, NY 4090/444, Bl. 6-8 (russisches Original), Bl. 3-5 (Übersetzung); siehe dazu Kap. B.IX.3.

28 Die Merkblätter beinhalteten Vorschläge zur Anwendung des Volkseigentumsschutzgesetzes, zur Anwendung des Handelsschutzgesetzes, zur Anwendung der Wirtschaftsstrafverordnung und Maßnahmen zur Regelung der Herausgabe von Gesetzen und Verordnungen mit strafrechtlichen Sanktionen. Sie wurden am 18.8. 1953 von Ulbricht an Benjamin übersandt, BAB, DP1 SE Nr. 3321.

29 Vgl. insgesamt dazu Scherstjanoi, Einleitung, in: SKK-Statut, S. 66.

30 Protokoll der Sitzung des Kleinen Sekretariats, 2. 9. 1949, SAPMO, DY 30 J IV 2/3/49, TOP 9.

31 Protokoll der Sitzung des Kleinen Sekretariats, 17. 10. 1949, SAPMO, DY 30 J IV 2/3/57, TOP 24. Ein direkter Zusammenhang mit dem Beschluß vom 2.9. 1949 ist nicht nachweisbar, jedoch sehr wahrscheinlich. 
Bedeutungsverlust der Justiz auch für die SED deutlich; das Diktum Max Fechners vom Januar 1948, demzufolge „die Justiz [...], richtig verstanden, auch nur ein Verwaltungszweig" 32 sei, fand in diesem Beschluß seinen sinnfälligen Ausdruck.

Diese Umstrukturierung bedeutete gleichzeitig eine Veränderung der Aufgaben des Justizressorts bei der SED. Mit den wegweisenden Beschlüssen vom Januar 1948 hatte die zentrale SED-Justizabteilung zunächst ihre innerparteiliche Aktivität verstärkt, die auf eine Effektivierung der Justizarbeit der Landesvorstände sowie eine Mobilisierung der in der SED organisierten Juristen hinauslief ${ }^{33}$. Aufgrund der föderalistischen Justizorganisation konnte die SED-Justizabteilung nur indirekt über die Landesvorstände versuchen, Einfluß zu nehmen, wie etwa mit einem Rundschreiben vom 18. August 1948. Darin machte Fechner auf eine Reihe politischer und organisatorischer Mängel der justizpolitischen Arbeit auf Landesebene aufmerksam: Unter anderem sei die Verbindung zwischen den SED-Genossen und den Landesjustizministerien sehr schlecht, die besondere Bedeutung der Justizkonferenzen von Juli und August sei verkannt worden, und den meisten Genossen aus der Justiz fehle es "ganz allgemein noch am geistigen Niveau und an Klarheit des politischen Denkens“. Da der SED-Zentrale direkte Verbindungen zur Landesjustiz fehlten, konnte Fechner mit seinen Anweisungen an die Landesvorstände lediglich indirekt auf die Justizpolitik einwirken. In der Personalpolitik etwa forderte Fechner, die SED-Genossen der Landesverbände anzuhalten, „alle Wahrnehmungen über reaktionäre Äußerungen sowie über rückschrittliches Verhalten" von Richtern oder Staatsanwälten an die Landesleitungen zu melden, die dann „in Zusammenarbeit mit den Genossen im Justizministerium“ die Vorfälle aufklären und daraus „die notwendigen Schlüsse“ ziehen sollten. Vor diesem Hintergrund war es nur konsequent, eine minimale Besetzung der Justizreferate bei den Landesverbänden mit zwei Genossen anzuordnen ${ }^{34}$.

Die Abteilung Justiz mußte des weiteren die SED-Genossen unter den Juristen in einem stärkeren Maße als bisher an die Partei binden und für ihre Zwecke einsetzen. Dazu waren den Justizbeschlüssen vom Januar 1948 zufolge Arbeitsgemeinschaften an den Sitzen der Landgerichte zu bilden, die die SED-Richter, -Staatsanwälte und -Rechtsanwälte zusammenfassen sollten ${ }^{35}$. Als wesentlichen Zweck der Arbeitsgemeinschaften nannte Schäfermeyer „die marxistische Durcharbeitung der Probleme des deutschen bürgerlichen Rechts“. Denn es galt zu verhindern, daß die in den Volksrichterschulen nur unzureichend ideologisch geschulten Genossen „nun ihrerseits ,Fachbeamte‘ und ,Formaljuristen“" wurden ${ }^{36}$.

32 Stenographische Niederschrift über die 3. Tagung des Ausschusses für Rechtsfragen beim Zentralsekretariat der SED, 3./4. 1. 1948, SAPMO, DY 30 IV 2/1.01/70, Bl. 12; zit. auch bei Werkentin, Politische Strafjustiz, S. 300.

33 Resolution des rechtspolitischen Beirats des SED-Zentralsekretariats, in: Amos, Justizverwaltung, S. 233.

34 An die Vorsitzenden der Landesleitung der SED-Mecklenburg, 19. 8. 1948, BAB, DP1 VA Nr. 20, Bl. 26-30; an die Vorsitzenden der Landesleitung der SED-Sachsen, BAB, DP1 VA Nr. 261, Bl. 26. Zur Kontrolle dieser Anordnungen vgl. den Bericht von Hilde Neumann über eine Besprechung in Halle am 25. 8. 1948, BAB, DP1 VA Nr. 6596, Bl. 41-44.

35 Resolution des rechtspolitischen Beirats des SED-Zentralsekretariats, in: Amos, Justizverwaltung, S. 233.

36 Memorandum für die Notwendigkeit der Gründung der Arbeitsgemeinschaft der Juristen der 
Die Anleitung der Arbeitsgemeinschaften sollte durch die Justizabteilung beim Zentralsekretariat erfolgen, die zu diesem Zweck ein eigenes Nachrichtenblatt herausgeben wollte. Während die Idee der Arbeitsgemeinschaften anscheinend nicht realisiert wurde ${ }^{37}$, erschien das Mitteilungsblatt der Justizabteilung zum ersten $\mathrm{Mal}$ im August 194838. In unregelmäßiger Folge gingen drei weitere Nummern der hektographierten Zeitschrift im Oktober und Dezember 1948 sowie wohl zum letzten Mal - im Mai 1949 an die SED-Genossen in der Justiz ${ }^{39}$. Sie enthielt Informationen unter anderem zur Justizpolitik, zu im Sinne der SED vorbildlicher Rechtsprechung sowie Hinweise auf einschlägige Veröffentlichungen. Inwieweit sie ihr Ziel einer stärkeren Mobilisierung der SED-Juristen erreichte, muß jedoch offen bleiben.

Wenngleich nie ausdrücklich als Aufgabe der Justizabteilung formuliert, versuchte diese auch, Einfluß auf die Arbeit in der DJV auszuüben. Einer Mitteilung vom 4. März 1948 zufolge fanden alle zwei Wochen Besprechungen mit der SEDBetriebsgruppe in der DJV statt ${ }^{40}$ : ein Kontakt, der sich nach der Berufung Fechners zum DJV-Präsidenten zunächst vermutlich intensivierte ${ }^{41}$. Die SED-Justizabteilung konnte außerdem in zunehmendem Maße ihr nicht genehme Projekte der DJV verhindern - wie etwa das Vorhaben Schiffers zur Neuorganisation des deutschen Gerichtswesen $s^{42}$ - oder andere mitgestalten - wie etwa den neuen Lehrplan für die Volksrichterschulen für 194943. Mit der Eingliederung der Unterabteilung Justiz in die Abteilung Staatliche Verwaltung erhielt die Funktion, die zentrale Justizbürokratie anzuleiten, Priorität gegenüber den parteiinternen Aufgaben. Denn gleichzeitig wurde mit Sekretariatsbeschluß vom 17. Oktober 1949 der Staatsapparat dem Parteiapparat eindeutig untergeordnet, da Regierungsbeschlüsse oder Volkskammerabstimmungen über wichtige Gesetze vom Politbüro oder Sekretariat abgesegnet werden mußten; vor dem Erlaß anderer bedeutsamer Anordnungen war die Zustimmung der zuständigen Abteilung beim Parteivorstand einzuholen. Für die obersten Justizorgane wurde die Abteilung Staatliche Verwaltung verantwortlich gemacht ${ }^{44}$. Mit dieser zu Recht als „heimliche Verfas-

SED, sowie über Funktionen und Aufgaben dieser Arbeitsgemeinschaften, 11. 3. 1948, SAPMO, DY 30 IV 2/5/201, Bl. 59-61.

37 Am 1. 4. 1948 entwarf die Organisationsabteilung beim ZS „Richtlinien zur Schaffung von Arbeitsgemeinschaften der Juristen der SED“, die Schäfermeyer am 24.4. 1948 kritisierte, ebenda, Bl. 62-64. Am 16. 8. 1948 stand die „Bildung von Arbeitsgemeinschaften für Justiz“ auf der Tagesordnung der Zentralsekretariatssitzung, Dahlem und Fechner wurden aber lediglich beauftragt, "die vorgelegten Grundsätze zu überprüfen“ (SAPMO, DY 30 IV 2/2.1/223, TOP 20). AnschlieBend tauchen die Arbeitsgemeinschaften nie mehr auf. Dies wird von Amos, Justizverwaltung, S. $95 \mathrm{f}$. nicht beachtet.

38 Mitteilungen der Abteilung Justiz des Zentralsekretariats der SED, August 1948, SAPMO, DY 30 IV $2 / 13 / 407$.

39 Überliefert in: BAB, DQ2, Nr. 1221. Diesen Hinweis verdanke ich Dr. Dierk Hoffmann.

40 Abt. Justiz an Fechner/Ulbricht, 4. 3. 1948, SAPMO, NY 4182/1086, Bl. 11. Amos, Justizverwaltung, S. 95, gilt diese Aussage als Beleg dafür, daß seit 1946 derartige Besprechungen durchgeführt wurden, obwohl in der Mitteilung davon nicht die Rede ist.

41 Vgl. u. a. die Tagesordnung einer Besprechung am 29. 12. 1948, $16 \mathrm{Uhr}$, in der Lothringer Str.1 [also der SED-Zentrale] - Zimmer des Gen. Fechner. Im Verteiler waren Fechner, Melsheimer, Benjamin, Nathan, Weiß, Schäfermeyer, Neumann und Berger aufgeführt, BAB DP1 SE Nr. 3145.

42 Siehe die Stellungnahme vom 30. 4. 1948, BAB, DP1 VA Nr. 7844, B1. 20-24.

43 Vgl. Wentker, Volksrichter, S. 56.

44 Richtlinien über die Fertigstellung von Regierungsvorlagen zur Entscheidung durch die zuständi- 
sung der DDR “45 bezeichneten Festlegung wurde der Sektor Justiz zur wichtigsten anleitenden Parteiinstanz des Justizministeriums, des Obersten Gerichts und der Obersten Staatsanwaltschaft. Unmittelbar nach Gründung der DDR wurde der Parteiapparat formell somit in die Lage versetzt, den Staatsapparat zu lenken und zu kontrollieren; demgegenüber traten die mobilisierenden Parteiaufgaben in den Hintergrund. Dies wird auch in der Aufgabenbeschreibung des Justizsektors deutlich, die am 14. August 1950 die Zustimmung des Sekretariats fand: „Vorbereitung von Beschlüssen, Gesetzesvorlagen usw. für das Gebiet der Justiz und die Kontrolle ihrer Durchführung; Kontrolle der Rechtsprechung, der Struktur und der Arbeitsmethoden des Justizapparates; Auswertung der Kontrolle und Ausarbeitung konkreter Vorschläge zur Verbesserung der justizpolitischen Arbeit."46

Das für diese Aufgaben zur Verfügung stehende Personal wechselte zwischen 1948 und 1952 häufig und erfüllte oft nicht die Erwartungen der SED-Führung. Ein schmerzlicher Verlust aus deren Sicht bildete der Weggang des Abteilungsleiters Polak im Frühjahr 1948. Polak strebte spätestens seit November 1947, als ihm Sonderurlaub für die Anfertigung einer Habilitationsschrift gewährt worden war, eine wissenschaftliche Karriere an und wollte die administrative Arbeit im Parteiapparat, die er als „leer und quälend empfand“ 47 , aufgeben. Die Parteispitze wollte ihn zunächst nicht gehen lassen ${ }^{48}$; erst nach einem Gespräch mit seinem Gönner Ulbricht und mit Fechner konnte er die Entbindung von seinem Posten erreichen $^{49}$. Der entsprechende Zentralsekretariatsbeschluß vom 12. April 1948 befreite Polak zwar von seinen Verpflichtungen als Abteilungsleiter; er mußte aber für den Parteivorstand tätig bleiben und wurde nur für seine Lehrveranstaltungen freigestellt ${ }^{50}$. Noch über ein Jahr verblieb er als den beiden Vorsitzenden direkt unterstellter Mitarbeiter ${ }^{51}$ in der Parteizentrale, bis er laut Sekretariatsbeschluß vom 16. Mai 1949 zum Monatsende endgültig ausschied ${ }^{52}$. Auch dieser Beschluß wurde indes nur unter der Voraussetzung gefaßt, daß er sich auch weiterhin "auf jeweiligen besonderen Abruf der Partei für die Erfüllung von Sonderaufgaben, soweit sie auf staatsrechtlichem Gebiete liegen“, zur Verfügung stellte ${ }^{53}$.

Sowohl im Hinblick auf politische Zuverlässigkeit als auch auf fachliche Kompetenz war ein gleichwertiger Ersatz für Polak nur schwer zu finden. Zunächst wurde dessen bisheriger Stellvertreter, Reinhold Schäfermeyer, zum Abteilungsleiter ernannt ${ }^{54}$. Mitte 1949 stellte sich jedoch heraus, daß er in seinem Personalbogen seine Mitgliedschaft in verschiedenen NS-Organisationen verschwiegen

gen Organe des Parteivorstandes, in: DzD II/2, S. 687-689. Vgl. dazu auch Kaiser, Zentrale der Diktatur, S. 78-80.

45 So Jessen, Partei, S. 77.

46 Protokoll der Sekretariatssitzung, 14. 8. 1950, SAPMO, DY 30 JIV 2/3/130, TOP 7, Anlage Nr. 6.

47 Polak an Friedrich Behrens, 31. 3. 1948, ebenda, Bl. 68.

48 Vgl. dazu Polak an Pieck und Grotewohl, 13. 3. 1948, 31. 1. 1949, BAB, DP1 VA Nr. 6596, Bl. 65 f., 86.

49 Polak an Pieck und Grotewohl, 31. 3. 1948, ebenda, Bl. 69.

50 Protokoll der Zentralsekretariatssitzung, 12. 4. 1948, SAPMO, DY 30 IV 2/2.1/189, TOP 12.

51 Hausmitteilung Grotewohls an Geschäftsabteilung, SAPMO, NY 4090/303, Bl. 141.

52 Protokoll der Sitzung des Kleinen Sekretariats, 16. 5. 1949, SAPMO, DY 30 J IV 2/3/27, TOP 14.

53 Grotewohl an Polak, 16. 5. 1949, SAPMO, NY 4090/303, Bl. 144.

54 Protokoll der Zentralsekretariatssitzung, 12.4. 1948, SAPMO, DY 30 IV 2/2.1/189, TOP 14. Die Gleichstellung mit Polak war schon vorher erreicht: vgl. Fechner an Gehaltskommission, 23. 12. 1947, BAB, DP1 VA Nr. 6956, Bl. 104. 
hatte. Auf Vorschlag der Zentralen Parteikontrollkommission vom 21. Oktober beschloß das Politbüro vier Tage später, ihn aus der SED auszuschließen ${ }^{55}$. Mit der Leitung der neu gebildeten Unterabteilung Justiz wurde nun deren langjähriger Mitarbeiter Götz Berger betraut ${ }^{56}$, der aber nur bis August 1950 blieb, als er der Deutschen Verwaltungsakademie als Dozent und Prodekan zur Verfügung gestellt wurde ${ }^{57}$. Der Sektor Justiz wurde in den folgenden zwei Jahren mit Personal besetzt, das durchweg keine Erfahrung im Parteiapparat besaß und zudem weniger qualifiziert war als Polak und seine Mitarbeiter. Zunächst trat Dr. Willy Kulaszewski an die Stelle von Berger, ein Volljurist, der jedoch offensichtlich der NSDAP angehört hatte ${ }^{58}$ und im Juli 1951 „wegen seiner Tätigkeit als Staatsanwalt zwischen 1933 und $1945^{\text {" entlassen wurde }}$ ". Als neue Leiterin des Sektors bestätigte das Sekretariat am 6. August 1951 Gertrud Finke ${ }^{60}$, die erste Volksrichterin auf diesem Posten. Nach Besuch des Richterlehrgangs in Bad Schandau 1948/49 hatte sie nach gut einjähriger Tätigkeit am Amtsgericht Mittweida seit Mai 1950 als Landgerichtspräsidentin zunächst in Plauen und dann in Zwickau Karriere gemacht ${ }^{61}$. Kritik an der Arbeit des Justizsektors im Herbst 1951 und der Beschluß, die Parteiarbeit in der Justiz zu verbessern, bildeten den Hintergrund für die Versetzung Finkes innerhalb der Abteilung Staatliche Verwaltung im Januar auf eine untergeordnete Funktion ${ }^{62}$. Neuer Leiter des Justizsektors wurde Richard Spank, ebenfalls Absolvent eines Richterlehrganges, der nach seiner Ausbildung als Staatsanwalt in Bautzen und unmittelbar vor seiner Berufung in die Abteilung Staatliche Verwaltung als Oberstaatsanwalt und stellvertretender Landestaatsanwalt in Mecklenburg tätig gewesen war. Seine besondere „Qualifikation" bestand darin, daß er als Staatsanwalt an den Waldheimer Prozessen teilgenommen hatte ${ }^{63}$. Spank blieb Leiter des Sektors nachweislich bis Ende August 195364; im September wurde er von Josef Streit abgelöst, der bis 1962 diesen Posten inne hatte ${ }^{65}$. Die Justizabteilung bzw. der Sektor Justiz verfügte bis 1953 nur

55 Vgl. Dreier u. a., Rechtswissenschaft, S. 37, Anm. 7; Protokoll der Politbürositzung, 25. 10. 1949, SAPMO, DY 30 J IV 2/2/53, TOP 10. Später floh Schäfermeyer in die Bundesrepublik: siehe SBZHandbuch, S. 1013.

56 Protokoll der Sitzung des Kleinen Sekretariats, 17. 10. 1949, SAPMO, DY 30 J IV 2/3/57, TOP 24.

57 Protokoll der Sekretariatssitzung, 14. 8. 1950, SAPMO, DY 30 J IV 2/3/130, TOP 7. Berger blieb dort bis April 1951, ging dann bis Ende 1955 ans Landgericht Berlin, war von 1956 bis Anfang 1958 hauptamtlicher Sekretär der VDJ und wechselte am 1.2. 1958 zur Anwaltschaft. Am 30. 1. 1958 wurde er als GI für das MfS angeworben, ohne eine Verpflichtungerklärung zu unterschreiben; die Zusammenarbeit mit ihm wurde am 20.4. 1961 eingestellt: siehe BStU, MfS AIM 2528/61, T.I. Wegen seiner Verteidigung von Robert Havemann wurde ihm 1976 seine Zulassung als Rechtsanwalt entzogen; er starb am 6.3. 1996 im sogenannten "Havemann-Verfahren“ im Gerichtssaal: vgl. Fricke, Opposition und Widerstand in der DDR-Strafjustiz, S. 39, Vollnhals, Fall Havemann, S. 59 f., Rottleuthner, Havemann-Verfahren, S. 73.

58 Bericht von GI „Spree“" (Rothschild) o.D., BStU, MfS AP 2257/55, Bl. 3.

59 Protokoll der Sekretariatssitzung, 2. 7. 1951, SAPMO, DY 30 J IV 2/3/210, TOP 41.

60 Protokoll der Sekretariatssitzung, 6. 8. 1951, SAPMO, DY 30 J IV 2/3/221, TOP 19.

61 Siehe die biographische Angabe in: BAB, DP1 SE Nr. A3.

62 Zur Kritik an der Justizarbeit der SED und zum Justizbeschluß siehe Kap. B.IX.1. Finke wurde zum Instrukteur im Sektor Kader degradiert: Protokoll der Sekretariatssitzung, 17.1. 1952, SAPMO, DY 30 J IV 2/3/262, TOP 24.

63 Ebenda und Finn, Politische Häftlinge, S. 86.

64 Vgl. Werkentin, Politische Strafjustiz, S. 140, Anm. 189.

$65 \mathrm{Zu}$ Streit, der ebenfalls eine Volksrichterschule besucht hatte, siehe Barth u.a., Wer war wer in der 
über sehr wenige Stellen, die oft nicht vollständig besetzt waren. Waren im Oktober 1947 neben zwei Sekretärinnen und zwei Stenotypistinnen dort vier Personen tätig (Polak und Schäfermeyer als Abteilungsleiter, Berger und Neumann als Hauptreferenten) $)^{66}$, waren es nach dem Ausscheiden Polaks und Neumanns ${ }^{67} \mathrm{zu}^{\mathrm{u}}$ nächst nur noch zwei; im April 1949 wurde ein nicht näher bekannter Fritz Krüger als Referent eingestellt ${ }^{68}$; wie lange er blieb, ist unbekannt. Nach der Umstrukturierung vom Oktober 1949 kamen zwar zwei weitere Referenten hinzu69; nur einer von ihnen, Walter Kampfrad, war dort noch im August 1950 tätig, obwohl der Sektor über insgesamt drei Instrukteursstellen verfügte ${ }^{70}$. Die beiden freien Stellen wurden erst im Oktober 1950 bzw. im Januar 1951 mit Martha Fuchs und Erwin Reisler besetzt ${ }^{71}$; Kampfrad schied zum 30. Juni 1951 wieder aus dem Parteiapparat aus ${ }^{72}$. Aufgrund einer Parteistrafe durfte Reisler ab April 1952 für ein Jahr keine Parteifunktion mehr ausüben und konnte somit auch nicht weiter im Justizsektor beschäftigt werden; Martha Fuchs wurde im August 1953 abberufen ${ }^{73}$. Die Lücken wurden nur unvollständig geschlossen; das Sekretariat ernannte im Januar 1952 mit Herbert Kern lediglich einen weiteren Instrukteur ${ }^{74}$.

Über die Instrukteure im Justizsektor ist meist nur wenig bekannt. Während es sich bei dem im Dezember 1949 eingestellten Dr. Arved Schulz wohl um einen Juristen mit akademischem Abschluß handelte, hatten Reisler, Kampfrad und Kern alle Volksrichterlehrgänge absolviert. Reisler war nach Besuch eines Richterlehrgangs 1946 in der brandenburgischen Justizverwaltung und seit der ersten Jahreshälfte 1949 in der DJV bzw. im MdJ als Oberreferent tätig gewesen ${ }^{75}$; zudem hatte er bei den Waldheimer Prozessen als stellvertretender Chefinstrukteur mitgewirkt ${ }^{76}$. Die ständig steigende Anzahl von linientreuen, zum Teil in „Sonderaufgaben" bewährten Volksrichtern legt den Schluß nahe, daß bei der Besetzung des Sektors zu Beginn der fünfziger Jahre primär auf die politische und erst in zweiter Linie auf die fachliche Qualifikation der Mitarbeiter geachtet wurde. Bemerkenswert ist darüber hinaus die ab 1948 gegenüber den vorangegangenen Jahren stark

DDR, S. $721 \mathrm{f}$. und die Vermerke der MfS-Hauptabteilung V vom 26. und 27. 9. 1961, BStU, MfS HA XX Nr. 2944, Bl. 737-742.

66 Arbeitsplan für die Abteilung Justiz, 8. 10. 1947, BAB, DP1 VA Nr. 6596, Bl. 126-137, hier 137.

67 Neumann wurde am 10. 2. 1949 Landgerichtspräsidentin in Berlin: siehe Protokoll der Sitzung des Kleinen Sekretariats, 7. 2. 1950, SAPMO, DY 30 J IV 2/3/3, TOP 17, und Begründung zum Antrag auf Verleihung des Vaterländischen Verdienstordens an die Genossin Hilde Neumann zum 7. Oktober 1958, BAB, DP1 VA Nr. 6699.

68 Protokoll der Sekretariatssitzung, 14. 4. 1949, SAPMO, DY 30 J IV 2/3/21, TOP1f.

69 Dr. Arved Schulz und Walter Kampfrad: Protokolle der Sekretariatssitzungen, 12.12. 1949 und 16. 1. 1950, SAPMO, DY 30 J IV 2/3/72, TOP 29, und 2/3/79, TOP 13.

70 Protokoll der Sekretariatssitzung, 14. 8. 1950, SAPMO, DY 30 J IV 2/3/130, Anlage Nr. 6.

71 Protokolle der Sekretariatssitzungen, 2. 10. 1950 und 15. 1. 1951, SAPMO, DY 30 J IV 2/3/142, TOP 45, und 2/3/167, TOP 21.

72 Protokoll der Sekretariatssitzung, 2. 7. 1951, SAPMO, DY 30 J IV 2/3/210, TOP 40. Nach seinem Ausscheiden leitete Kampfrad kommissarisch die Staatsanwaltschaft Leipzig: siehe Beurteilung des Ersten Staatsanwalts Kampfrad, 21. 12. 1951, BStU, MfS AS 24/55, Bl. 53; vgl. auch Lebenslauf Kampfrads, ebenda, Bl. $51 \mathrm{f}$.

73 Protokolle der Sekretariatssitzungen, 10.4. 1952 und 3.8. 1953, SAPMO, DY 30 J IV 2/3/282, TOP 24, und 2/3/393, TOP 21.

74 Protokoll der Sekretariatssitzung, 17. 1. 1952, SAPMO, DY 30 J IV 2/3/262, TOP 24.

75 Personalbogen Reislers, in: BStU, MfS AP 11333/56, Bl. 8f.; Bericht über die Entwicklung der Justiz in der SBZ im ersten Halbjahr 1949, BAB, DP1 VA Nr. 145.

76 Vgl. Finn, Politische Häftlinge, S. 86. 
erhöhte Personalfluktuation, deren Ursachen nur in Einzelfällen bekannt sind. Insgesamt dürften die unzureichende Besetzung, die mangelnde Qualifikation der Mitarbeiter und die häufigen Personalwechsel den Sektor Justiz in seiner Tätigkeit in den Jahren bis 1953 erheblich beeinträchtigt haben. Innerhalb des Parteiführung erklärten das Sekretariat Paul Wessel und das Politbüro Helmut Lehmann als für die Justiz zuständig77; sie übten jedoch keinen erkennbaren Einfluß auf die Politik in ihren Arbeitsgebieten aus. Es war daher nur konsequent und entsprach sehr viel eher den realen Machtverhältnissen in der SED-Führung, daß Ulbricht als zuständiger Sekretär für die Abteilung Staatliche Verwaltung mit deren Reorganisation auch für Justizfragen verantwortlich wurde ${ }^{78}$. Freilich mußte die Anleitung der Obersten Justizorgane auch ohne die Herbeiführung von Beschlüssen in den Führungsgremien der Partei, über direkte Anweisungen des Justizsektors möglich sein. Derartige "Arbeitskontakte“ wurden zwischen Justizministerium und Parteiapparat durchaus gepflegt, sie verliefen jedoch keineswegs so, wie Fechner sich dies vorstellte. Seiner Meinung nach war er als ZK-Mitglied ranghöher als die Mitarbeiter der Abteilung Staatliche Verwaltung, die nur Angestellte des Zentralkomitees seien 79 . Er „sei die Partei im MdJ, da er als verantwortlicher politischer Funktionär dahin gestellt worden sei“" 80 . Die Kontakte zum Justizsektor hatten daher ausschließlich über ihn zu laufen ${ }^{81}$. Dabei spielten sowohl seine persönliche Eitelkeit als auch die durch seine Inkompetenz hervorgerufene Unsicherheit eine Rolle. $\mathrm{Da}$ er sich von den Mitarbeitern des $\mathrm{ZK}$ kontrolliert fühlte, reagierte er äußerst heftig, wenn er erfuhr, daß die MdJ-Abteilungsleiter hinter seinem Rücken die zuständige Abteilung des Parteiapparats konsultierten ${ }^{82}$. Durch das berechtigte Mißtrauen des Ministers gegenüber seinen ,Kontrolleuren' ergab sich somit ein gestörtes Verhältnis zwischen MdJ und Justizsektor. Der konnte zwar „über eine Abteilung oder einen Genossen“ seine Anweisungen an das Justizministerium weitergeben ${ }^{83}$, war sich indes nie sicher, ob diese nicht von Fechner konterkariert würden. Trotz Besetzung des Justizressorts mit einem Minister, dessen einzige Qualifikation seine Parteizugehörigkeit darstellte, ergaben sich aufgrund persönlicher Eitelkeiten und fachlicher Inkompetenz Probleme zwischen Partei- und Staatsapparat, die die Umsetzung der politischen Konzeption der SED-Führung beeinträchtigten.

77 Protokolle der Sitzungen des Kleinen Sekretariats, 31. 1. 1949, SAPMO, DY 30 J IV 2/3/1, und des Politbüros, 15. 2. 1949, 2/2/3, TOP 2. Vgl. Kaiser, Zentrale der Diktatur, S. 47.

78 Lehmann schied im Juli 1950, Wessel im Februar 1950 aus. Für die Zuständigkeit Ulbrichts siehe Protokoll der Sekretariatssitzung, 26. 7. 1950, SAPMO, DY 30 J IV 2/3/127, TOP 7.

74 Zitat aus Aussagen Fechners in: Betr.: Fechner, BStU, MfS AU 307/55 (HA/GA) Bd 1., Bl. 33.

80 So Fechner nach einer Aussage Scheeles, in: Bericht betr.: Aufhebung der Internierung von Scheele, 3. 8. 1953, BStU, MfS AU 307/55 Bd. 4, Bl. 76.

81 Vgl. Bericht Kulaszewskis vom 15.12. 1950, SAPMO, DY 30 IV 2/11/V1386, Bl. 115.

82 So führte Fechner nach einem anonymen Bericht in seiner Personalakte in einer Besprechung im MdJ vom 21. 11. 1950 als Beispiel „eine Sache an, die die Gen. Heinze an den Gen. Hentschel [stellvertretender Leiter der Abteilung Staatliche Verwaltung] gegeben hätte und für die er dann von dem Gen. Grotewohl eine, dicke Zigarre“ erhalten habe. Als die Gen. Heinze fragte, ob sie gehen könne, sagte der Gen. Fechner, daß das, , was hier behandelt würde, wohl wichtiger sei, als wenn sie stundenlang in in der Staatlichen Verwaltung sitze“". (Vermerk, 28. 11. 1950, ebenda, Bl. 50).

83 Bericht Scheeles, in: BStU, MfS, AU 307/55 Bd. 6, Bl. 173. 


\section{Personalaustausch und Strukturwandel in der DJV 1948/49}

\section{Neue Abteilungsleiter und ein neuer DJV-Präsident}

Der Kurswechsel von 1948 hatte, wie vor allem am Personalaustausch in der DJV ${ }^{84}$ deutlich wird, unmittelbare politische Konsequenzen. Dabei ging die Initiative eindeutig von der SED aus, die ihr Gewicht in der Zentralverwaltung durch die Besetzung weiterer Abteilungsleiterposten mit zuverlässigen Genossen erhöhen wollte. So schlugen Fechner und Ulbricht am 28. April 1948 im Rückgriff auf die seit Herbst 1947 angestellten Erwägungen zur „Verstärkung der Zentralverwaltung für Justiz" vor, Hildegard Heinze in die DJV einzuberufen und „nach Rücksprache mit den Genossen der DJV und der SMAD als Leiterin der Abteilung für Kontrolle [...] einzubauen " 85 .

Bei Hildegard Heinze handelte es sich um eine der wenigen kommunistischen „Kader“, die eine volle juristische Ausbildung absolviert hatten. Geboren 1910 als Tochter des Kaufmanns Fehlig, seit 1921 Direktor der Thyssen AG in Leipzig, wuchs sie in einem großbürgerlichen Umfeld auf, geriet aber schon frühzeitig in Gegensatz zu den deutschnationalen, später nationalsozialistischen Ansichten ihres Vaters. Nach dem juristischen Studium, das sie in ihrem Drang nach Unabhängigkeit vom Elternhaus von 1930 bis 1934 absolvierte, begegnete sie während des Referendariats 1936 ihrem späteren Mann, Wolfgang Heinze, der nach ihrer eigenen Aussage „ein klarer Marxist-Leninist war, über große theoretische Kenntnisse und praktische und politische Erfahrungen verfügte" 86 . Ähnlich wie Hilde Benjamin kam sie erst aufgrund ihrer persönlichen Beziehung zu Heinze zum Kommunismus. Nach Großer Staatsprüfung (1938) und Hochzeit (1939) wurde sie beim Arbeitsamt Leipzig angestellt, während ihr Mann als Syndikus in der Leitung der Köllmann-Werke arbeitete ${ }^{87}$. Für den kommunistischen Widerstand in der sogenannten "Georg-Schumann-Gruppe" aktiv, wurden beide verhaftet, als die Gruppe 1944 aufflog. Während Wolfgang Heinze vom Volksgerichtshof am 24. November 1944 wegen Hochverrats zum Tode verurteilt und am 12. Januar 1945 hingerichtet wurde ${ }^{88}$, erhielt seine Frau, die erfolglos versucht hatte, ihn von seiner Tätigkeit abzubringen, wegen „Nichtanzeige eines hoch- und landesverräterischen Vorhabens" und Rundfunkverbrechens eine zweijährige Zuchthausstrafe $^{89}$. Ein späterer Vorwurf aus dem Jahre 1951, Hildegard Heinze habe der NSDAP angehört, ist unzutreffend ${ }^{90}$; sie war nur dem NSRB, der NSV und der

84 Auf die unzutreffenden Darlegungen dieser Vorgänge von Anders, Demokratisierung, in: Jahrbuch für Geschichte, S. 433, ist bereits von Lorenz, Zentralverwaltung, S. 141, und Amos, Justizverwaltung, S. 97, hingewiesen worden.

85 Fechner/Ulbricht an Dahlem und Gniffke, 28. 4. 1948, Eilt!, BAB, DP1 VA Nr. 1, Bl. 290.

86 Lebenslauf von Heinze, 14. 2. 1951, SAPMO, DY 30 IV 2/11/173, Bl. 61.

87 Personalien von Heinze, 20.6. 1951, BStU, MfS AP 2257/55, Bl. 7; zu Wolfgang Heinze siehe Weiß, Vom Tagebuch, S. 155.

88 Zur Verhandlung vor dem Volksgerichtshof, zur Urteilsbegründung und zum Todesurteil von Wolfgang Heinze ausführlich ebenda, S. 198-225, 273-276.

89 Urteil vom 24.11. 1944 in: Widerstand als Hochverrat, Fiche 0456; eine unvollständige Urteilsabschrift in: BStU, MfS AP 2257/55, Bl. 74-76, hier 75.

90 So die Beschuldigung in einem anonymen Schreiben an Ulbricht vom 1.8. 1951, ebenda, Bl. $68 \mathrm{f}$. Im Urteil vom 24.11. 1944 heißt es hingegen explizit: „Parteigenossin ist sie nicht“. 
DAF beigetreten ${ }^{91}$. Bei Kriegsende aus der Haft befreit, trat sie am 1. Juli 1945 der KPD bei und wurde wieder im Arbeitsamt Leipzig tätig, diesmal jedoch im Rang eines Regierungsrats. Im September 1945 wechselte sie zum sächsischen Ministerium für Arbeit und Sozialfürsorge, wo sie 1947 zum Ministerialdirektor befördert wurde und die Hauptabteilung Arbeit leitete92. Wie Hildegard Heinze, deren Biographie Parallelen zu der Hilde Benjamins aufweist und die sich zu einer ähnlich „furchtbaren Juristin“ entwickeln sollte, 1948 von der SED-Spitze ,entdeckt wurde, ist nicht ganz klar. Möglicherweise hatte Wolfgang Weiß ihren Namen ins Spiel gebracht, der mit Wolfgang Heinze seit dem Studium eng befreundet gewesen war und dessen Verteidigung vor dem Volksgerichtshof übernommen hatte ${ }^{93}$. Die Initiative von Ende April 1948 erwies sich nur als Vorstufe eines sehr viel umfassenderen Reorganisationsentwurfs für die DJV-Spitze. Denn am 5. Juni unterbreitete die Abteilung Justiz Fechner den Vorschlag, neben Melsheimer Benjamin als 2. Vizepräsidenten einzuberufen. Mit einer genauen Kompetenzaufteilung zwischen beiden Vizepräsidenten wollte die Justizabteilung vor allem verhindern, „daß sich Dr. Schiffer dazwischen schaltet“. Benjamin sollte auch weiterhin, unterstützt von einem noch einzustellenden „befähigte[n] Volksrichter“, die Ausbildungsabteilung leiten. Für die Leitung der Abteilung III war Heinze vorgesehen, während Nathan zum Direktor befördert und die Abteilung V übernehmen sollte. Wolfgang Weiß schließlich war unter Beförderung zum Ministerialdirigenten ebenfalls in der Abteilung $\mathrm{V}$ einzusetzen. Fechner fügte, bevor er die Vorlage dem Zentralsekretariat zur Beschlußfassung unterbreitete, noch hinzu: „Bei dieser Gelegenheit erfolgt durch die Umstellung zugleich eine Bereinigung des obersten Apparates durch Versetzungen und Freistellungen."94 Die Realisierung dieses Vorschlages, dem das Zentralsekretariat am 21. Juni zustimmte ${ }^{95}$, hätte eine faktische Machtübernahme durch die SED in der DJV bedeutet, bei der Schiffer zu einer bürgerlichen Galionsfigur degradiert worden wäre.

Die Umsetzung des Beschlusses setzte die Kooperation mit der SMAD-Rechtsabteilung voraus, die vor den Neubesetzungen die amtierenden Abteilungsleiter entlassen mußte. Zuerst traf es den Leiter der Abteilung I, Rosenthal-Pelldram (SPD), der am 16. Juni 1948 auf Anordnung des Chefs der SMAD-Rechtsabteilung gezwungen war, die DJV zu verlassen ${ }^{96}$. Am 24. Juni wurde als Begründung nachgeschoben, die Entlassung sei aufgrund von SMAD-Befehl Nr. 204 vom 23. August 1947 erfolgt. Das war jedoch ein Vorwand, da Rosenthal-Pelldram zwar während des Dritten Reiches im Justizdienst verblieben, er aber nicht zu den Personen zu zählen war, die, wie der Befehl ausführte, „an den Strafmethoden des Hitlerregimes unmittelbaren Anteil“" gehabt hatten"7. Durch Verfügung Schiffers

91 Personal-Fragebogen von Hildegard Heinze, 4. 9. 1948, BStU, MfS AIM 401/53, Bl. 2-4, hier 3.

92 Ebenda und Personalien von Heinze, 20. 6. 1951, BStU, MfS AP 2257/55, Bl. 7.

93 Vgl. Weiß, Vom Tagebuch, passim. Hildegard Heinze wird von Weiß nur am Rande erwähnt.

94 Abteilung Justiz an Fechner, 5. 6. 1948, BAB, DP1 VA Nr. 1, Bl. 291. Dort auch die Korrekturen und der Zusatz Fechners. Vgl. Amos, Justizverwaltung, S. 100.

95 Protokoll der Zentralsekretariatssitzung, 21. 6. 1948, SAPMO, DY 30 IV 2/2.1/209, TOP 8.

96 Verfügung Schiffers, 16. 6. 1948, in: Personalakte Rosenthal-Pelldram, BAB, DP1 SE Nr. 59; vgl. Amos, Justizverwaltung, S. 99.

97 Chef der DJV an Rosenthal-Pelldram, 24.6. 1948, BAB, DP1 SE Nr. 59; der Befehlstext in: ZVOBl. 1947, S. 191. 
vom 19. Juni 1948 trat der bisherige Leiter der Abteilung III, Winkelmann, „bis auf weiteres" an die Stelle Rosenthal-Pelldrams, so daß der von der SED für Heinze reklamierte Posten vakant wurde ${ }^{98}$. Danach nahm die SED den Leiter der Abteilung V, den ebenfalls der SPD angehörenden Karl Guski, ins Visier. Mitte Juli wurde ihm von seiten eines Genossen vorgeworfen, daß er einen Gesetzentwurf zur Reform des Unehelichenrechts für den Sozialpolitischen Ausschuß der SPD angefertigt und er bei der Bearbeitung von Handelsregistereintragungen eine Auslegungsmethode angewandt habe, durch die „einerseits fortschrittliche Maßnahmen gebremst, andererseits im Interesse der enteigneten Unternehmer liegende Methoden begünstigt worden" seien. Außerdem habe er gegenüber Weiß und Nathan erklärt, daß er sich an dem vom 2. Volkskongreß beschlossenen „Volksbegehren für Einheit und gerechten Frieden “99 nicht beteiligen werde, „da er der Parteidisziplin der SPD unterstehe" 100 . Zur selben Zeit ergab sich zudem die - von der SED-Führung nicht einkalkulierte - Chance, sich eines weiteren nicht-kommunistischen Abteilungsleiters zu entledigen. Denn Baptist Lentz (CDU) hatte sich, unter Verlängerung seines Urlaubs, zu einer Kur nach Bad Nauheim in die amerikanische Zone begeben. Schiffers Zweifel an der Absicht von Lentz, „seinen Dienst bei der DJV fortzusetzen“"101, erwiesen sich als berechtigt: Am 1. August 1948 bat dieser schriftlich um seine Entlassung aufgrund seines Gesundheitszustands ${ }^{102}$.

Die SED-Justizabteilung legte daraufhin - während des Urlaubs von Schiffer Fechner und Ulbricht nahe, Guski und Lentz aus der DJV zu entfernen, „damit die Genossin Heinze und der Genosse Nathan die politisch wichtigen Funktionen in der Deutschen Justizverwaltung übernehmen können “. Die beigefügten Entlassungsgründe wirkten wie nachgeschoben: Guski wurde vorgeworfen, daß er „die ihm im Rahmen der Justizverwaltung zugänglichen Informationen benutzt, um sie der SPD zuzuleiten und gleichzeitig seine Schumacher-Politik in der Deutschen Justizverwaltung durchzuführen“, und Lentz kreidete man seine - seit 1945 bekannte - Tätigkeit als Referent beim Reichskommissar zur Verwaltung feindlichen Vermögens während des Zweiten Weltkrieges an, und daß er seine Reise in den Westen „mit einem Flugzeug und mit Interzonenpaß der amerikanischen Regierung " durchgeführt habe ${ }^{103}$. Die SED-Justizabteilung, der offensichtlich das Abschiedsgesuch von Lentz nicht bekannt war, wollte folglich die Gunst der Stunde nutzen, um eine noch stärkere Bereinigung der DJV-Führungsspitze vorzunehmen, als der Zentralsekretariatsbeschluß vom 21. Juni vorgesehen hatte. Die Zusammenarbeit mit der SMAD-Rechtsabteilung funktionierte reibungslos. Nach der entsprechenden mündlichen Anweisung Jakupows vom 13. August

98 Verfügung Schiffers, 19. 6. 1948, BAB, DP1 VA Nr. 1044, Bl. 146.

${ }_{99}$ Das am 18.3. beschlossene Volksbegehren wurde vom 23.5. bis zum 13.6. 1948 durchgeführt: siehe SBZ von 1945 bis 1954, S. $71,77$.

100 Betrifft: Guski - Deutsche Justizverwaltung, 14. 7. 1948, BAB, DP1 VA Nr. 3, Bl. 165. Der oder die Verfasser des Vermerks sind nicht bekannt. Vgl. dazu Amos, Justizverwaltung, S. 98.

101 Chef der DJV an SMAD-Rechtsabteilung, 22. 7. 1948, BAB, DP1 VA Nr. 3, Bl. 166 f.; am 21. 7. 1948 hatte er bei Lentz angefragt, ob dieser in die DJV zurückkehren wolle, Personalakte Lentz, BAB, DP1 SE Nr. 91, Bl. 619.

102 Lentz an Schiffer, 1.8. 1948, ebenda, Bl. 622.

103 Abteilung Justiz an Fechner/Ulbricht, 5. 8. 1948, BAB, DP1 VA Nr. 1, Bl. 294. Vgl. dazu Amos, Justizverwaltung, S. $97 \mathrm{f}$. 
wurde Lentz tags darauf "wegen eigenmächtigen Verlassens des Dienstes“ suspendiert ${ }^{104}$. Am 14. August ordnete Jakupow an, die Abteilungsleiterstellen neu zu besetzen und gleichzeitig Guski „wegen Mangels einer Stelle im Stellenplan zu entlassen" ${ }^{105}$. Da Guski trotz Besetzung der Abteilungsleiterstelle nie zum Direktor befördert worden, sondern stets Dirigent geblieben war, traf dies nicht zu, was Jakupow umgehend mitgeteilt wurde. Wie zweitrangig solche Begründungen waren, zeigt die daraufhin gegebene Anweisung, Guski lediglich unter dem Hinweis zu entlassen, „daß dies auf Anordnung der SMAD geschehe“106. Noch am selben Tag führte Melsheimer die Order Jakupows aus ${ }^{107}$.

Am 14. August übermittelte Jakupow ebenfalls die Weisung der SMADRechtsabteilung, die vakanten Abteilungsleiterstellen neu zu besetzen: Während Heinze die Abteilung III zu übernehmen hatte, waren Weiß zum Leiter der Abteilung V und Nathan zum Leiter der Abteilung VII zu ernennen. Winkelmann, Benjamin, Gentz und Hartwig wurden gleichzeitig als Leiter der Abteilungen I, II, IV und VI bestätigt ${ }^{108}$. Die SMAD-Rechtsabteilung handelte damit ganz im Einvernehmen mit den zuständigen SED-Genossen. Denn es ging der SED-Justizabteilung sowie Melsheimer und Benjamin darum, Nathan in Abwesenheit von Schiffer „zunächst einmal zum Direktor zu machen“; danach, so das Kalkül, könne er auch unter der Ägide Schiffers sehr viel leichter „in die Leitung der Gesetzgebungsabteilung hinüberrutschen " 109 . Obgleich die SED-Spitze bereits im Juli bei Sokolowski Fechner als DJV-Präsidenten vorgeschlagen hatte ${ }^{110}$, rechneten die führenden SED-Juristen anscheinend noch mit Eugen Schiffer als Kontrahenten und wollten die Auseinandersetzung aus einer möglichst günstigen Ausgangsposition heraus führen.

Der DJV-Präsident, der in der ersten Augusthälfte in Urlaub war, wurde bei den Personalentscheidungen vom 14. August bewußt übergangen: Denn die SMAD-Rechtsabteilung ließ der DJV übermitteln, daß ihr Befehl zur Neubesetzung der Abteilungsleiterstellen „sofort auszuführen und nach seiner Ausführung Herrn Dr. Schiffer mitzuteilen" sei111. Auch als der beauftragte Dolmetscher der DJV auf die Anweisung Schiffers hinwies, „ihn vor jeder Personalveränderung davon in Kenntnis zu setzen", bekräftigte Jakupow die Entscheidung der Rechtsabteilung und fügte hinzu: „Dr. Melsheimer ist ja jetzt der Leiter der Deutschen Justizverwaltung." 112 Schiffer blieb nichts anderes übrig, als nachträglich die Gesprächsvermerke abzuzeichnen und zur Kenntnis zu nehmen. Damit stand für ihn eindeutig fest, daß die Rechtsabteilung ihm das Vertrauen entzogen hatte, und er reichte seinen Rücktritt ein ${ }^{113}$. Bereits zuvor, im April 1948, war Schiffer mit sei-

10+ Vermerk über Unterredung Jakupows mit Melsheimer, 13. 8. 1948; Chef der DJV an Lentz, 14. 8. 1948, Personalakte Lentz, BAB, DP1 SE Nr. 91, Bl. 627, 629.

105 Vermerk über ein Telefonat mit Jakupow, 14. 8. 1948, BAB, DP1 SE Nr. 3596, Bl. 931.

106 Vermerk über Unterredung mit Jakupow, 14. 8. 1948, ebenda, Bl. 932.

107 Chef der DJV an Guski, 14. 8. 1948, Personalakte Guski, BAB, DP1 SE Nr. 13, Bl. 87.

108 Vermerk über ein Telefonat mit Jakupow, 14. 8. 1948, BAB, DP1 SE Nr. 3596, Bl. 931.

109 Nathan, Aus der Geschichte der Zentralen Justizverwaltung, BAB, DP1 VA Nr. 6832, Bl. $12 \mathrm{f}$.

110 Siehe Kap. B.I.

111 Vermerk über ein Telefonat mit Jakupow, 14. 8. 1948, BAB, DP1 SE Nr. 3596, Bl. 931.

112 Vermerk über Unterredung mit Jakupow, 14. 8. 1948, ebenda, Bl. 932.

113 Darin ist die wichtigste Rücktrittsursache zu sehen: ähnlich Lorenz, Zentralverwaltung, S. 140, und Bordjugov, Rechtsabteilung, S. 79. Schiffer selbst äußerte sich auf einer Zusammenkunft der 
nem Projekt zur Reform des Gerichtsverfassungsgesetzes - einem Kernpunkt seiner Reformbestrebungen - am Widerstand von SMAD-Rechtsabteilung und SED gescheitert ${ }^{114}$. Möglicherweise trug auch die Verhaftung von Hermann Becker, des Vorsitzenden der LDP-Landtagsfraktion in Thüringen, am 23. Juli 1948 zu Schiffers Abschied bei. Denn der DJV-Präsident und weitere LDP-Vorstandsmitglieder hatten Becker Mitte Juli noch beschworen, in der SBZ zu bleiben, und speziell Schiffer hatte ihm zugesichert, ihn gegebenenfalls aus der Haft zu befreien, was sich jedoch angesichts der Verschleppung des LDP-Politikers durch die sowjetische Geheimpolizei als illusorisch erwies ${ }^{115}$. Aufgrund des Abschiedsgesuchs, das in den Akten nicht auffindbar ist, entließ Sokolowski den DJV-Präsidenten am 23. August mit Befehl Nr. 146 ${ }^{116}$, der Schiffer von Karassjow zwei Tage darauf in den Räumen der Zentralverwaltung eröffnet wurde. Es war zwar ein ehrenvoller Abschied - Schiffer wurde eine Pension von 80 Prozent seines Grundgehaltes gewährt -, aber Karassjow verlor bei dieser Gelegenheit kein Wort des Bedauerns ${ }^{117}$. Obgleich damit das "Stück gemeinsamen Weges“ zu Ende war, wollte die neue Führung den Kontakt zu Schiffer nicht ganz abreißen lassen und bot ihm bei der Staatsgründung sogar an, Präsident des Obersten Gerichts zu werden ${ }^{118}$. Schiffer ließ sich zwar nicht erneut einspannen, nahm aber die Ehrungen der DDR-Regierung zu seinem 90. und 91. Geburtstag dankend entgegen: Persönliche Eitelkeit und die illusionäre Hoffnung, auf diese Weise zur Aufrechterhaltung der deutschen Einheit beitragen zu können, mögen ihn zu diesem Verhalten bewogen haben ${ }^{119}$.

$\mathrm{Ob}$ in der SMAD, wie die Äußerung Jakupows vom 14. August nahelegt, erwogen wurde, Melsheimer zum Nachfolger Schiffers zu ernennen, läßt sich nicht klären. Am 2. Oktober hatte sie sich jedenfalls anders entschieden und ernannte mit Befehl Nr. 158 Fechner zum Präsidenten der DJV120. Zwar befand sich nunmehr die Leitung der Zentralverwaltung fest in den Händen der SED; dennoch waren die "Genossen Juristen“ in der DJV, wie sich Scheele 1953 erinnerte, alles andere als erfreut, einen Nicht-Juristen vorgesetzt zu bekommen. Außerdem hatte Melsheimer „wohl damit gerechnet, selbst Präsident zu werden“. Die Begründung Fechners für die Wahl seiner Person, „daß ein Politiker die Leitung übernehmen solle“, konnte Melsheimer, der sich ebenfalls als politischen Menschen betrachtete, nicht akzeptieren ${ }^{121}$. Wenngleich die DJV-Spitze nunmehr politisch homogen war, herrschten von Anfang an Spannungen unter den führenden Genossen ${ }^{122}$, die

stellvertretenden LDP-Vorsitzenden und Vertretern der Landesverbände am 6. 9. 1948 sehr zurückhaltend: Sein Ausscheiden sei ,in vollem Einvernehmen mit allen zuständigen Stellen aus rein sachlichen Meinungsverschiedenheiten erfolgt“, ADL, LDPD, L4, Nr. 367.

114 Vgl. dazu Kap. B.IX.2.

115 Vgl. Louis, Liberal-Demokratische Partei in Thüringen, S. 144, 146.

116 Vgl. Inventar, S. 159. Der Befehl zit. bei Amos, S. $105 \mathrm{f}$.

117 Vermerk über Besuch Karassjows bei Schiffer, BAB, DP1 SE Nr. 3596, Bl. 934.

118 Siehe dazu Kap. B.VII.2.

119 Zum 90 . Geburtstag veranstaltete die DDR-Regierung einen Festakt zu Ehren Schiffers: siehe NJ 4 (1950), S. 33. Schiffers Dankesschreiben an Melsheimer vom 25.2. 1950, in: BAB, DP1 SE Nr. 3596, Bl. 1246; das Glückwunschschreiben Ulbrichts zum 91. Geburtstag vom 14.2. und Schiffers Antwort vom 19. 2. 1951 in: Eberle, Mit sozialistischem Gruß, S. $110 \mathrm{f}$.

120 Siehe Kap. B.I.

121 Darlegungen Scheeles, BStU, MfS AU 307/55, Bd. 6, Bl. 172.

122 Fechner wollte anläßlich einer Abteilungsleitersitzung sogar „die Genossin Benjamin aus dem 
das Betriebsklima sowohl in der Zentralverwaltung als auch im Justizministerium in der Ära Fechner stark beeinträchtigten.

\section{Personalaustausch im höheren Dienst der DJV 1948/49}

Der Austausch der Abteilungsleiter war 1948 noch nicht abgeschlossen. Bereits bei Jahresende stand fest, daß Winkelmann, dessen Stelle im Geschäftsverteilungsplan für 1949 ohnehin nicht mehr vorgesehen war, ebenfalls ausscheiden würde; dies geschah am 15. Januar 1949 „im gegenseitigen Einverständnis“"123. Der Leiter des Zentralbüros, Wilhelm Eickhoff (LDP), verließ die DJV zum 31. März 1949, da er, wie es in den Akten heißt, „politisch nicht mehr mit[wollte]“124. Beide Männer waren offensichtlich nicht mehr bereit, auf der Leitungsebene einer Zentralverwaltung mitzuarbeiten, in der sie, die nicht der SED angehörten, eine absolute Minderheit darstellten. Nur der angepaßte Otto Hartwig (CDU) blieb als einziger nicht-kommunistischer Abteilungsleiter in der DJV und wechselte sogar noch mit hinüber ins MdJ.

Das Personalkarussell erfaßte 1948/49 die gesamte Zentralverwaltung. Auf allen Ebenen schieden in zunehmendem Maße diejenigen aus, die unter der Hegemonie der SED nicht mehr weiterarbeiten wollten oder durften. So ordnete die SMAD-Rechtsabteilung am 21. September 1948 an, die noch verbliebenen acht SPD-Mitglieder mit sofortiger Wirkung aus der DJV zu entlassen ${ }^{125}$. Einer genaueren Betrachtung bedürfen die dem höheren Dienst zuzurechnenden Vortragenden Räte und Oberjustizräte. Insgesamt schieden damals 14 Mitglieder des höheren Dienstes aus, davon zwei zum 31. März 1948. Diese beiden, der parteilose, aber mit der Linken sympathisierende Wolfgang Abendroth und Wilhelm Kolbe (LDP), verließen die DJV noch bevor dort das große Revirement einsetzte: Während Abendroth einem Ruf auf das völkerrechtliche Extraordinariat der Universität Leipzig folgte ${ }^{126}$, wechselte Kolbe auf eigenen Wunsch zur Zentralverwaltung für Umsiedler, wo er zum 1. April 1948 als Referent eingestellt wurde' ${ }^{127}$. Somit bleiben zwölf Vortragende Räte und Oberjustizräte, die die DJV nach den weitreichenden personellen Veränderungen auf der Leitungsebene verließen. Von diesen gehörten zwei der SED und drei der CDU an, während es sich bei den restlichen sieben um Parteilose handelte. Von den beiden SED-Mitgliedern, die erst 1948 eingestellt worden waren, erwies sich der eine, der Volksrichter Hellmuth

Amt werfen“: siehe Aktenvermerk über Unterredung mit Weiß, 12. 2. 1954, BStU MfS AU 307/55, Bd. 2, Bl. 52.

${ }_{123}$ Verzeichnis der seit 1945 ausgeschiedenen Angehörigen der DJV, BAB, DP1 VA Nr. 1009, Bl. 71.

124 Ebenda, Bl. 67.

125 Verfügung Melsheimers, 22. 9. 1948, BAB, DP1 VA Nr. 1, Bl. 296. Diese sowjetische Anordnung betraf ausschließlich Angehörige des gehobenen, mittleren und einfachen Justizdienstes und nicht, wie Lorenz, Zentralverwaltung, S. 141, Anm. 27 nahelegt, leitende Angestellte der DJV.

126 Vgl. Sterzel, Abendroth, S. 479. Dort auch Angaben zu seinem weiteren Lebensweg, der ihn 1951 an die Universität Marburg führte.

127 Vgl. Kolbe an Chef der DJV, 25. 2. 1948, Personalakte Kolbe, BAB, DP1 SE Nr. 90, Bl. 26. Die Information zur weiteren Verwendung Kolbes verdanke ich Dr. Michael Schwartz. 
Rehse ${ }^{128}$, als unfähig, während der andere, Horst Schulze, wegen Krankheit die DJV verließ129.

Die Ursachen für das Ausscheiden der übrigen zehn sind vielfältig; die Quellen enthalten so gut wie nie einen Hinweis auf politische Hintergründe. So wurden Krankheit ${ }^{130}$, Unfähigkeit ${ }^{131}$ und der Wunsch nach einem anderen Arbeitsgebiet ${ }^{132}$ angegeben; nur der Vermerk „Westen“ hinter den Namen der zwei ausgeschiedenen CDU-Mitglieder Wilhelm Casser und Josef Marx ${ }^{133}$ deutet auf eine möglicherweise politisch motivierte Flucht in die Westzonen hin. Damit ist jedoch keineswegs ausgeschlossen, daß politische Gründe den Ausschlag für das Ausscheiden aus der DJV gaben; bei Harald Poelchau ist dies aus seinen Erinnerungen sogar belegt ${ }^{134}$. Zudem ist auffällig, daß sechs Vortragende Räte und Oberjustizräte aus der Kontrollabteilung und der Gesetzgebungsabteilung innerhalb weniger Monate nach dem Abteilungsleiterwechsel die DJV verließen. Mit ziemlicher Sicherheit ist deshalb davon auszugehen, daß diese Mitarbeiter auch deshalb ausschieden, weil sie nicht "mehr mitkonnten oder mitwollten“"135. Nur die zwei parteilosen altgedienten Vortragenden Räte Ernst Meyer und Hermann Hirschfeld vollzogen den Wechsel ins DDR-Justizministerium, schieden jedoch zum 31. Dezember 1949 bzw. zum 30. April 1950 aus ${ }^{136}$. Lediglich Anton Vössing, der als Justizrat im September 1945 in der DJV begonnen hatte und zwischenzeitlich zum Oberjustizrat befördert worden war, wechselte als Hauptreferent ${ }^{137}$ ins MdJ und verblieb dort bis zum 31. Januar 1954138.

Als Ersatz für die ausgeschiedenen Angehörigen des höheren Dienstes wurden in den Jahren 1948/49 durchweg SED-Genossen eingestellt. Unter den elf Perso-

128 Vgl. Chef der DJV an SMAD-Rechtsabteilung, 8. 4. 1949, in: Personalakte Richter, BAB, DP1 SE Nr. 59.

129 Verzeichnis der seit 1945 ausgeschiedenen Angehörigen der DJV, BAB, DP1 VA Nr. 1009, Bl. 71.

130 Bei Martin Fenner, Else Koffka (beide parteilos) und Bernhard Schreiber (CDU): ebenda, Bl. $67 \mathrm{f}$., Personalakte Fenner, BAB, DP1 SE Nr. 13, Bl. 131-135, Personalakte Schreiber, BAB, DP1 SE Nr. 61, Bl. 461.

131 So die Angaben zu Irmela Ackermann und Joachim Seibt (beide parteilos), in: Verzeichnis der seit 1945 ausgeschiedenen Angehörigen der DJV, BAB, DP1 VA Nr. 1009, Bl. 66, 71.

132 So die Vermerke zu Harald Poelchau, Josef Weist, Kurt Zimmereimer (alle parteilos), ebenda, Bl. 70 f., Personalakte Weist, BAB, DP1 SE Nr. 2492. Weist und Zimmereimer wollten als Rechtsanwälte tätig werden.

133 Verzeichnis der seit 1945 ausgeschiedenen Angehörigen der DJV, BAB, DP1 VA Nr. 1009, Bl. 66,69 .

134 Vgl. zu dieser Problematik auch Amos, Justizverwaltung, S. 91 f.; zu Poelchaus Ausscheiden siehe Kap. B.V.2.

135 Seibt, Ackermann und Schreiber verließen die Abteilung III zum 31. 12. 1948, 15. 1. 1949 und 30. 6. 1949; Zimmereimer, Fenner und Weist schieden zum 31. 12. 1948, 30. 4. 1949 und 31. 8. 1949 aus der Abteilung $V$ aus. Das Zitat aus Benjamin, Bericht über die Entwicklung der Justiz in der SBZ im ersten Halbjahr 1949, BAB, DP1 VA Nr. 145, teilweise zit. bei Lorenz, Zentralverwaltung, S. $140 \mathrm{f}$.

136 Siehe Personalakte Meyer, BAB, DP1 SE Nr. 14. Hirschfeld wurde gekündigt, da er seinen Wohnsitz im Westsektor Berlins besaß: siehe MdJ an MdI, 17. 5. 1950, BAB, DP1 SE Nr. 448.

137 Nach dem ersten Quartal 1949 wurden in der DJV die Bezeichnungen Hauptabteilungsleiter für Direktor, Abteilungsleiter für Dirigent, Hauptreferent für Vortragender Rat, Oberreferent für Oberjustizrat und Referent für Justizrat eingeführt: vgl. Brather, Zonale Einrichtungen, S. 89. Diese Bezeichnungen wurden auch im MdJ beibehalten.

138 Vermerk 14. 1. 1954, BAB, DP1 SE Nr. 74. Vössing war Informant des UfJ; nach seiner Entlassung ging er nach West-Berlin: Vernehmungsprotokoll Reinartz, 11.3. 1955, BStU, MfS AU386/55, Bd. 1, Bl. 146; Eidesstattliche Erklärung Vössings, 18. 10. 1954, ebenda, Bd. 2, Bl. $213 \mathrm{f}$. 
nen befanden sich mit Hellmuth Rehse und Dorothea Stolzenburg erstmals auch zwei Absolventen von Volksrichterschulen ${ }^{139}$. Hinzu kamen zwei weitere, die nicht über eine akademische Juristenausbildung, aber über Erfahrungen im Justizdienst verfügten. Julie Ganske hatte vor 1933 als Bürovorsteherin bei einem Rechtsanwalt gearbeitet, wollte sich nach 1945 für die gehobene Justizlaufbahn ausbilden lassen, wurde aber 1946 aufgrund der Juristenknappheit zum Amtsanwalt und ein Jahr später zum Staatsanwalt ernannt. Ende Oktober 1948 als Vortragender Rat in die Abteilung III einberufen, bewährte sie sich dort und holte, ohne den Lehrgang selbst besucht zu haben, im März 1950 die Abschlußprüfung für Volksrichter in Berlin nach ${ }^{140}$. Kurt Richter, der im April 1949 als Hauptreferent in die Personalabteilung eingestellt wurde, war ebenfalls bei einem Rechtsanwalt tätig gewesen, bevor er nach einer entsprechenden Ausbildung 1923 im gehobenen Justizdienst angestellt worden war ${ }^{141}$. Sechs der verbleibenden sieben Personen hatten die traditionelle Juristenausbildung absolviert ${ }^{142}$; Karl Kroll war vor dem Krieg Sportlehrer gewesen ${ }^{143}$. Zusammen mit den Abteilungsleitern bildeten die Volljuristen nach wie vor die deutliche Mehrheit im höheren Dienst; unter kommunistischer Hegemonie war jedoch das „Volljuristenmonopol“ gelockert worden. Denn nur so konnten offensichtlich genügend Mitarbeiter rekrutiert werden, die neben einer fachlichen auch die erforderliche politische Qualifikation mitbrachten.

Die Mitglieder des höheren Dienstes wiesen zudem nicht mehr - wie noch vor 1948 - durchweg eine bürgerliche Herkunft auf ${ }^{144}$. Kommunistische kaderpolitische Prinzipien machten sich nun auch in der DJV bemerkbar, was einen deutlichen Bruch zu den Verhältnissen vor 1948 darstellte. Das Dritte Reich hatten einige der Hauptreferenten und späteren Abteilungsleiter im MdJ nur mit Karrierebrüchen oder zumindest beruflichen Benachteiligungen überstanden. So war das langjährige SPD-Mitglied Kurt Richter 1933 aufgrund des Gesetzes zur Wiederherstellung des Berufsbeamtentums aus dem Justizdienst entlassen, wegen illegaler Tätigkeit für die SPD 1935 verhaftet und zu einer zweijährigen Zuchthausstrafe verurteilt worden ${ }^{145}$. Weniger hart traf es den im Februar 1949 einberufenen Heinrich Reuter, dem im Dritten Reich aufgrund einer jüdischen Großmutter zwar die Zulassung als Rechtsanwalt entzogen wurde, der aber als Teilhaber in die Stahlgroßhandlung seines Vaters eintreten konnte ${ }^{146}$. Benachteiligungen hatte auch Hans-Joachim Schoeps zu ertragen, dessen Vater seit 1926 SPD-Provinzial-

139 Rehse hatte den ersten brandenburgischen, Stolzenburg den ersten mecklenburgischen Richterlehrgang absolviert: siehe Einsatz der Absolventen der 1.-3. Richterlehrgänge bei den Gerichten der Länder, 1950, BAB, DP1 VA Nr. 874, Bl. 4, 1.

140 Lebenslauf Ganskes, 1. 3. 1950, Personalakte Ganske, BAB, DP1 SE Nr. 74.

${ }^{141}$ Auszug aus den Personalakten des Ministerialrats Kurt Richter, in: Personalakte Richter, BAB, DP1 SE Nr. 59. Vgl. auch Lebenslauf Richter, 30. 7. 1952, BStU, Drdn AIM 1229/67, Bl. $23 \mathrm{f}$.

142 Werner Artzt, Rudolf Reinartz, Heinrich Reuter, Carlota Schindowski, Hans-Joachim Schoeps und Horst Schulze.

143 Vernehmungsprotokoll Fechner, 11. 8. 1953, BStU, MfS AU 307/55, Bd. 1, Bl. $101 \mathrm{f}$.

144 Dies traf nur auf Artzt, Reuter, Schindowski und Schoeps zu; Ganske, Rehse, Reinartz und Richter entstammten Arbeiterfamilien; über die drei anderen liegen keine Angaben vor.

${ }_{1+5}$ Auszug aus den Personalakten des Ministerialrats Kurt Richter, in: Personalakte Richter, BAB, DP1 SE Nr. 59; Lebenslauf Richter, 30. 7. 1952, BStU, Drdn AIM 1229/67, Bl. 23 f.

${ }^{146}$ Lebenslauf Heinrich Reuter, in: Personalakte Reuter, BAB, DP1 SE Nr. 59. 
landtagsabgeordneter in Breslau gewesen war. Schoeps, vor 1933 politisch nicht organisiert, trat trotz entsprechenden Drucks während seines Referendariats nicht in die NSDAP ein; 1935 wurde ihm die Stundung der Examensgebühren verweigert und vom Berliner Kammergerichtspräsidenten die Aussichtslosigkeit seiner juristischen Laufbahn verdeutlicht, so daß er ohne zweites Staatsexamen aus dem Justizdienst ausschied. Dies holte er erst 1946 als einer der ersten Prüfungskandidaten vor dem Prüfungsamt der DJV nach ${ }^{147}$. Der Ende 1949 ins MdJ einberufene, schwer kriegsversehrte Hauptreferent Rudolf Reinartz schließlich gab 1951 an, während seines Kriegsdienstes in der Wehrmacht „als Gegner der faschistischen Partei und des faschistischen Staates bekannt" gewesen zu sein. Daher sei er - im Unterschied zu anderen - nicht zu seinem Ersatztruppenteil zurückversetzt und an der Front durch einen Bombentreffer schwer verwundet worden ${ }^{148}$. Dabei handelte es sich freilich um eine "Reinterpretation“ mit der er offensichtlich verdecken wollte, daß er - was erst 1955 zutage gefördert wurde - von 1937 bis 1945 der NSDAP angehört hatte ${ }^{149}$. Als einziger der neu eingestellten Mitglieder des höheren Dienstes gab Werner Artzt eine Kompromittierung mit dem NS-Regime zu. 1933 war er kurz vor Abschluß seines Referendariats einem „Lehrsturm“ der SA als Anwärter beigetreten, um der Forderung nach Eintritt in eine NS-Organisation Genüge zu tun. Nachdem er sein Assessorexamen 1933 bestanden hatte, sei er dem SA-Dienst jedoch ferngeblieben und 1934 wieder ausgeschlossen worden. Als ,Pluspunkt ' in seinem Lebenslauf galt den Kommunisten dagegen vermutlich seine Teilnahme an Lehrgängen auf sowjetischen „Antifa-Schulen“ während seiner Kriegsgefangenschaft ${ }^{150}$. Einen solchen Vorzug konnte Karl Kroll, immerhin ein ehemaliger Wehrmachtsoffizier, nicht aufweisen. Er war als Bekannter Scheeles eingestellt worden, ohne daß dieser Aspekt seiner Vergangenheit thematisiert worden war ${ }^{151}$. Insgesamt handelte es sich bei den 1948/49 in den höheren Dienst Eingestellten daher in aller Regel nicht um Helden des „antifaschistischen Widerstands"; ihm gehörten mit Scheele und Reinartz jedoch nur zwei ehemalige NSDAP-Mitglieder an.

Bei der Rekrutierung der neuen leitenden Angestellten der DJV gab es nach wie vor Probleme mit den Landesjustizministerien, die sich noch im Frühjahr 1948 auf den Standpunkt stellten, daß sie „berechtigt seien, die Überlassung von juristischen Kräften an die Deutsche Justizverwaltung nicht mehr durchzuführen“152. Solche Konflikte sind noch bis 1949 nachweisbar. Besonders heftig gestaltete sich die Auseinandersetzung um die Einberufung von Schoeps aus dem brandenburgischen Justizministerium in die DJV. Aufgrund von Protesten von Innenminister Bechler gegen den Abzug von Schoeps wurde sogar die Personalabteilung des Zentralsekretariats eingeschaltet, bevor dieser zum 20. Juni seinen Dienst bei der

147 Lebenslauf Hans-Joachim Schoeps, in: Personalakte Schoeps, BAB, DP1 SE Nr. 61, Bl. $250 \mathrm{f.}$

148 Lebenslauf Rudolf Reinartz, 14. 1. 1950, SAPMO, DY 30 IV 2/11/176, B1. 209-211, hier 210; Lebenslauf vom 28. 11. 1952, BStU, MfS AU 386/55, Bd. 1, Bl. $75 \mathrm{f}$.

149 Vernehmungsprotokoll Reinartz, 3. 2. 1955, ebenda, Bl. 140.

150 Lebenslauf Werner Artzt, 24. 4. 1951, SAPMO, DY 30 IV 2/11/171, Bl. 51-54, hier $52 \mathrm{f}$.

151 Vernehmungsprotokoll Fechner, 11. 8. 1953, BStU, MfS AU 307/55, Bd. 1, Bl. $101 \mathrm{f}$.

152 So Schiffer gegenüber Karassjow, in: Nachtrag zum Vermerk vom 20.4. über die Unterredung Schiffers mit Karassjow, 24. 4. 1948, BAB, DP1 VA Nr. 11, Bl. 139. Karassjow wies die Auffassung der Länder zurück. 
DJV aufnahm ${ }^{153}$. Die DJV wiederum schaltete die SMAD-Rechtsabteilung ein und verbesserte unter den gegenüber den Jahren 1945 bis 1947 stärker zentralisierten Bedingungen ihre Position erheblich, so daß diese Konflikte nunmehr kaum noch zugunsten der betroffenen Länder ausgingen ${ }^{154}$. Die Zentralverwaltung konnte in dieser Zeit daher nicht nur Richter und Staatsanwälte, sondern auch Personal rekrutieren, das, wie Hans-Joachim Schoeps, Horst Schulze, Kurt Richter und Carlota Schindowski, durch seine Tätigkeit in einem Landesjustizministerium $^{155}$ auch Erfahrungen in der Justizverwaltung gesammelt hatte.

\section{Der Übergang zu einer neuen Struktur und einer neuen Arbeitsweise in der DJV 1948/49}

Die DJV erfuhr 1948/49 nicht nur eine weitgehende personelle, sondern auch eine strukturelle Veränderung. Bereits im Februar 1948 überprüfte eine auf SMADBefehl eingesetzte Personalbestandskommission bei der Zentralen Finanzverwaltung auftragsgemäß den Struktur- und Stellenplan der DJV und wies diese an, sowohl die Abteilungen VI und II als auch das Zentralbüro und die Abteilung VII miteinander zu vereinigen ${ }^{156}$. Schiffer, der Anfang 1948 noch ein gewisses Maß an Eigenständigkeit gegenüber SED und SMAD wahrte, führte diese Anweisung, die vor allem eine Ausweitung von Benjamins Kompetenzen bedeutet hätte, nicht aus $^{157}$. Als im Herbst 1948 die Deutsche Wirtschaftskommission, in der die Zentrale Finanzverwaltung inzwischen aufgegangen war, auf Weisung der SMAD eine Kürzung der Personalmittel um 20 Prozent des gesamten Verwaltungsapparats und einen entsprechenden Abbau von Planstellen anordnete, machte die DJV darauf aufmerksam, daß eine Verminderung ihrer Kräfte, „selbst wenn die Aufgaben nicht anwachsen, sondern nur die gleichen bleiben, nicht möglich [sei], wenn die Arbeitsfähigkeit der Verwaltung und der einzelnen Mitarbeiter erhalten bleiben soll“"158. Nach einer weiteren Aufforderung der DWK-Personalbestandskommission an die DJV, nochmals ihre Struktur und die Zahl ihrer Angestellten auf Einsparungsmöglichkeiten zu überprüfen ${ }^{159}$, signalisierte diese jedoch Entgegenkommen. Nach den DJV-Vorstellungen sollten an die Stelle der sieben Abteilungen und des Zentralbüros eine Verwaltungsabteilung und drei Hauptabteilungen tre-

153 Vermerk Benjamins, 17. 6. 1949, BAB, DP1 SE Nr. 3145, Bl. 271.

${ }^{154}$ So weigerte sich etwa das sächsische Justizministerium, am 21.12. 1948, Reuter für die DJV freizugeben (BAB, DP1 VA Nr. 1025, Bl. 146), hatte damit jedoch keinen Erfolg; das thüringische Justizministerium konnte mit seinem Protest vom 24. 12.1948 (ebenda, Bl. 148) die Einberufung von Witold Deutsch in die DJV verhindern. Fechner hatte beides gegenüber Jakupow vorgebracht: siehe Vermerk über die Besprechung Fechners mit Jakupow am 5. 1. 1949, BAB, DP1 VA Nr. 11, Bl. 159.

155 Schulze und Schoeps kamen aus der Justizverwaltung in Potsdam, während Richter und Schindowski in den Justizministerien in Dresden bzw. in Halle gearbeitet hatten.

156 Personalbestandskommission der DZFV an Chef der DJV, BAB, DP1 VA Nr. 7346. Dort auch SMAD-Befehl Nr. 23 vom 6. 2. 1948, auf dessen Grundlage die Kommission eingesetzt worden und in Aktion getreten war.

157 Benjamin an SED-Justizabteilung, 11. 10. 1948, BAB, DP1 VA Nr. 1, Bl. 300.

158 Darstellung der Personallage in der Justiz, 9. 9. 1948, BAB, DP1 VA Nr. 3, Bl. 168-170, hier 170.

159 Das Schreiben der DWK-Bestandskommission vom 21. 9. 1948 ist nicht erhalten; seine Existenz und sein Inhalt lassen sich jedoch aus dem Antwortschreiben der DJV vom 9. 10. 1948, BAB, DP1 VA Nr. 7852, erschließen. 
ten. In Hauptabteilung I (Leitung: Benjamin) wurde die ehemalige Personal- und die Ausbildungsabteilung zusammengefaßt. Hauptabteilung II (Leitung: Heinze) umfaßte die ehemalige Kontrollabteilung sowie die Strafvollzugsabteilung, während Hauptabteilung III (Leitung: Nathan) für Gesetzgebung zuständig war. Die ehemaligen Abteilungen I und VII wurden gestrichen; bestehen blieb lediglich eine Verwaltungsabteilung, die dem Leiter des Zentralbüros, Eickhoff, unterstellt werden sollte. Neben dem jeweiligen Hauptabteilungsleiter wurde jeder Hauptabteilung ein Abteilungsleiter zugeteilt, der ein geschlossenes Arbeitsgebiet zu bearbeiten hatte: In Hauptabteilung I war dies Hartwig (zuständig für Ausbildung), in Hauptabteilung II Gentz (zuständig für Strafvollzug) und in Hauptabteilung III Weiß (zuständig für Strafrecht) ${ }^{160}$.

Die Hintergründe für den Sinneswandel sind einmal darin zu suchen, daß man die Anordnungen der DWK - im Unterschied zur Zentralen Finanzverwaltung nicht mehr einfach ignorieren konnten. So wurde in dem Schreiben an die DWKPersonalbestandskommission darauf hingewiesen, daß mit dieser Neuorganisation der DJV immerhin sieben Stellen eingespart werden könnten ${ }^{161}$. Zweitens betonte die neue DJV-Spitze, daß die Reorganisation auch zu einer Optimierung des Verwaltungsaufbaus führe, bei der Abteilungen entstünden, „die alles Zusammengehörige konzentrieren"162. Dies traf zweifellos auf die Arbeitsgebiete Personalverwaltung und Ausbildung zu, da nicht nur Entlassungen und Neueinstellungen, sondern auch Aus- und Weiterbildungsmaßnahmen eng miteinander koordiniert werden mußten, um den Personalaustausch im Justizwesen zu effektivieren. Die Zusammenlegung der Kontroll- und der Strafvollzugsabteilung erscheint hingegen wenig sinnvoll, da die Kontrolle der Gerichte und die Überwachung der Strafvollzugseinrichtungen zwei deutlich voneinander getrennte Aufgabenbereiche darstellten. Schließlich - und darin liegt wohl die entscheidende Ursache für die Unterbreitung dieses Vorschlags - konnte mit Hilfe dieser Organisation die Hegemonie der SED-Juristen in der DJV noch weiter ausgebaut und abgesichert werden. Denn der einzige noch verbleibende nicht-kommunistische Abteilungsleiter, Hartwig, wurde nun auch formell Benjamin unterstellt, und für den Leiter der ehemaligen Abteilung I, Winkelmann, war keine entsprechende Stellung mehr vorgesehen.

Der neue Strukturplan, den Melsheimer bei der Amtseinführung von Fechner als Präsident der DJV am 8. Oktober 1948 Jakupow vortrug ${ }^{163}$, wurde von der SMAD-Rechtsabteilung in seinen Grundzügen genehmigt und trat zum 1. Januar 1949 mit einigen leichten Modifikationen in Kraft ${ }^{164}$. Die drei Hauptabteilungen firmierten nun als Hauptarbeitsgebiete, was einen etwas lockereren Zusammenhang innerhalb der Struktureinheit implizierte. Dieser Eindruck wird durch die Arbeitsaufteilung in einzelne Abteilungen verstärkt: So wurden im Hauptarbeits-

160 Siehe ebenda und DJV an Chef der SMAD-Rechtsabteilung, 9.10. 1948, BAB, DP1 VA Nr. 3, Bl. 183.

${ }_{161}$ Chef der DJV an DWK-Personalbestandskommission, 9. 10. 1948, BAB, DP1 VA Nr. 7852.

162 So Benjamin an SED-Justizabteilung, 11. 10. 1948, BAB, DP1 VA Nr. 1, Bl. 300.

${ }^{163}$ Siehe ebenda und Mitteilung Fechners vom 8. 10. 1948, BAB, DP1 VA Nr. 3, Bl. 177, daß er „mit dem heutigen Tage" sein Amt angetreten habe.

164 Siehe Chef der DJV an DWK-Personalbestandskommission, 17.12. 1948, BAB, DP1 VA Nr. 1, Bl. 304-309; Verfügung Fechners, 28. 12. 1948, BAB, DP1 VA Nr. 6213. 
gebiet I die Abteilungen 1 (Personal) und 2 (Schulung), im Hauptarbeitsgebiet II die Abteilungen 3 (Kontrolle und Statistik) und 4 (Strafvollzug) und im Hauptarbeitsgebiet 3 die Abteilungen 5 (Zivilrecht, öffentliches Recht) und 6 (Strafrecht, Zeitschrift) getrennt ausgewiesen. Die drei Hauptarbeitsgebiete unterstanden zwar, wie im Oktober in Aussicht genommen, jeweils einem Hauptabteilungsleiter; jedoch war dessen Kompetenz gegenüber dem damaligen Vorschlag eingeengt worden. „Die 6 Abteilungen der Hauptarbeitsgebiete I-III“, so hieß es in einem erläuternden Zusatz, „arbeiten auf den ihnen zugewiesenen Spezialgebieten selbständig und sind direkt dem Präsidenten bzw. Vizepräsidenten verantwortlich. Fragen von grundsätzlicher Bedeutung bedürfen der Mitwirkung des Leiters des Hauptarbeitsgebietes." Somit waren die Hauptabteilungsleiter primär für die ihnen unmittelbar zugeordneten Abteilungen - also Benjamin für Abteilung I/1 (Personal), Heinze für Abteilung II/3 (Kontrolle und Statistik) und Nathan für Abteilung III/5 (Zivilrecht, öffentliches Recht) - zuständig und nicht befugt, in die Angelegenheiten des jeweils anderen Abteilungsleiters einzugreifen. Wenngleich die Grundstruktur des SED-Konzepts beibehalten worden war, bildete nun wieder die Abteilung - und nicht die Hauptabteilung - das konstitutive Strukturelement der DJV. Die SMAD-Rechtsabteilung wollte anscheinend bei der Umstrukturierung der DJV weniger radikal vorgehen als die SED-Juristen.

Eine weitere strukturelle und personelle Änderung war einem persönlichen Wunsch Fechners geschuldet. So setzte er sich gegenüber der SMAD-Rechtsabteilung Anfang November dafür ein, daß sein Vertrauter Scheele in der DJV nicht nur als sein persönlicher Referent, sondern zugleich als Leiter der allgemeinen Verwaltungsabteilung eingestellt werden sollte, „die dann als Hauptabteilung neben die drei anderen Abteilungen zu stellen" sei ${ }^{165}$. Sein Antrag wurde, wie aus dem für 1949 genehmigten Strukturplan hervorgeht, bewilligt, so daß Eickhoff entgegen der ursprünglichen Planung - nicht mehr die Abteilung leitete, sondern nur noch als Referatsleiter innerhalb dieses Hauptarbeitsgebiets fungierte. Damit war für Scheele nicht zuletzt eine erhebliche materielle Besserstellung verbunden ${ }^{166}$.

Anfang 1949 wurden darüber hinaus, ebenfalls in Zusammenarbeit mit Karlshorst, die Voraussetzungen zur Umsetzung des justizpolitischen Programms der SED geschaffen. Seit der Justizkonferenz von Ende November 1948 wurde es bei weiteren Anlässen - sogar auf der Parteikonferenz vom Januar 1949167 - von Fechner vorgetragen ${ }^{168}$ und dessen Realisierung durch einzelne Maßnahmen, etwa in der Personalpolitik ${ }^{169}$, befördert. Dies genügte der SMAD-Rechtsabteilung nicht, die für Februar eine Besprechung mit der DJV-Spitze in Karlshorst ansetzte, um einen „perspektivische[n] Plan“ über konkrete Maßnahmen der Zentralverwaltung im Jahre 1949 zu besprechen; dazu hatte die Rechtsabteilung bereits Vorar-

165 Chef der DJV an SMAD-Rechtsabteilung, 5. 11. 1948, BAB, DP1 VA Nr. 1, Bl. 298.

166 Im Zentralsekretariat hatte er 1100, - Reichsmark verdient; in der DJV waren es 1583,-: siehe Protokoll der Zentralsekretariatssitzung, 24.6. 1947, SAPMO, DY 30 IV 2/2.1/104, TOP 14, und Amos, Justizverwaltung, S. 119.

167 Protokoll der Ersten Parteikonferenz, S. 246-251.

168 Siehe auch die Erklärung Fechners auf einer Arbeitstagung der leitenden Juristen der SBZ am 15. 1.

1949, in: Für die Festigung der demokratischen Rechtsordnung, in: NJ 3 (1949), S. 1-3.

169 Vgl. etwa Dok. 40 in: Wentker, Volksrichter, S. 227. 
beiten geleistet ${ }^{170}$. Ende Januar/Anfang Februar 1949 erstellten auch alle DJV-Abteilungen einen Halbjahresplan für ihre Sachgebiete ${ }^{171}$, der am 9. Februar in einer ganztägigen Sitzung in Karlshorst besprochen wurde ${ }^{172}$. In seinen einleitenden Ausführungen definierte Fechner - unter Rückgriff auf erprobte Floskeln - die Aufgaben der Justiz mit Blick auf die Sicherung der „demokratischen Errungenschaften" und des im Zeichen des Zweijahrplans stehenden wirtschaftlichen Wiederaufbaus. Zum Schutz des „demokratischen Aufbaues“ und vor allem des Volkseigentums "gegen Saboteure" müsse die Justiz hart und konsequent vorgehen. Zentrale Lenkungsinstanz war für ihn die DJV, deren Zuständigkeit daher gegenüber den Landesjustizministerien „zu stärken und auszubauen“ sei ${ }^{173}$. Unter diesen Voraussetzungen wurden in einem sehr viel stärkeren Maße als bisher die justizpolitischen Vorgaben der SED, wie sie in den Resolutionen der Justizkonferenz vom November formuliert worden waren, auch für die Arbeit der einzelnen Abteilungen relevant. Die sowjetische Mitwirkung an der Formulierung des Halbjahrplans ist vor allem für die Kontrollabteilung, die in besonderem Maße für die Durchführung des Zweijahrplans verantwortlich gemacht wurde, nachweisbar: Denn Nikolajew gab insbesondere Schwerpunkte sowie Bewertungsmaßstäbe für die Steuerung der Rechtsprechung vor ${ }^{174}$. Die Formulierung von Arbeitsplänen und die Überprüfung im Hinblick auf die Planerfüllung trugen indes nicht nur zur inhaltlichen Umsetzung der SED-Vorstellungen bei; auch äußerlich versuchte die Justizverwaltung dadurch zu signalisieren, daß sie nun nicht mehr der Wirtschaft und der Verwaltung "hinterherhinkte“, sondern aufgeholt hatte ${ }^{175}$.

\section{Die Ernennung von Helmut Brandt zum 2. Vizepräsidenten}

Angesichts der systematischen Verdrängung der Nicht-Kommunisten aus der Führungsetage der DJV in den Jahren 1948/49 überrascht die Ernennung des damals in der Berliner Landespolitik hervorgetretenen CDU-Politikers Helmut Brandt zum 2. Vizepräsidenten im April 1949. Sie widersprach insbesondere der Zielsetzung des SED-Zentralsekretariats, das ja am 21. Juni 1948 noch beschlossen hatte, Benjamin zur 2. Vizepräsidentin vorzuschlagen: eine Entscheidung, die zeigt, daß die SED-Führung damals nicht mehr gewillt war, bei der Besetzung von Stellen den durch die Blockpolitik vorgegebenen Parteienproporz zu berücksichtigen ${ }^{176}$.

170 Vermerk über Unterredung zwischen Fechner und Nikolajew am 18. 1. 1949, BAB, DP1 VA Nr. 11, Bl. 160.

171 Siehe die Arbeitspläne der einzelnen Abteilungen in: BAB, DP1 VA Nr. 6214.

172 Verfügung Fechners, 7. 2. 1949, BAB, DP1 VA Nr. 289, Bl. 19.

173 Disposition für den Vortrag in Karlshorst am 9. 2. 1949, BAB, DP1 VA Nr. 3, Bl. 207-216, hier 208, 210.

174 Siehe dazu Kap. B.VIII.1.

$175 \mathrm{Vgl}$. in diesem Zusammenhang auch die Veröffentlichungen von Scheele, Auch die Justiz, sowie von Heinze, Kritisches zum ersten Arbeitsplan.

176 Daher ist die Erklärung von Amos, Justizverwaltung, S. 112f., die Auswahl von Brandt für die Vizepräsidentenstelle sei „dem Parteienproporz geschuldet“ gewesen, unzutreffend. Dies schließt nicht aus, daß er, einmal im Amt, durchaus als blockpolitisches ,Feigenblatt' vorgezeigt werden konnte. 
Geboren 1911 als Sohn eines Polizeibeamten in Berlin-Spandau, besuchte Brandt zuerst ein Lehrerseminar, wechselte jedoch 1920 zur Oberrealschule und 1923 zum Gymnasium, wo er 1929 die Reifeprüfung ablegte. Nachdem er bereits gegen Ende seiner Schulzeit Vorlesungen an der Hochschule für Politik gehört hatte, schrieb er sich dort 1929 ein, studierte aber gleichzeitig an der Berliner Universität Rechtswissenschaft und Nationalökonomie. Nebenbei belegte er russische und japanische Sprachkurse. Nach seinem Studium legte er in Politik und Volkswirtschaft die Diplomprüfungen ab (1931 und 1932), bestand das erste und zweite juristische Staatsexamen (1933 und 1937) und wurde zudem noch „summa cum laude" zum Dr. rer. pol. und zum Dr. iur. promoviert (1933 und 1936) ${ }^{177}$. Parallel zu seinem Referendariat war er als Volontär bei der Deutschen Bank tätig. Im Anschluß an seine Studien wurde Brandt 1937 Referent für internationales Wirtschaftsrecht an dem renommierten Kaiser-Wilhelm-Institut für ausländisches öffentliches Recht und Völkerrecht in Berlin und verschaffte sich zudem ein zweites berufliches Standbein, indem er nebenher seit 1938 als Anwaltsassessor in der Rechtsanwaltspraxis von Karl von Lewinski arbeitete. 1940 erhielt er eine eigene Zulassung als Rechtsanwalt. Brandt wurde im September 1939 eingezogen und nahm sowohl am Westfeldzug als auch am Krieg gegen die Sowjetunion teil. Ab Oktober 1942 war er im Wirtschafts- und Rüstungsamt des OKW tätig; nach dessen Zerschlagung arbeitete er von Juli bis November 1943 im Rüstungsministerium ${ }^{178}$. Anschließend erneut an die Ostfront abkommandiert, geriet er wenige Tage nach der deutschen Kapitulation in britische Gefangenschaft. Sechs Wochen danach an die Amerikaner übergeben, ließen ihn diese im Juni frei, so daß er bereits im Juli 1945 wieder nach Berlin zurückkehren konnte ${ }^{179}$.

Politisch hatte sich Brandt aufgrund einer Begegnung mit Stresemann seit 1929 in der DVP betätigt und war nach 1931 Volontär der DVP-Fraktion im Reichstag geworden. Brandt konnte während des Dritten Reiches zwar einen Beitritt zur NSDAP vermeiden und wurde lediglich Mitglied des NSRB, zählte eigenem Bekunden zufolge dort jedoch „zu den Personen, die als politisch nicht einwandfrei galten“180. Dem NS-Regime stand er distanziert gegenüber. Dies zeigt unter anderem seine Bekanntschaft mit dem Berliner Völkerrechtler Erich Kaufmann, dem die Nationalsozialisten die Lehrbefugnis entzogen hatten. Brandt nahm an den in dessen Privathaus stattfindenden Treffen teil, wo "gegen Hitler diskutiert [wurde], ohne jedoch etwas gegen ihn zu unternehmen"181. Nach seiner Rückkehr nach Berlin im Juli 1945 arbeitete er zunächst als Syndikus beim Bezirksamt Spandau und wurde im Frühsommer 1946 sogar zum 2. Bürgermeister von Spandau gewählt; da er von der britischen Besatzungsmacht jedoch nicht bestätigt wurde,

177 Ebenda und Vernehmung Brandts, 19. 9. 1950, BStU, MfS AU 449/54, Bd. 3, Bl. 218f.; Personalfragebogen Brandts, 12.4. 1949, ebd., Bl. 65; Lebenslauf Brandt, 14.12. 1949, BAB, DP1 VA Nr. 855, Bl. 4.

178 Die Tätigkeit beim OKW und im Rüstungsministerium hatte Brandt von 1945 bis 1951 aus Furcht vor Karrierebeeinträchtigungen verschwiegen: siehe Vernehmungsprotokoll, 12. 5. 1951, BStU, MfS AU 449/54, Bd. 14, Bl. $86 \mathrm{f}$.

179 Vernehmung Brandts, 19. 9. 1950, BStU, MfS AU 449/54, Bd. 3, Bl. 220-223.

180 Ebenda, Bl. 219.

181 Vernehmung Brandts, 1. 12. 1958, BStU, MfS AU 335/59 UV, Bd. 1, Bl. 384 (Zitat); Aussage Brandts im Prozeßbericht, BStU, MfS AU 449/54, Bd. 23, Bl. 95. 
konzentrierte er sich nun wieder auf seine Anwaltspraxis, die er seit 1945 wiederaufgebaut hatte. Trotz fortbestehender wissenschaftlicher Interessen - seit 1946 war er als Lehrbeauftragter für internationales und öffentliches Recht an der Berliner Universität tätig - war ihm die berufliche Absicherung durch seine Berliner Anwaltspraxis anscheinend wichtiger als eine wissenschaftliche Laufbahn im Westen, die er auch hätte einschlagen können ${ }^{182}$. Politisch engagierte er sich seit seiner Rückkehr aus der Gefangenschaft im August 1945 in der CDU. In deren Hauptgeschäftsstelle in Berlin wurde er 1946 Referent für Verfassungsfragen, Verwaltungsaufbau und Kommunalpolitik ${ }^{183}$. Außerdem hatte er seit Herbst 1946 ein Mandat für die CDU in der Berliner Stadtverordnetenversammlung inne ${ }^{184}$.

Brandt verzieh dem im Dezember 1947 von der SMAD abgesetzten CDU-Vorsitzenden Jakob Kaiser nie, die Ost-CDU verlassen zu haben. Er selbst ließ sich am 18. März 1948 - angeblich im Auftrag von CDU-Generalsekretär Georg Dertinger - von dem am selben Tag zusammengetretenen 2. Volkskongreß in den Deutschen Volksrat wählen, wo er im Justiz- und Verfassungsausschuß wirkte ${ }^{185}$. Er setzte auf eine unabhängige, aber keine antisowjetische CDU in der SBZ und Berlin und übernahm den Vorsitz des am 24. April 1948 von der SMAD ins Leben gerufenen (CDU-),Arbeitskreises Groß-Berlin“, der dem westlich ausgerichteten Berliner Landesverband Konkurrenz machte. Wenngleich er dort nicht zu den radikalen, der sowjetischen Besatzungsmacht treu ergebenen Kräften zählte, diente er dem Arbeitskreis doch als „bürgerliches Aushängeschild“, das zudem im Westen der Stadt beruflich tätig war ${ }^{186}$. Mit Hilfe des Arbeitskreises, der vom CDUHauptvorstand schon bald als neuer Berliner Landesverband anerkannt wurde, gelang schließlich die Spaltung der Berliner CDU; Brandt hatte durchaus dazu beigetragen. Ein zweites Mal wollte er sich jedoch nicht als „repräsentatives Ausstellungsstück mißbrauchen lassen“. Als er nach der Spaltung des Berliner Senats zum Oberbürgermeister im Ostteil der Stadt gewählt werden sollte, lehnte er ab; auf den Rat des Ost-CDU-Vorsitzenden Otto Nuschke fand er sich aber bereit, formell Friedrich Ebert von der SED zu nominieren ${ }^{187}$.

Die Besatzungsmacht protegierte Brandt auch in der Ausübung seines Anwaltsberufs. Als dieser im April 1948 bei der DJV beantragte, ihm eine Genehmigung zum Auftreten als Strafverteidiger in der SBZ zu erteilen, lehnte die Zentralverwaltung dies zunächst unter Berufung auf eine Anweisung der SMAD-Rechtsabteilung ab ${ }^{188}$. Am 29. April teilte Nikolajew jedoch mit, „daß die Rechtsabtei-

182 Vernehmung Brandts, 17. 10. 1950, BStU, MfS AU 449/54, Bd. 3, Bl. 234.

$183 \mathrm{Vgl}$. Struktur und Besetzung der Reichsgeschäftsstelle am 31.12. 1945 sowie im 1. Halbjahr 1946, in: Wilde, SBZ-CDU, S. 531-533.

184 Vernehmungsprotokoll, 16. 7. 1951, BStU, MfS AU 449/54, Bd. 3, Bl. $248 \mathrm{f}$.

185 Ebenda, BI. 251 f.; Braas, Verfassungsgebung, S. 375. Brandt wurde wegen seiner Teilnahme am Volkskongreß von der CDU-Stadtverordnetenfraktion am 15.4. 1948 ausgeschlossen: vgl. Schlegelmilch, Hauptstadt, S. 315.

186 Vgl. Richter, Ost-CDU, S. 139 f. Brandt argumentierte gegenüber dem MfS, er sei in dem Arbeitskreis nur aktiv geworden, um die dort tätigen "fortschrittlichen“ Kräfte zu isolieren (Vernehmungsprotokoll, 16. 7. 1951, BStU, MfS AU 449/54, Bd.3, Bl. 253 f.). Möglicherweise wurde Brandt diese Lesart vom MfS in den Mund gelegt. Er benutzte dasselbe Argument nach seiner Haftentlassung, Brandt an Dufhues, 15. 5. 1965, ACDP I-296.

187 Vgl. ebenda (Zitat) und Richter, Ost-CDU, S. $151 \mathrm{f}$.

188 Brandt an DJV, 10. 4. 1948, DJV an Brandt, April 1948, BAB, DP1 SE Nr. 3536. 
lung der SMAD keine Einwendungen gegen die generelle Zulassung des Rechtsanwalts Brandt bei den Gerichten der SBZ habe " 189 . Brandt beantragte - wohl auf sowjetische Veranlassung - am 24. Juli erneut seine Zulassung vor den Gerichten der SBZ. Noch bevor Brandt den Antrag gestellt hatte, erteilte die SMAD-Rechtsabteilung ihr Plazet, so daß die DJV am 2. August Brandt eine entsprechende Bescheinigung über seine Zulassung vor allen Gerichten der SBZ übersandte ${ }^{190}$. Auf Nachfrage der DJV in Berlin-Karlshorst erhielt sie von dort die Auskunft, daß es sich dabei um einen „Ausnahmefall“ handle: „es bestehe nicht die Absicht, dieselben Rechte einem anderen Rechtsanwalt zu gewähren. "191 Die Auftrittsgenehmigung vor den Gerichten in der SBZ war offensichtlich eine Gegenleistung der sowjetischen Besatzungsmacht gegenüber dem West-Berliner Anwalt, der sich bereit gefunden hatte, an die Spitze des „Arbeitskreises Groß-Berlin“ zu treten.

Die Ernennung Brandts zum 2. Vizepräsidenten der DJV ist zweifellos auch auf die sowjetische Besatzungsmacht zurückzuführen. Im Hintergrund stand die zunehmende Verdrängung Brandts aus dem Vorstand des Ost-Berliner CDUVerbands durch offen prosowjetische Kräfte um Arnold Gohr. Die SMAD wollte jedoch Brandt nicht fallen lassen, und nahm ihn aus der Schußlinie, indem sie ihn zum DJV-Vizepräsidenten „beförderte[.]“"192. Warum besaß die Besatzungsınacht aber ein solches Interesse an dem CDU-Politiker? Der Schlüssel zu diesem Problem liegt wohl in der sowjetischen Deutschlandpolitik. Einer nachträglichen Aussage Brandts zufolge teilte der Ost-CDU-Vorsitzende ihm im Frühjahr 1949 mit, daß die Sowjetunion im Zusammenhang mit den nach Beendigung der Berlin-Krise wieder aufzunehmenden Viermächte-Verhandlungen möglicherweise beide, Nuschke und Brandt, für Funktionen in einer gesamtdeutschen Regierung vorschlagen wolle. „Zur Vorbereitung einer solchen Tätigkeit" habe die SMAD den Eintritt Brandts als Vizepräsident in die DJV vorgesehen ${ }^{193}$. Angesichts anderer Indizien, die auf die Wiederbelebung der gesamtdeutschen sowjetischen Zielsetzung in dieser Zeit hindeuten ${ }^{194}$, spricht einiges für diese Begründung.

Die weiteren Schritte waren rasch vollzogen. Nachdem das Kleine Sekretariat des SED-Politbüros am 4. März sein Plazet gegeben hatte ${ }^{195}$, wurde tags darauf in einer Besprechung mit Brandt in der DJV vereinbart, daß er sich vor allem um Angelegenheiten des Strafvollzugs, die Bibliothek und die Herausgabe von Gesetzestexten kümmern solle; sein Wunsch, sich mit verfassungs- und völkerrechtlichen Fragen beschäftigen zu dürfen, wurde ebenfalls erfüllt. Außerdem bestand „Übereinstimmung darüber, daß der Vizepräsident Dr. Melsheimer den Chef in dessen Abwesenheit oder in seinem Auftrage in bisher üblicher Weise vertritt" ${ }^{196}$. Sowohl

189 Vermerk über Telefonat mit Nikolajew, 29. 4. 1948, ebenda.

190 Brandt an DJV, 24. 7. 1948; Vermerk über Telefonat mit Nikolajew, 20. 7. 1948; DJV an Brandt, 2. 8. 1948 , ebenda.

191 DJV an SMAD-Rechtsabteilung, 4. 8. 1948; Vermerk Walter, 13. 8. 1948, ebenda.

192 So Richter, Ost-CDU, S. 153, der darin die Hauptursache von Brandts Wechsel zur DJV sieht. „Der Abend" meldete bereits am 19.2. 1949 die bevorstehende Ernennung Brandts zum Vizepräsidenten („Zum Präsidenten hinausbefördert“).

193 Vernehmungsprotokoll, 17. 9./26. 9. 1958, BStU, MfS AU 335/59 UV, Bd. 1, Bl. 135 f.; vgl. auch Vernehmungsprotokoll, 10./10./27. 10. 1958, ebenda, Bl. 223.

194 Vgl. Keiderling, Vehikel-Funktion, S. 54.

195 Protokoll der Sitzung des Kleinen Sekretariats, 4. 3. 1949, SAPMO, DY 30 J IV 2/3/10, TOP 29. 196 Vermerk über die Besprechung mit Brandt am 5. 3. 1949, 7. 3. 1949, BAB, DP1 VA Nr. 855. Ver- 
mit der Beschränkung von Brandt auf Arbeitsgebiete von untergeordneter Bedeutung als auch durch die eindeutige Klärung der Vertretungsfrage war sichergestellt, daß dieser aus seiner Ernennung zum Vizepräsidenten, die schließlich am 11. April 1949 erfolgte, keinen Führungsanspruch ableitete. Brandt nahm dies alles anscheinend nur deshalb hin, weil er, wie er rückblickend darlegte, seine Tätigkeit in der Justizverwaltung "nur als vorübergehend“ betrachtete ${ }^{197}$.

\section{Das Justizministerium in der Ära Fechner: Struktur, Personalpolitik und Besetzung}

\section{Die Struktur des MdJ zwischen Kontinuität und Wandel}

Die DJV gehörte zu den Zentralbehörden, die laut Gesetz „mit ihren Aufgaben in die entsprechenden Ministerien der Deutschen Demokratischen Republik eingegliedert" 198 wurden. De facto wechselte die Zentralverwaltung mit der DDRGründung lediglich den Namen in "Ministerium der Justiz“. Der ab dem 1. November 1949 gültige Strukturplan des Mdj199 wies jedoch - trotz erkennbarer Kontinuitäten - eine Reihe von Unterschieden gegenüber dem der DJV vom Januar desselben Jahres auf. Am auffälligsten ist der weitgehende Wegfall der jeweils zwei Abteilungen umfassenden „Hauptarbeitsgebiete“, so daß Ausbildungs- und Personalangelegenheiten wieder in zwei voneinander getrennten Abteilungen ("Schulung" und „Personal“) bearbeitet wurden. Auch zur Behandlung der Verwaltungsangelegenheiten mußte fortan eine Abteilung genügen. Neben diesen drei Abteilungen wies der neue Strukturplan drei Hauptabteilungen auf: Gesetzgebung (Hauptabteilung I), Rechtsprechung, Revision und Statistik (Hauptabteilung II) und Strafvollzug (Hauptabteilung III). Das „Hauptarbeitsgebiet“ Gesetzgebung hatte lediglich eine andere Bezeichnung erhalten; innerhalb der Hauptabteilung blieben die beiden Abteilungen für Bürgerliches Recht, Zivilprozeß und öffentliches Recht sowie für Strafrecht und Strafverfahren bestehen. Das Hauptarbeitsgebiet II (Kontrolle, Statistik und Strafvollzug) war in zwei Hauptabteilungen aufgegliedert worden. Dies entsprach zum einen der gesteigerten Bedeutung der Justizsteuerung als Aufgabe des MdJ; zum anderen wurden mit der Schaffung einer Hauptabteilung Strafvollzug Planungen zum Ausbau der Abteilung konsequent umgesetz ${ }^{200}$. Es handelte sich bei diesen Änderungen zwar nicht um eine grundlegende Neuordnung, jedoch auch nicht um eine einfache Übernahme der DJV-Struktur ins MdJ201.

Vor der Genehmigung des detaillierten Struktur- und Stellenplans fand am 2. November 1949 eine Unterredung zwischen hochgestellten Vertretern des Ju-

mutlich war Benjamin seine Gesprächspartnerin. Vgl. auch Verfügung Fechners, 19. 4. 1949, BAB, DP1 VA Nr. 3, Bl. 250.

197 Vernehmungsprotokoll, 17.9./26. 9. 1958, BStU, MfS AU 335/59 UV, Bd. 1, Bl. 136.

198 Gesetz zur Uberleitung der Verwaltung, 12. 10. 1949, in: GBl. 1949, S. 17.

199 Vgl. Bekanntmachung über den Strukturplan der Provisorischen Regierung der DDR vom 1.11. 1949, in: Ministerialblatt 1949, S. 2-4, hier 4.

200 Siehe Kap. B.V.2.

201 Dies im Gegensatz zu Künzel, Ministerium der Justiz, S. 170. 
stizministeriums sowie des Innen- und des Finanzministeriums statt. Dabei blieben vor allem zwei Stellenwünsche des MdJ auf der Strecke: Weder die Hauptabteilung II noch die Hauptabteilung III erhielt die angestrebten Abteilungsleiterstellen. Gebilligt wurde jedoch, daß der persönliche Referent des Ministers weiterhin in Personalunion mit der Leitung der - nunmehr sehr viel niedriger eingestuften - Verwaltungsabteilung betraut wurde und dafür ein Hauptabteilungsleitergehalt bezog: Scheele sollte sich schließlich durch den Wechsel von der DJV zum MdJ nicht verschlechtern ${ }^{202 !}$

Die SKK übte heftige Kritik an dem Strukturplan. Der Leiter der Verwaltungsabteilung Kabanow monierte in einem Schreiben an Ulbricht, daß die von Fechner vorgeschlagene und von der DDR-Regierung akzeptierte Struktur nur ein Personalreferat vorsehe, während in der DJV eine mit sehr weitgehenden Kompetenzen ausgestattete Personalabteilung existiert habe. Die „Liquidierung der Personalabteilung und die Bildung eines rechtlosen Personalreferates an deren Stelle [sei] das Ergebnis von Fechners Bemühungen, sich von einem speziellen Organ zu befreien, das die Arbeit mit Kadern kontrolliert und leitet und sich freie Hand in der Durchführung seiner eigenen Kaderpolitik zu lassen“. Fechners Kaderpolitik sei aber, wie an dessen ungerechtfertigten Anträgen auf Ausnahmeregelungen bei der Anwendung des Befehls Nr. 204 ersichtlich, zu liberal. Daher forderte Kabanow abschließend „die Änderung der Struktur des Justizministeriums der DDR zwecks Bildung einer Personalabteilung “203. Während das Anliegen, die Personalarbeit von Fechner fernzuhalten und in die Hände eines „erfahrenen und parteitreuen Parteifunktionär[s]“ zu legen, nachvollziehbar ist, entbehrt der Vorwurf gegen den Justizminister, ein Personalreferat und nicht eine Personalabteilung eingerichtet zu haben, jeder Grundlage ${ }^{204}$. Denn in dem im Ministerialblatt abgedruckten Organisationsschema, auf das sich Kabanow offensichtlich bezog205, wird eine Personalabteilung aufgeführt. Es handelte sich somit um ein Mißverständnis auf seiten der SKK, das möglicherweise darauf zurückgeführt werden kann, daß, wie aus den Strukturplanentwürfen vom 6. und 25. Oktober hervorgeht, die drei Abteilungen des MdJ dem Minister "unmittelbar unterstellt" waren ${ }^{206}$. Außerdem wurde die Personalabteilung nach Benjamins Ausscheiden zunächst nicht von einem hauptamtlichen Abteilungsleiter, sondern lediglich von einem Hauptreferenten, dem ehemaligen Sozialdemokraten und Fechner-Protegé Richter, kommissarisch geleitet. Welche Konsequenzen aus dem Brief gezogen wurden, ist nicht bekannt: An der Behandlung der Personalfragen innerhalb einer Personalabteilung änderte sich jedenfalls nichts. Die SKK blieb jedoch weiterhin

202 Vgl. Strukturplan des MdJ, 25. 10. 1949, und Niederschrift über die Besprechung des Strukturund Stellenplanes des Ministeriums der Justiz (früher Deutsche Justizverwaltung), 2.11. 1949, BAB, DP1 VA Nr. 5577, Bl. 24-27, 35 f.

${ }^{203}$ Kabanow an Ulbricht, 17. 1. 1950, in: Amos, Justizverwaltung, S. $257 \mathrm{f}$.

204 Dies im Gegensatz zu Amos, Justizverwaltung, S. 120, die den Vorwurf Kabanows als gerechtfertigt ansieht.

205 Der einleitende Satz des Schreibens lautet: „Die Regierung der Deutschen Demokratischen Republik hat am 10. November 1949 die von Minister Max Fechner vorgeschlagene Struktur des Justizministeriums der DDR angenommen." Die Bekanntmachung über die Regierungsstruktur im Ministerialblatt datiert zwar vom 1.11. 1949, die Ausgabe des Ministerialblatts jedoch vom 10.11. 1949.

206 Beide in: BAB, DP1 VA Nr. 5577, Bl. 2-6, 24-27. 
an der Aufwertung der "Kaderarbeit“ interessiert und wies Fechner im Sommer 1950 an, „alle Schritte zu unternehmen, die erforderlich sind, um eine Hauptabteilung Personal und Schulung [...] unter der Leitung eines Hauptabteilungsleiters bestätigt zu erhalten "207. Deutlich wird an diesen Vorstößen nicht nur, daß die SKK ein sehr weitgehendes Mitspracherecht für sich beanspruchte, sondern auch in Fechner nicht mehr als eine Galionsfigur sah, die zentrale Fragen der Justizpolitik den politisch dafür geeigneten „Kadern“ überlassen sollte.

Die 1949 festgelegte Struktur des MdJ hatte Bestand bis Ende 1952, sieht man einmal davon $\mathrm{ab}$, daß mit dem endgültigen Übergang der letzten Haftanstalten an das Innenministerium die seit Anfang 1951 als „Hauptabteilung Justizhaftanstalten" firmierende Hauptabteilung III zum 30. Juni 1952 aufgelöst wurde 208 . Erst Anfang 1953 erfolgten weitere Änderungen, die vor allem auf die Übernahme des sowjetischen Modells nach der Reise einer Juristendelegation aus der DDR in die Sowjetunion im Juni 1952 zurückzuführen sind ${ }^{209}$. Dazu zählten die - jetzt durchgeführte - Zusammenlegung der Personal- und der Schulungsabteilung zu einer Abteilung Kader (Februar 1953) ${ }^{210}$, die Einrichtung der „Abteilung Notariat und Rechtsanwaltschaft" im März $1953^{211}$ und die Bildung des Kollegiums des Ministeriums der Justiz im Juli 1952, das, wie in allen anderen Ministerien auch, dem Minister als Beratungsgremium dienen und die Kollektivität der Führung gewährleisten sollte ${ }^{212}$. In der Ära Fechner setzte es sich aus dem Minister, seinem persönlichen Referenten, dem Staatssekretär sowie den Hauptabteilungs- und Abteilungsleitern zusammen und war im Grunde nicht mehr als eine Abteilungsleiterrunde $^{213}$. Arbeitsweise und Effektivität des Kollegiums wurden nach Fechners Ablösung heftig kritisiert: Die oft überfrachteten Tagesordnungen seien nicht vom Minister, sondern von den Hauptabteilungsleitern festgelegt worden, die Unterlagen befänden sich „in großer Unordnung“, Fechner habe die Sitzungen durch die Besprechung von Nebensächlichkeiten in die Länge gezogen ${ }^{214}$. Bei aller Kritik darf jedoch nicht vergessen werden, daß die wöchentlich stattfindenden Kollegiumssitzungen zu einem formalisierteren Anleitungsverfahren von seiten des MdJ führten; außerdem stellte es ein Gremium dar, in dem zentrale Vorhaben des Ministeriums beraten und beschlossen werden konnten ${ }^{215}$.

207 Zit. nach: Fechner an Ministerium der Finanzen, 30. 8. 1952, BAB, DP1 VA Nr. 6478. Fechner drang damit vorerst jedoch nicht durch.

208 Siehe u. a. Personalabteilung des MdJ, Arbeitsbericht für das Jahr 1952, 3. 1. 1953, BAB, DP1 SE Nr. 1328.

${ }^{209}$ Siehe dazu Kap. B.IX.2. Auswertung der Ergebnisse [der Studiendelegation], BAB, DP1 VA Nr. 175.

210 Vermerk von Toeplitz über Unterredung mit einer Vertreterin der Staatlichen Stellenplankommission, 11.2. 1953, BAB, DP1 VA Nr. 6176, Bl. 44-47; Struktur- und Stellenplan des MdJ, 16. 2. 1953, ebenda, Bl. 14-22, hier $15 \mathrm{f}$. Vgl. Künzel, Ministerium der Justiz, S. 184.

211 Siehe Strukturplan des Ministeriums der Justiz, März 1953, ebenda, S. 248.

212 Mit Verordnung vom 17. 7. 1952 (Ministerialblatt 1952, S. $109 \mathrm{f}$.) mußten in allen Ministerien und Staatssekretariaten Kollegien gebildet werden.

${ }^{213}$ Am 11. 8. 1952 wurden Scheele, Artzt, Böhme, Klühsendorf, Grube und Reinartz zu Kollegiumsmitgliedern ernannt, was Grotewohl am 23.8. bestätigte: Fechner an Grotewohl, 11.8. 1952, BAB, DP1 VA Nr. 136; Geyer an Fechner, 23. 8. 1952, BAB, DP1 VA Nr. 1232, Bl. 1.

214 Vgl. Bericht der ZKK, 29. 9. 1953, SAPMO, NY 4090/408, Bl. 16-51, hier 56f.; Vermerk Muths über Unterredung mit Böhme am 22. 1. 1954, BStU, MfS AU 307/55, Bd. 2, Bl. $17 \mathrm{f}$.

215 Vgl. Kap. B.IX.3 und Künzel, Ministerium der Justiz, S. 186-191. 


\section{Befugnisse und Einflüsse von SED und MdI anf die Personalpolitik im MdJ}

Der umfassende Lenkungs- und Kontrollanspruch der SED-Führung gegenüber dem Staatsapparat machte sich vor allem bei der Besetzung der Spitzenpositionen in den Zentralverwaltungen und in den DDR-Ministerien bemerkbar. Anfang 1949 kam es der SED offensichtlich darauf an, das Verfahren bei derartigen Personalentscheidungen zu formalisieren, um die Parteiherrschaft im Staatsapparat dauerhaft zu verankern. Erste Ansätze dazu bildeten die nach der Ersten Parteikonferenz gefaßten Beschlüsse vom März 1949, denen zufolge das Politbüro unter anderem über die „Präsidenten und Vizepräsidenten der Deutschen Verwaltung für Inneres, für Justiz und Volksbildung" und das Kleine Sekretariat über die Hauptabteilungsleiter in diesen Zentralverwaltungen entscheiden sollten, sofern es sich um SED-Funktionäre handelte ${ }^{216}$. Damit wurden in der SBZ wesentliche Elemente des Kadernomenklatursystems eingeführt, das - wie in der Sowjetunion - je nach Nomenklaturstufe die Parteiinstanz festlegte, die die Besetzung bestimmter Führungspositionen vorzunehmen hatte ${ }^{217}$. Mit der DDR-Gründung wurde dieses System ausgebaut und verfeinert: Ab Oktober 1949 mußte über alle „Kaderfragen“, die Leitungspositionen in den Ministerien betrafen, vor der Besprechung im Politbüro oder im Kleinen Sekretariat mit dem Leiter der Abteilung Staatliche Verwaltung ein Konsens erzielt werden ${ }^{218}$. Im Mai 1951 legte das SEDSekretariat schließlich fest, daß Minister und Staatssekretäre erst nach einem Politbüro-, Hauptabteilungsleiter und Personalleiter erst nach einem Sekretariatsbeschluß zu ernennen und Abteilungsleiter sowie persönliche Referenten der Minister und Staatssekretäre durch Vereinbarung der zuständigen Fach- und Kaderabteilung und Gegenzeichnung des zuständigen Sekretariatsmitglieds zu bestätigen waren ${ }^{219}$. Da hier nicht mehr ausdrücklich darauf aufmerksam gemacht wurde, $\mathrm{daß}$ diese Regelung nur für SED-Mitglieder galt, ist davon auszugehen, daß auch Parteilose und Angehörige anderer Parteien in die Nomenklatur der SED-Führung fielen220.

Ein Blick auf das Justizministerium zeigt, daß bei der Regierungsbildung im Oktober 1949 diese Regelungen durchaus Beachtung fanden: So wurde der Besetzung der Hauptabteilungen des MdJ mit Nathan, Heinze und Gentz zunächst vom Sekretariat und am 25. Oktober 1949 auch vom Politbüro zugestimmt ${ }^{221}$. Auch der Einstellung von Franz Genrich als Leiter der Personalabteilung stimmte das Sekretariat am 1. September 1950 noch zu222. Von den zahlreichen Neubesetzungen bis 1953 wurden jedoch nur drei durch formale Entscheidungen dieses SED-Führungsgremiums abgesegnet: die Ernennung von Rudolf Reinartz zum

216 Protokoll der Sitzung des Kleinen Sekretariats, 1. 3. 1949, SAPMO, DY 30 J IV 2/3/9, TOP 1, Anlage Nr. 1; Protokoll der Politbürositzung, 9. 3. 1949, SAPMO, DY 30 J IV 2/2/9, TOP 1.

217 Vgl. dazu Glaeßner, Herrschaft, sowie jüngst Wagner, Gerüst der Macht.

218 Protokoll der Sitzung des Kleinen Sekretariats, 6. 10. 1949, SAPMO, DY 30 J IV 2/3/55, TOP 2.

219 Protokoll der Sekretariatssitzung, 28. 5. 1951, SAPMO, DY 30 J IV 2/3/199, TOP 28, Anlage Nr. 19.

${ }_{220} \mathrm{Zu}$ den entsprechenden Regelungen des Jahres 1953 siehe Amos, Justizverwaltung, S. $125 \mathrm{f}$.; speziell bezüglich des MdJ Werkentin, Politische Strafjustiz, S. $34 \mathrm{f}$.

221 Protokoll der Sekretariatssitzung, 17. 10. 1949, SAPMO, DY 30 J IV 2/3/57, TOP 20; Protokoll der Politbürositzung, 25. 10. 1949, SAPMO, DY 30 J IV 2/2/53, TOP 12.

222 Protokoll der Sekretariatssitzung, 1. 9. 1950, SAPMO, DY 30 J IV 2/3/135, TOP 21. 
Abteilungsleiter am 28. August 1952 sowie die von Martin Spranger zum Abteilungsleiter und von Helmut Ostmann zum Hauptabteilungsleiter am 16. September 1953223. Dies zeigt, daß der SED-Apparat, trotz prinzipieller Aufrechterhaltung seines Entscheidungsanspruches bei der Besetzung von Spitzenposten im Staatsapparat, möglicherweise aufgrund von Überbeanspruchung nicht immer so funktionierte, wie er es selbst festgelegt hatte. Daraus abzuleiten, die Personalentscheidungen des MdJ seien ohne den Parteiapparat getroffen worden, erscheint jedoch verfehlt, da nicht schriftlich fixierte Absprachen sehr wahrscheinlich sind.

Die SED-Führung hatte zudem die systematische Kontrolle über den Personalbestand des Staatsapparats an die DVdI und, nach der DDR-Gründung, an das MdI delegiert. Das Innenressort, seit 1945 fest in kommunistischer Hand, bekam auf Länderebene bereits mit der Festlegung der Innenministerkonferenz vom 20. Dezember 1946 weitgehende Kompetenzen zugewiesen: Seine Personalabteilung sollte fortan „für alle Einstellungen und Entlassungen, die im Regierungsapparat erfolgen", verantwortlich zeichnen ${ }^{224}$. Im Zuge der Verwaltungszentralisierung in der SBZ erhielt die DVdI - spätestens seit der staatspolitischen Konferenz von Werder im Juli 1948 - auf zentraler Ebene die Aufgabe, „eine einheitliche Personalpolitik in der Verwaltung zu sichern" 225 , was Kontrollen der ihr untergeordneten Innenministerien ebenso wie der ihr nebengeordneten anderen Zentralverwaltungen mit einschloß. Auch das DVdI-Statut verankerte deren übergeordnete personalpolitische Kompetenz. Denn dort wurde zum einen „die Kontrolle der Personalpolitik aller Verwaltungen im Zonen- und Landesmaßstab“ $(\$ 4)$ als zentrale Aufgabe der Hauptabteilung Personal aufgeführt und zum anderen die Weisungsbefugnis des DVdI-Präsidenten „auf dem Gebiete der Personalpolitik und Personalkontrolle" festgeschrieben $(\$ 5)^{226}$.

Mit Gründung der DDR gingen diese Befugnisse an das Innenministerium in Ost-Berlin über, wobei dessen Kontrollrecht im Hinblick auf das Personal in den Ministerien präzisiert wurde. Die am 20. Oktober 1949 verabschiedete Geschäftsordnung der DDR-Regierung und die im Politbüro am 15. November 1949 beschlossenen (ausführlicheren) „Richtlinien für die Personalarbeit der staatlichen Verwaltung" legten die Zustimmungspflicht des Innenministeriums bei Einstellung und Entlassung aller Regierungsangestellten vom Hauptreferenten aufwärts fest; bei Einstellung und Entlassung der übrigen Angestellten bestand Informationspflicht gegenüber dem MdI, dessen Einspruch in jedem Fall entsprochen werden mußte227. Dadurch wurde das MdI für Personalfragen, die Angestellte vom

223 Protokolle der Sekretariatssitzungen, 28. 8. 1952, 16. 9. 1953, SAPMO, DY 30 J IV 2/3/320, TOP 27, 399, TOP 14, 16.

${ }^{224}$ Zit. nach Müller, Parteiministerien, S. 357.

${ }^{225}$ Siche den in Werder gefaßten Beschluß: Stellung der SED zur Personalpolitik in der Verwaltung, in: Die neuen Aufgaben, S. 97, sowie Mielkes Referat, Die Personalpolitik in der Verwaltung, ebenda, S. 67. Vgl. dazu Boyer, Kader, S. $18 \mathrm{f}$., $21 \mathrm{f}$.

${ }^{226}$ Entwurf des DVdI-Statuts, DO1/7, Nr. 6, Bl. 122-126. Der Entwurf wurde in der polizeilichen Beratung der DVdI am 5.11. 1948 verlesen und „mit geringfügigen Änderungen angenommen“, ebenda, Bl. 96. Das Politbüro stimmte dem Statut am 29. 3. 1949 zu, SAPMO, DY 30 J IV 2/2/13, TOP 5.

227 Die Geschäftsordnung der DDR-Regierung wurde am 18. 10.1949 im Politbüro (SAPMO, DY 30 J IV 2/2/51, TOP 6, Anlage Nr. 3) und in der Regierungssitzung vom 20. 10. 1949 verabschiedet (Auszug aus dem Sitzungsprotokoll in: DzD II/2, S. 698). Die Bestimmungen in $₫ 13$ beziehen sich 
Hauptreferenten ,abwärts' betrafen, zum verlängerten Arm der SED im Staatsapparat. Bei Personalentscheidungen hinsichtlich der höhergestellten Mitarbeiter war eine doppelte Sicherung eingebaut: Während für die formale Überprüfung der kaderpolitischen Grundsätze das MdI zuständig war, konnten die SED-Führungsgremien bei der von ihnen zu treffenden Entscheidung auch andere Gesichtspunkte geltend machen.

Wie sich diese personalpolitische Kompetenz des MdI im MdJ geltend machte, läßt sich nur punktuell anhand einiger Personalakten nachvollziehen. Daraus geht hervor, daß die Personalabteilung des Justizministeriums sich insofern an die „Richtlinien für die Personalarbeit" hielt, als sie die Hauptabteilung Personal des MdI pflichtgemäß um Genehmigung entsprechender personalpolitischer Entscheidungen bat. Da keine grundlegenden Divergenzen zwischen beiden Personalressorts bestanden, kam es kaum zu Konflikten. Nur bei der Einstellung des Staatsanwalts Erich Liss in die Hauptabteilung Gesetzgebung im Juni 1950 widersetzte sich das Justizministerium dem Innenministerium. Dieser gehörte zwar der LDP an, galt aber als überdurchschnittlich begabter Jurist, der zudem die Deutsche Verwaltungsakademie (DVA) „Walter Ulbricht" besucht und eine positive Beurteilung erhalten hatte 228. Obwohl das Innenministerium - vermutlich aufgrund der LDP-Mitgliedschaft von Liss - Einspruch erhob ${ }^{229}$, machte das Justizministerium seine Einstellung nicht rückgängig, da es im MdJ an fähigen Juristen mangelte, diese aber in der Hauptabteilung Gesetzgebung dringend benötigt wurden230. Schließlich gestand das MdI dem MdJ zu, Liss „vorläufig“ weiter zu beschäftigen, ohne aber die Angelegenheit nochmals zu thematisieren ${ }^{231}$. Das Justizministerium war somit, ohne die Unterordnung unter das MdI in der Personalpolitik grundsätzlich in Frage zu stellen, durchaus in der Lage, bisweilen dessen starre Regeln zu unterlaufen.

\section{Das Grundproblem des MdJ: Personal- und Stellenmangel bei erweiterten Aufgaben}

Die Umstände der Einstellung von Erich Liss werfen ein bezeichnendes Licht auf die Personallage des MdJ im ersten Jahr seiner Existenz. Die unzureichende Besetzung der Planstellen hatte schon der DJV zu schaffen gemacht; das Problem verschärfte sich indes durch die "Säuberungen“ in DJV und MdJ während der Jahre 1948/49, so daß Anfang Oktober 1949 nur noch 85 Personen dort beschäftigt waren. Auch nach der DDR-Staatsgründung schieden weitere Mitarbeiter aus: Die prominentesten unter ihnen waren Ernst Melsheimer, der Generalstaatsanwalt der DDR wurde, Hilde Benjamin, die als Vizepräsidentin an das Oberste Gericht wechselte, und Hildegard Heinze, die im September 1950 zur Obersten Staats-

nur auf Einstellung und Ernennung der Regierungsangestellten. Die „Richtlinien für die Personalarbeit" betrafen auch deren Entlassung: siehe Protokoll der Politbürositzung, 15.11. 1949, SAPMO, DY 30 J IV 2/2/56, Anlage Nr. 8.

${ }_{228} \mathrm{MdJ}$ an MdI, 6. 6. 1950, Personalakte Liss, BAB, DP1 SE Nr. 90, Bl. 176.

${ }^{229} \mathrm{MdI}$ an MdJ, 27. 6. 1950, ebenda, Bl. 182.

230 Nathan machte zudem die staatstragende Einstellung von Liss geltend: Siehe Charakteristik Nathans, 5. 7. 1950, ebenda, Bl. 183-185.

231 Vermerk der Personalabteilung [im MdJ], 13. 7. 1950, ebenda, Bl. 186. 
anwaltschaft abgestellt wurde ${ }^{232}$. Insgesamt schieden bis Ende September 1950 49 Angestellte aus, „so daß die Personalabteilung vor der schwierigen Aufgabe stand, die fehlenden Arbeitskräfte heranzuschaffen, um den Personalbestand auf die festgesetzte Sollstärke von 111 Angestellten zu bringen“. Diese Bemühungen wurden durch das geringe Angebot an qualifizierten Kräften, „die selbstverständlich bewußt fortschrittlich sein mußten", erheblich erschwert ${ }^{233}$. Hatte vor 1948 die alleinige Schwierigkeit darin bestanden, im Sinne der strikten Entnazifizierungsbestimmungen „unbelastete“ Juristen zu finden, mußten nun für die freigewordenen Stellen sowohl politisch zuverlässige als auch fachlich geeignete Personen gefunden werden. Zwar konnten zwischen Anfang Oktober 1949 und Ende September 1950 insgesamt 71 Mitarbeiter neu eingestellt werden, so daß das MdJ insgesamt über 107 Angestellte verfügte234; in der Hauptabteilung Gesetzgebung blieben indes bis Ende 1950 drei Hauptreferentenstellen unbesetz $\mathrm{t}^{235}$.

In den anderen Abteilungen konnten die Stellen zwar weitgehend besetzt werden; die zunehmende Zentralisierung des Justizwesens und neu hinzukommende Steuerungsaufgaben erhöhten aber den Arbeitsanfall, insbesondere in der Abteilung Schulung und in der Hauptabteilung II ${ }^{236}$. Die Abteilungsleiter entwarfen daher stark erweiterte Stellenpläne für ihre Arbeitsbereiche, so daß der für das ganze Ministerium 1951 beantragte neue Struktur- und Stellenplan statt der bisherigen 111 insgesamt 154 Stellen vorsah ${ }^{237}$. Von den 33 neu beantragten Stellen sollten immerhin eine von einem Hauptabteilungsleiter, zwei von Abteilungsleitern, vier von Hauptreferenten und 5 von Oberreferenten besetzt werden. Eine derartige Steigerung war nicht auf einmal durchzusetzen, und das MdJ mußte sich im Januar 1951 mit 133 Stellen begnügen238. Bis zum 31. Dezember 1951 ließ sich diese Zahl aber auf 153 und bis zum 1. März 1952 sogar auf 167 steigern $^{239}$. Zwar stieg auch die Zahl der Einstellungen kontinuierlich von 130 (Ende Juni 1951) auf 143 am 31. März 1952240; alle Stellen konnten jedoch nicht besetzt werden, so daß bis ins Frühjahr 1952 hinein im Justizministerium Personalmangel herrschte. Das Mißverhältnis zwischen Stellen- und Angestelltenzahlen wurde erst im Mai 1952 ausgeglichen, freilich nicht durch vermehrte Einstellungen, sondern durch die Kürzung der Stellenzahl auf 129241. Nur auf diese Weise war es möglich, in der

${ }^{232} \mathrm{Zu}$ Heinze siehe Kap. B.VII.3.

233 Jahresbericht der Abteilung 1, 22. 9. 1950, BAB, DP1 SE Nr. 3560.

234 Ebenda.

235 2. Halbjahresbericht 1950, 1. Personal, BAB, DP1 SE Nr. 3560. Vgl. auch die Arbeitsberichte der Personalabteilung für das zweite und dritte Quartal 1950, BAB, DP1 VA Nr. 1009, Bl. 136 f., 155.

236 Vgl. die Arbeitsberichte der Personalabteilung für das erste und zweite Quartal 1950, ebenda, Bl. $117 \mathrm{f} ., 137$.

237 Entwurf eines Struktur- und Stellenplanes der Abt. Schulung des MdJ, 21. 7. 1950, BAB, DP1 SE Nr. 3551; Entwurf des Strukturplans für die HA II mit Begründung, BAB, DP1 VA Nr. 5572; Fechner an Ministerium der Finanzen, 30. 8. 1950, BAB, DP1 VA Nr. 6478; vgl. auch Arbeitsbericht der Personalabteilung für das dritte Quartal 1950, BAB, DP1 VA Nr. 1009, Bl. 156.

238 Siehe den Struktur- und Stellenplan des MdJ vom Januar 1951, BAB, DP1 VA Nr. 5577, Bl. 57-76.

${ }^{239}$ Arbeitsbericht der Personalabteilung für das Jahr 1952, 3. 1. 1953, BAB, DP1 SE Nr. 1328.

240 Siehe die Arbeitsberichte der Personalabteilung für das zweite, dritte und vierte Quartal 1951 und für das erste Quartal 1952, BAB, DP1 SE Nr. 755.

241 Arbeitsbericht der Personalabteilung für das Jahr 1952, 3. 1. 1953, BAB, DP1 SE Nr. 1328. 
zweiten Jahreshälfte 1952 und Anfang 1953 so gut wie alle Stellen im Justizministerium zu besetzen ${ }^{242}$.

Die Schwierigkeiten, geeignete Mitarbeiter für das MdJ zu rekrutieren, nahmen zwischen 1949 und 1952/53 mit der Weiterentwicklung der Aus- und Weiterbildung der Justizjuristen in der DDR und mit der zunehmenden Zentralisierung der Justizverwaltung tendenziell ab. Inwieweit die Stellenreduzierung angesichts der dem MdJ gestellten Aufgaben von diesem verkraftet werden konnte, ist nicht eindeutig zu beantworten. Es scheint jedoch, daß einerseits das Zusammenspiel von $\mathrm{MdJ}$ und den direkt von ihm abhängigen Justizverwaltungsstellen in den Bezirken zu einer Effektivierung und Rationalisierung der Arbeitsabläufe beitrugen. Andererseits verlor das Justizministerium bis 1952/53 gegenüber dem Obersten Gericht und der Obersten Staatsanwaltschaft Kompetenzen, so daß tendenziell weniger Arbeit anfiel, für deren Bewältigung auch weniger Personal notwendig war.

\section{Personalpolitik im MdJ 1949-1952/53}

Der Übergang des Personals von der DJV zum MdJ verlief ohne Probleme, da die wesentlichen personellen Umstrukturierungen bereits vor der DDR-Gründung erfolgt waren. Das Ausscheiden der letzten aus der DJV übernommenen nichtkommunistischen Angestellten des höheren Dienstes Meyer, Hirschfeld und Hartwig Ende 1949/Anfang 1950 bildete nur noch einen Ausläufer der 1948 in Gang gesetzten „Säuberungen“ und war im Falle von Hartwig eindeutig und ausschließlich altersbedingt ${ }^{243}$. Die Führungsebene des MdJ (Hauptabteilungleiter und Abteilungsleiter) setzte sich ausschließlich aus SED-Genossen zusammen, und auch bei den Hauptreferenten waren in der Ära Fechner insgesamt nur vier Nicht-Kommunisten beschäftigt ${ }^{244}$.

Nur Staatssekretär Helmut Brandt gehörte der CDU an. Für seine Übernahme ins MdJ waren blockpolitische Rücksichtnahmen der SED bei der Regierungsbildung ausschlaggebend. Denn aus der Einbeziehung der Blockparteien in die DDR-Regierung ergab sich, daß diese auch mit Minister- und Staatssekretärsposten versorgt werden mußten, um so den Charakter der DDR als Diktatur der SED verschleiern und die Führungen der anderen Parteien bei der Stange zu halten. Spätestens am 3. Oktober 1949 stand die Nominierung Brandts zum Staatssekretär für die SED- und die CDU-Führung fest ${ }^{245}$; am 14 . Oktober wurde er von der Regierung ernannt ${ }^{246}$. Diskussionen gab es um seine Person und seine Stellung nicht: Denn er war als DJV-Vizepräsident nicht weiter aufgefallen, die CDU hielt

242 So waren Ende September 1952124 Angestellte im MdJ beschäftigt: siehe Arbeitsbericht der Personalabteilung für das dritte Quartal 1952, BAB, DP1 SE Nr. 755. Nach einer Aufstellung vom 16. 1. 1953 waren 132 Angestellte im MdJ tätig, BAB, DP1 VA Nr. 7621; der Struktur- und Stellenplan des MdJ vom 16. 2. 1953 war auf 120 Stellen ausgelegt, BAB, DP1 VA Nr. 6176.

${ }^{243}$ Hartwig schied auf eigenen Wunsch am 31. 12. 1949 aus, war aber 1950 noch ehrenamtlich als Chef des Prüfungsamtes tätig. Auf Fechners Antrag hin wurde ihm eine Ehrenpension gewährt. Siehe Personalakte Hartwig, BAB, DP1 VA Nr. 7638; Fechner an Grotewohl, 23. 12. 1949, SAPMO, NY 4090/440, Bl. 3 f.; Fechner an Hartwig, 31. 12. 1949, BAB, DP1 VA Nr. 5805.

${ }^{244}$ Erich Liss (LDP) und die parteilosen Anton Vössing, Wolfgang Koch und Wolfgang Vogel.

245 Vgl. Dertinger an Grotewohl, 3. 10. 1949, in: DzD II/2, S. 509.

246 Siehe Staatssekretär der Provisorischen Regierung der DDR an MdJ, 15. 10. 1949, BAB, DP1 VA Nr. 855; DzD II/2, S. 191, Anm. 6. 
an ihm fest, und das Staatssekretärsamt im MdJ wurde als zu unbedeutend angesehen, als daß seine Besetzung längere Auseinandersetzungen herausgefordert hätte ${ }^{247}$. Seine Stellung im MdJ brachte ihm - wie zuvor das Vizepräsidentenamt kaum reale Einflußmöglichkeiten auf die Justizpolitik. Seine Versuche, den personalpolitischen Einfluß der CDU im MdJ und am Obersten Gericht zu verstärken - er wollte Hildegard Heinze und Hilde Benjamin durch CDU-Juristen ersetzen - waren zum Scheitern verurteilt ${ }^{248}$. Daher sind auch an seiner nachträglichen Selbsteinschätzung, er habe im MdJ als „Repräsentant der CDU Kontrollrechte für seine Partei ausgeübt", erhebliche Zweifel angebracht ${ }^{249}$. Er war nach wie vor lediglich für Belange des Strafvollzugs zuständig und besuchte auch als Staatssekretär zahlreiche Haftanstalten 250. Aufgrund seiner Zugehörigkeit zur CDU wurde Brandt, der auch nach der Gründung der DDR seine Anwaltspraxis aufrechterhielt, oftmals von Parteifreunden und anderen um Rat und Hilfe für inhaftierte Angehörige gebeten ${ }^{251}$; außerdem blieben Mitarbeiter seiner Anwaltskanzlei vor DDR-Gerichten tätig. Dies war der SED-Führung, die unter anderem über die ZKK davon erfuhr ${ }^{252}$, ein Dorn im Auge, und Anfang Juni 1950 mußte Brandt sich bereit erklären, sich von seiner Anwaltspraxis zu trennen ${ }^{253}$.

Das Ende von Brandts Karriere im Justizministerium wurde schließlich durch sein Engagement im Zusammenhang mit den Waldheimer Prozessen herbeigeführt. Er hatte zufällig Ende April 1950 vom sächsischen Justizminister Dieckmann davon erfahren, stattete daraufhin dem Ort des Geschehens zwei Besuche ab, und auf Brandts Anregung hin forderte Nuschke im Ministerrat am 10. August 1950, die in Waldheim ausgesprochenen Urteile für ungültig zu erklären und sämtliche Prozesse neu zu verhandeln ${ }^{254}$. Weder dieser Antrag noch ein am 18. August an Fechner übersandter Vorschlag Nuschkes zur Einsetzung eines Prüfungsausschusses in dieser Angelegenheit ${ }^{255}$ führten zu einem positiven Ergebnis. Denn am 31. August ließ Grotewohl unvermittelt in der Regierungssitzung über Nuschkes Antrag abstimmen; dieser und die CDU-Minister beharrten

$247 \mathrm{Vgl}$. Aktennotiz über die Besprechung zwischen Brandt, Dertinger und Grotewohl, 6. 10. 1949, ebenda, S. 608. Schiffer hatte erfahren, daß die CDU „die größten Bedenken“ gegen Brandt habe und wollte statt seiner am 6.10. auf der LDP-Vorstandssitzung von Stoltzenberg (LDP) ins Spiel bringen, ebenda, S. 600. Solche „Bedenken“ hegten nur Gohr und seine Weggefährten, die im Oktober 1949 in Kooperation mit SED und SMAD Brandts Ernennung zum Staatssekretär zu verhindern suchten: siehe Ernst Hoffmann an Ulbricht, 6.10., und an Grotewohl, 11. 10. 1949, BStU, MfS AU 449/54, Bd. 3, Bl. 33, $31 \mathrm{f}$.

248 Aufzeichnung Brandts zur eigenen Person, o.D. [vermutlich 1953], ebenda, Bl. 305.

${ }^{249}$ Aussage Brandts, zit. nach Frank, Justizministerium, S. 89.

250 Vernehmung Brandts, 17. 10. 1950, BStU, MfS AU 449/54, Bd. 3, Bl. 245 f.

251 Siehe die Akte BAB, DP1 VA Nr. 6223, die zahlreiche diesbezügliche Schreiben an Brandt enthält.

252 Vgl. den zusammenfassenden Bericht der ZKK, 7. 9. 1950, BStU, MfS AU 449/54, Bd. 3, Bl. 81-86.

253 Vgl. Fechner an Sekretariat Grotewohl, 6. 6. 1950, BAB, DP1 VA Nr. 5805. Vorangegangen waren ein umfangreicher Briefwechsel sowie eine Besprechung zwischen Grotewohl und Fechner am 19. 5. 1950: Fechner an Grotewohl, 6. 4. 1950, BAB, DP1 VA Nr. 266, Bl. 128f., Fechner an Grotewohl, 16. 5. 1950, BAB, DP1 VA Nr. 5805, Aktenvermerk über Besprechung Grotewohls mit Fechner, 19. 5. 1950, BAB, DP1 VA Nr. 7311, Bl. 348, Tzschorn an Fechner, 31. 5. 1950, BAB, DP1 VA Nr. 5805. Brandt unterhielt seine Anwaltspraxis jedoch auch nach diesem Zeitpunkt: siehe Vernehmungsprotokoll vom 16. 6. 1951, BStU, MfS AU 449/54, Bd. 3, Bl. 250.

${ }^{254}$ Vgl. Brandt, Hinter den Kulissen, S. 5-9. Zur Datierung Wentker, Helmut Brandt (Manuskript), S. 24.

255 Exposé vom 17. 8. 1950, in: Wendel, Ulbricht als Richter, S. 61-64; vgl. auch Klonovsky/Flocken, Stalins Lager, S. $220 \mathrm{f}$. 
zwar auf ihrer Auffassung, wurden aber überstimmt ${ }^{256}$. Während Nuschke in Amt und Würden blieb, wurde Brandt am 6. September 1950 durch das MfS verhaftet ${ }^{257}$ und nach drei Jahren und neun Monaten als angebliches Mitglied der „Verschwörergruppe Dertinger" am 4. Juni 1954 zu zehn Jahren Zuchthaus verurteilt. Zwei Tage nach seiner (vorzeitigen) Entlassung am 7. September 1958 bei seinem Versuch, sich nach West-Berlin zu begeben, erneut festgenommen, erfolgte am 19. März 1959 die zweite Verurteilung Brandts zu zehn Jahren Zuchthaus. Erst am 18. August 1964 erlangte er nach Freikauf durch die Bundesregierung seine Freiheit und konnte in den Westen ausreisen 258.

Als Nachfolger Brandts wurde am 18. November 1950 der ebenfalls der CDU angehörende Heinrich Toeplitz zum Staatssekretär ernannt ${ }^{259}$. Im Unterschied zur Regierungsbildung von 1949 traf Nuschke angesichts der Erfahrungen der SED mit Brandt nun auf starke Widerstände bei dem Versuch, der CDU die Staatssekretärsstelle im MdJ zu erhalten ${ }^{260}$. Geboren 1914 als Sohn eines Juristen, studierte Toeplitz nach dem Besuch des Gymnasiums Rechtswissenschaften an den Universitäten Leipzig und Breslau. 1936 absolvierte er die erste juristische Staatsprüfung, im Jahr darauf wurde er in Breslau zum Dr. jur. promoviert, aber aufgrund seiner teils jüdischen Abstammung nicht in den Vorbereitungsdienst übernommen. Nach Berufstätigkeit in der Wirtschaft und im Ausland leistete er ab Kriegsbeginn Militärdienst, wurde aber - da er als „Halbjude“ galt - 1940 aus der Wehrmacht entlassen und aus „rassischen“ Gründen verfolgt. Er wurde nun Angehöriger der Organisation Todt und leistete 1944/45 Zwangsarbeit in Frankreich und den Niederlanden. Nach Rückkehr aus der Gefangenschaft 1945 als Hilfsrichter in Berlin eingesetzt, absolvierte er gleichzeitig sein Referendariat und legte 1947 seine 2. Staatsprüfung ab. Im Anschluß daran arbeitete Toeplitz, der 1949 der CDU beitrat, bis 1950 als Hauptreferent beim Stadtrat für Justiz im OstBerliner Magistrat. In der Partei machte er rasch Karriere: Nachdem er 1950 vorübergehend Leiter der Hauptabteilung Politik im CDU-Parteivorstand gewesen war, avancierte er 1952 zum Mitglied des Politischen Ausschusses bzw. des Präsidiums des CDU-Hauptvorstands ${ }^{261}$. In dieser Funktion unterstützte er Generalsekretär Götting bei der Umwandlung der Union in eine der SED gefügige Blockpartei262. Die Befürchtungen der SED-Führung im Hinblick auf Toeplitz erwiesen sich daher als unbegründet. Die SED-Betriebsparteiorganisation des MdJ bescheinigte ihm im Oktober 1952 nicht nur umfangreiche fachwissenschaftliche Kenntnisse, sondern erkannte ebenfalls an, „daß Dr. T. bemüht ist, die primäre Rolle der

${ }^{256}$ Brandt, Hinter den Kulissen, S. 9. Im Protokoll der Regierungssitzung, BAB, DC 20 I/3 Nr. 28, TOP 19, ist lediglich vermerkt, daß Heinze gegen die Stimmen der CDU-Minister zur Staatsanwältin bei der Obersten Staatsanwaltschaft ernannt wurde.

257 Vgl. zu den genaueren Umständen Bericht betr.: Festnahme des Dr. Helmut Brandt, 6. 9. 1950, BStU, MfS AU 449/54, Bd. 3, Bl. 154.

258 Vgl. dazu u. a. Beckert, Instanz, S. 144, 150-153; Fricke, Geschichte und Legende, S. 1182 f.; Höfer, Vierzehn Jahre; Wentker, Helmut Brandt (Manuskript), S. 28-37. Brandt wurde Gutachter im Wissenschaftlichen Dienst des Deutschen Bundestages; er starb am 31. 10. 1998, ebenda, S. 38-40.

259 Siehe Beurteilung von Toeplitz durch die SED-BPO im MdJ, 15.10. 1952, BAB, DP1 VA Nr. 6699.

260 Vgl. Richter, Ost-CDU, S. 298.

261 Vgl. Buch, Namen und Daten, S. 325 f.; Schneider, Der deutsche Einheitsjurist, S. 250.

262 Vgl. Kiefer, Lenkungs- und Kontrollstrukturen, S. 146; vgl. Rißmann, Kaderschulung, S. 145, 147. 
Arbeiterklasse zu begreifen und sich damit vertraut macht, daß auf dem Gebiet der Rechtswissenschaft der Marxismus-Leninismus die Grundwissenschaft bil-

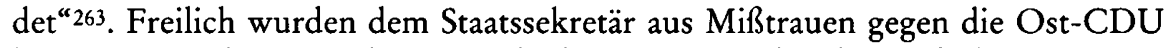
keine seinem Ehrgeiz und seinen Fähigkeiten entsprechenden Aufgaben zugewiesen, und er mußte sich damit begnügen, das MdJ bei der Leitung von Konferenzen und Schulungen zu repräsentieren. Als die Parteileitung im MdJ im November 1952 feststellte, daß Toeplitz sich veranlaßt gesehen habe, „sich mit Angelegenheiten zu befassen, die ihn im Grunde genommen nichts angehen", faßte sie den Entschluß, ihn zur Mitarbeit im Redaktionskollegium der „Neuen Justiz“, im Rechtswissenschaftlichen Institut und am Mitteilungsblatt des MdJ heranzuziehen, um „ihn fachlich mehr zu binden und zum anderen bei ihm den Eindruck [zu] verwischen, daß er bei uns isoliert wäre"264. Insgesamt erwies sich Toeplitz als so linientreu, daß er 1954 sogar die Verantwortung für die Hauptabteilung Gesetzgebung und für die Abteilungen Haushalt und Allgemeine Verwaltung innehatte ${ }^{265}$. Toeplitz behielt seine Stellung bis zum April 1960, als er eine weitere Sprosse auf der Karriereleiter erklomm und Präsident des Obersten Gerichts wurde.

Die Leiter der Abteilungen und Hauptabteilungen gehörten Ende 1949/Anfang 1950 alle der SED an, jedoch blieb keiner von ihnen bis zum Ende der Ära Fechner auf seinem Posten. Die Abteilung 1 (Personal) wurde nach dem Weggang von Benjamin zum Obersten Gericht bis zum 30. September 1950 kommissarisch von Hauptreferent Richter geleitet; zum 1. Oktober 1950 wurde Franz Genrich als Abteilungsleiter einberufen. „Kaderpolitisch“ brachte er die notwendigen Voraussetzungen mit: Sohn eines Ofenarbeiters, gelernter Dreher, 1933 aus dem öffentlichen Dienst aufgrund seiner Zugehörigkeit zur KPD entlassen, Absolvent des vierten Richterlehrgangs in Mecklenburg, seit November 1949 Amtsrichter am Amtsgericht Hagenow, war er zusätzlich "qualifiziert" durch seine Teilnahme an den Waldheimer Prozessen ${ }^{266}$. Er erwies sich jedoch seinen Aufgaben als Personalleiter nicht gewachsen 267 und wurde daher am 18. Februar 1952 durch Helmuth Klühsendorf ersetz $\mathrm{t}^{268}$. Klühsendorf, ehemaliger Friseur, hatte noch nicht einmal eine Volksrichterausbildung, sammelte aber nach 1945 als Amtsanwalt im Spreewald einige Erfahrungen im Justizdienst. Dort wurde er von Plenikowski entdeckt und gefördert, absolvierte dann den ersten Fortbildungslehrgang für Juristen in Kienbaum (vom 1. November 1951 bis 15. Februar 1952), um anschließend zum Leiter der Personalabteilung ernannt zu werden ${ }^{269}$.

${ }^{263}$ Beurteilung von Toeplitz durch die SED-BPO im MdJ, 15. 10. 1952, BAB, DP1 VA Nr. 6699.

${ }_{264}$ Protokoll über die außerordentliche Parteileitungssitzung am 4.11. 1952, ebenda.

265 Beurteilung von Toeplitz, o.D. [1954], ebenda.

266 Lebenslauf Genrich, 4. 2. 1951, SAPMO, DY 30 IV 2/11/172, Bl. 241-244; Kurzbiographie Genrich, 22. 9. 1960, BStU, MfS AIM 3246/69, Bl. $21 \mathrm{f}$. In der Beurteilung seiner Waldheimer Richtertätigkeit heißt es: „Fiel durch seine Härte und politische Konsequenz angenehm auf." $Z$ it. nach Mollnau, Sozialistische Gesetzlichkeit, S. $100 \mathrm{f}$.

267 Abschlußeinschätzung der Sonderkommission, 25. 8. 1951, SAPMO, DY 30 IV 2/11/167, Bl. 149; vgl. auch Zeugnis für Genrich, 8. 8. 1952, BAB, DP1 SE Nr. 74.

268 Genrich ging am 31. 7. 1952 an das Berliner Stadtgericht, wo er vom 28.12.1961 bis 27. 2. 1969 als GI für das MfS tätig war: BStU, MfS AIM 3246/69, Bl. 33-35, 45, 66.

${ }^{269}$ Siehe Karteikarte Klühsendorf, BAB, DP1 SE Nr. 74; Besetzungsliste MdJ, o.D. [1. Halbjahr 
Die Abteilung 2 (Schulung) wurde, nachdem Hartwig in den Ruhestand getreten war, von dem Volljuristen Hans-Joachim Schoeps geleitet, der dort bereits seit Juli 1949 tätig gewesen war. Der ehemalige Sozialdemokrat ${ }^{270}$ zählte im MdJ zu dem engeren Kreis um Fechner ${ }^{271}$; die SED-Betriebsgruppe bezichtigte ihn, versöhnlerischer' Neigungen, „da er klaren Entscheidungen, welche im Interesse des

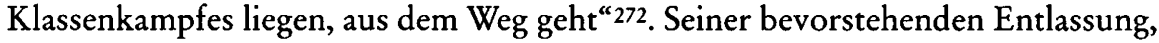
die von der SED-Sonderkommission im April 1951 empfohlen worden war, kam er im September 1951 durch Flucht in den Westen zuvor ${ }^{273}$. Nachfolger von Schoeps wurde Max Weigel, der die „kaderpolitischen“ Voraussetzungen der SED voll und ganz erfüllte: Proletarischer Herkunft, gelernter Handschuhzuschneider, seit $1930 \mathrm{KPD}$, im Dritten Reich wegen illegaler Tätigkeit für die KPD über vier Jahre im Zuchthaus, wurde er nach 1945 hauptamtlicher Parteifunktionär zunächst in der KPD und anschließend in der SED 274 . Ohne juristische Vorbildung arbeitete er seit dem 1. Juni 1950 als Dozent für Gesellschaftswissenschaft an der Zentralen Richterschule. In Ermangelung eines anderen Kandidaten stellte das MdJ Weigel am 14. Februar 1952 ein. Bereits zum 1. August 1952 wurde er jedoch - wahrscheinlich aufgrund seiner positiven Beurteilung - zum Innenministerium versetzt ${ }^{275}$. An seine Stelle trat am 1 . September 1952 Gerda Grube, Lehrgangsabsolventin und als KPD-Mitglied „Aktivistin der ersten Stunde“. Nach Verwendungen als Jugendrichterin in Leipzig und Vorsitzende einer Strafkammer nach SMAD-Befehl Nr. 201 am dortigen Landgericht wurde sie 1949 Leiterin des Amtsgerichts Oelsnitz ${ }^{276}$. Zum 1. Mai 1950 als Oberreferentin in die Schulungsabteilung des MdJ eingestellt, wurde sie am 1. Oktober 1950 zur Hauptreferentin, und, nach einem Qualifizierungslehrgang an der DVA, am 1. September 1952 zur Abteilungsleiterin befördert ${ }^{277}$. Von Reinartz als „beste Bolschewistin im JustizMinisterium“ bezeichnet, hielt sie engen Kontakt zum Sektor Justiz des ZK, was $\mathrm{zu}$ „heftigsten Kämpfen zwischen ihr und Fechner“ führte278.

Der bewährte Leiter der Hauptabteilung I (Gesetzgebung), Nathan, schied aus dem MdJ aus, um am 1. April 1952 hauptamtlicher Chefredakteur der „Neuen Ju-

1952], BAB, DP1 SE Nr. 992; Bericht, 19. 11. 1953, AdsD, Ostbüro Nr. 0048a; vgl. Lehrplan für den 1. Fortbildungslehrgang für Juristen, BAB, DP1 SE Nr. 2741, Bl. 209-213.

270 Er war im September 1945 der SPD beigetreten: Personalakte Schoeps, BAB, DP1 SE Nr. 61, Bl. 250.

271 Vgl. den Bericht von Weiß, 27. 6. 1951, an das MfS, BStU, MfS AIM 6279/57, T.II, Bl. 9 f.

272 Charakteristik von Schoeps durch die SED-Betriebsgruppe, 22. 2. 1951, BAB, DP1 SE Nr. 6699.

Vgl. auch die ähnliche Charakterisierung durch die SED-Sonderkommission, 25.4. 1951, SAPMO, DY 30 IV 2/11/177, Bl. 175.

${ }^{273}$ Ebenda; Aktenvermerk Genrichs über Unterredung mit Reisler und Burkhardt, 10.10. 1951, BAB, DP1 SE Nr. 741; Genrich an Schoeps, 2. 10. 1951, Präsidium der Volkspolizei Berlin an MdJ, 11. 12. 1951, Personalakte Schoeps, BAB, DP1 SE Nr. 61, Bl. 291, 295.

274 Personalbogen und Lebenslauf Weigels, 3.10. 1950, in: Personalakte Weigel, BAB, DP1 SE Nr. 2492.

275 Vermerk 17. 1. 1952, ebenda; Beurteilung von Weigel, 25. 4. 1952, MdJ an MdI, 29. 7. 1952, BAB, DP1 SE Nr. 74.

276 Vgl. den Nachruf Benjamins auf Grube, in: NJ 21 (1967), S. 39. Benjamin bezeichnete sie als „Kind einer bewußten Arbeiterfamilie“; nach Auskunft von Reinartz war sie „ausgesprochen kleinbürgerlicher Herkunft": Bericht, 19. 11. 1953, AdsD, Ostbüro Nr. 0048a. Während des Richterlehrgangs heiratete sie Otto Grube, später Staatsanwalt bei der Obersten Staatsanwaltschaft.

277 Karteikarte Gerda Grube, BAB, DP1 SE A6; Personen, die im 2. Halbjahr gefördert worden sind, 8. 1. 1953, BAB, DP1 SE Nr. 1328.

278 Bericht, 19. 11. 1953, AdsD, Ostbüro Nr. 0048a. 
stiz" zu werden, die seit Januar 1951 von den drei obersten Justizorganen gemeinsam herausgegeben wurde 279. Seit dem 1. Oktober 1952 zusätzlich als Professor mit vollem Lehrauftrag für die Gebiete Zivil-, Familien- und Zivilprozeßrecht an die Humboldt-Universität berufen, wurde er nun vornehmlich auf wissenschaftlichem Gebiet tätig280. Seit Fechners Ernennung zum DJV-Präsidenten waren dessen Beziehungen zu Nathan sehr gespannt ${ }^{281}$. Fechner versuchte sogar noch im März 1953, Nathan gegenüber der ZPKK anzuschwärzen, um dessen Abberufung von seinem Posten als Chefredakteur der „Neuen Justiz“ zu erreichen ${ }^{282}$. Es kam dem Justizminister jedenfalls sehr gelegen, daß die SED-Sonderkommission im August 1951 aufgrund von Nathans familiären Bindungen nach West-Berlin, England und den Vereinigten Staaten dessen Entlassung forderte ${ }^{283}$. Aktuelle „Westkontakte" waren dann auch wohl die Ursache für seine Entfernung aus dem MdJ284. Nachfolger Nathans wurde am 1. April 1952 dessen Mitarbeiter Werner Artzt. Als Volljurist bürgerlicher Herkunft entsprach er zwar nicht dem kommunistischen „Kaderideal“, aber in der Gesetzgebungsabteilung des MdJ war primär juristischer Sachverstand gefragt, der ihm auch mehrfach bescheinigt wurde ${ }^{285}$.

Innerhalb der Hauptabteilung I leitete seit dem 1. Februar 1950 Fritz Niethammer die Abteilung Zivil- und öffentliches Recht. 1900 geboren, stammte auch er aus bürgerlichem Hause, hatte in Prag studiert, anschließend in der Wirtschaft gearbeitet und eine Ausbildung zum Rechtsanwalt absolviert, die er 1931 mit einer Prüfung abschloß. Trotz Engagements in der Deutschen Demokratischen Partei und Zugehörigkeit zu einer Freimaurerloge blieb er - nach kurzzeitigen Schwierigkeiten nach der deutschen Annexion des Sudetenlandes - bis 1941 als Anwalt tätig. Nach anschließendem Kriegsdienst und sowjetischer Kriegsgefangenschaft kehrte er im August 1945 in die Tschechoslowakei zurück, schloß sich aber noch im Oktober einem größeren Transport in die SBZ an. Nach einer Zwischenstation beim Landratsamt Sangerhausen ging er Anfang März 1946 zur provinzsächsischen Justizverwaltung, wo er bis zum Leiter der Rechtsprechungsabteilung aufstieg. Aus dieser Position wechselte der erfolgreiche SED-Jurist am 1. Februar 1950 schließlich ins DDR-Justizministerium ${ }^{286}$. Fachlich zwar sehr gut beurteilt ${ }^{287}$, ordnete die SED-Sonderkommission die Entfernung Niethammers von seinem Posten an, da er einer Freimaurerloge angehört hatte und Verwandtschaft in Westdeutschland und England besaß288. Zunächst verblieb er jedoch noch im

279 Beurteilung Nathans durch Klühsendorf, 11. 7. 1952, BAB, DP1 SE Nr. 74.

280 Vgl. Göhring, Nathan, S. $6 \mathrm{f}$.

281 Bericht Scheeles, BStU, MfS AU 307/55, Bd. 6, Bl. 172; Bericht von Weiß an das MfS, 27. 6. 1951, BStU, MfS AIM 6279/57, T.II, Bl. 9 f.

${ }^{282}$ Fechner an ZPKK, 4. 3. 1953, BAB, DP1 VA Nr. 8056, Bl. 195 f.; vgl. Amos, Justizverwaltung, S. 131.

${ }^{283}$ Abschlußeinschätzung der Sonderkommission, 25. 8. 1951, SAPMO, DY 30 IV 2/11/167, Bl. 152.

284 Vgl. Schneider, Der deutsche Einheitsjurist, S. 248.

285 Charakteristik von Artzt durch die SED-Betriebsgruppe, 29. 3. 1959, BAB, DP1 VA Nr. 6699; Beurteilung von Artzt durch Genrich, 6. 7. 1951, BAB, DP1 SE Nr. 2840.

286 Personalbogen und Lebenslauf von Niethammer, 29. 6. 1951, BAB, DP1 SE Nr. 446, Lebenslauf Niethammers, April 1951, SAPMO, DY 30 IV 2/11/175, B1. 629-631.

287 Siehe Charakteristik von Niethammer durch Nathan, 18.4. 1950, Beurteilung von Niethammer durch Klühsendorf, 25. 4. 1952, BAB, DP1 SE Nr. 74. Klühsendorf bemängelte jedoch seine „z.T. objektivistischen Ansichten" und daß er „nicht frei von kleinbürgerlichen Erwägungen“ sei.

288 Abschlußeinschätzung der Sonderkommission, 25. 8. 1951, SAPMO, DY 30 IV 2/11/167, BI. 152. 
MdJ und ging erst am 8. September 1952 - angeblich auf eigenen Wunsch - als Oberrichter an das Bezirksgericht Potsdam ${ }^{289}$. Seine Stelle im Justizministerium blieb aufgrund des Mangels an kommunistischen Volljuristen vakant.

Wolfgang Weiß leitete innerhalb der Gesetzgebungsabteilung die Abteilung Strafrecht. Seine Nachkriegslaufbahn erlebte einen Knick, als die SED-Sonderkommission im April 1951 aufdeckte, daß er sich 1945/46 mit dem ihm aus der gemeinsamen Zeit in der „roten Studentengruppe“ bekannten Fritz Opel dreimal getroffen hatte 290 . Opel hatte 1933/34 der KPO angehört, war über mehrere Stationen in die USA gelangt und als amerikanischer Soldat nach Deutschland zurückgekehrt ${ }^{291}$. Die SED-Untersuchungskommission, die Opel als „Trotzkisten und USA-Agenten" bezeichnete, gab dies umgehend an die ZPKK weiter; Weiß wurde „als parteifremdes Element“ aus der Partei ausgeschlossen ${ }^{292}$ und infolgedessen am 17. August 1951 vom Dienst im MdJ beurlaubt ${ }^{293}$. Interessanterweise sah das MfS, das Weiß am 18. Juni 1951 als GI mit Decknamen „Blanko“ zur Berichterstattung über das MdJ angeworben hatte ${ }^{294}$, darin keinen Anlaß, die Verbindung zu ihm abzubrechen. Sein Führungsoffizier Josef Sobeck kam vielmehr mit Plenikowski überein, Weiß weiter zu verwenden ${ }^{295}$. Auch in seiner neuen Position als wissenschaftlicher Mitarbeiter des Deutschen Instituts für Rechtswissenschaft, die er seit Anfang März 1952 bekleidete, war GI „Blanko“ weiter für das MfS tätig296. Trotz aller Bemühungen von Hauptabteilungsleiter Artzt blieb die Stelle von Weiß im MdJ unbesetzt. Erst im August 1952 wurde Hauptreferent Rudolf Reinartz, der seit dem Ausscheiden von Weiß die Abteilung Strafrecht kommissarisch geleitet hatte, zu deren Leiter ernannt ${ }^{297}$.

Die Leiterin der Hauptabteilung II (Rechtsprechung), Hildegard Heinze, die bereits von Mai bis Juli 1950 durch ihre Tätigkeit bei der Lenkung der Waldheimer Prozesse 298 für ihre Arbeit im Justizministerium ausgefallen war, wurde $a b$ September 1950 zur Obersten Staatsanwaltschaft abgestellt, so daß die in ihrer Hauptabteilung tätige Hauptreferentin Julie Ganske sie vertrat ${ }^{299}$. Erst mit ihrem endgültigen Wechsel zur Obersten Staatsanwaltschaft zum 1. Januar 1951 wurde

289 Siehe die Liste von Personen, die im 2. Halbjahr aus dem MdJ ausgeschieden sind, BAB, DP1 SE Nr. 1328. Nach einem Jahr ging er zum Deutschen Institut für Rechtswissenschaft und zur Akademie für Staat und Recht, wo er eine akademische Karriere machte: vgl. Breithaupt, Rechtswissenschaftliche Biographie, S. $402 \mathrm{f}$.

290 Protokoll der Sonderkommission, 25. 4. 1951, SAPMO, DY 30 IV 2/11/177, Bl. $610 \mathrm{f}$.

$291 \mathrm{Vgl}$. Foitzik, Zwischen den Fronten, S. 306.

292 Notiz betr. Weiß, o.D., SAPMO, DY 30 IV 2/11/177, Bl. 612. Nach Angabe des MfS wurde Weiß im August 1951 aus der SED ausgeschlossen: Beurteilung von Weiß, 17. 11. 1951, BStU, MfS AIM 6279/57 T.I, Bl. 19.

${ }_{293}$ Notiz der Personalabteilung, 18. 8. 1951, BAB, DP1 SE Nr. 2840.

${ }^{294}$ Siehe seine Verpflichtungserklärung, BStU, MfS AIM 6279/57 T.I, Bl. 16.

${ }^{295}$ Aktenvermerk Sobecks über Unterredung mit Weiß, 7.9. 1951, BStU, MfS AIM 6279/57 T.II, B1. 23.

296 Vermerk Sobecks, 21. 3. 1952, ebenda, Bl. 32; die Berichte von Weiß in derselben Akte. 1957 stellte das MfS die Arbeit mit ihm ein. Da ihm die Herausgabe der „Festschrift zum 40. Jahrestag der Großen Sozialistischen Oktoberrevolution" den Vorwurf des Revisionismus einbrachte, mußte er sein Institut verlassen; er starb am 22. 4. 1990: siehe Ehrendoktorwürde für Wolfgang Weiß sowie die Todesanzeige in: NJ 44 (1990), S. 143, 258.

297 Protokoll der Sekretariatssitzung, 28. 8. 1952, SAPMO, DY 30 J IV 2/3/320, TOP 27.

$298 \mathrm{Vgl}$. Werkentin, Politische Strafjustiz, S. 183.

299 Vgl. Beurteilung von Ganske durch Genrich, 13. 3. 1951, BAB, DP1 SE Nr. 74. 
sie von Fritz Böhme ersetzt. 1909 als Sohn eines Zimmermanns geboren, wurde er nach einer entsprechenden Lehre kaufmännischer Angestellter. Aus einem sozialdemokratischen Elternhaus stammend, kam er über die Sozialistische Arbeiterjugend zur SPD, der er 1929 beitrat. 1931 trat er der gerade neu gegründeten Sozialistischen Arbeiterpartei ${ }^{300}$ bei, weil er damals angeblich überzeugt war, „daß die SAP die einzige Arbeiterpartei sei, die die Einheit der Arbeiterklasse herstellen könnte und würde" ${ }^{301}$. Bis 1934 war Böhme für die SAP - nach 1933 in der Illegalität - in Dortmund tätig. Nach Teilnahme am Krieg ging er im Juni 1945 nach Dresden, trat am 1. Juli 1945 der KPD bei und erhielt zunächst bei der Polizei und anschließend bei der Kommunalverwaltung eine Anstellung. Dem Ruf der Partei folgend, absolvierte er vom 1. Februar bis 30. November 1946 den ersten sächsischen Richterlehrgang, wurde anschließend - gefördert von Hilde Benjamin Amtsgerichtsdirektor in Bautzen und, ab Dezember 1948, Hauptabteilungsleiter im Justizministerium in Halle ${ }^{302}$. Im Frühjahr 1951 hielt ihn die SED-Sonderkommission aufgrund zahlreicher - sowohl ideologischer als auch persönlicher - Mängel für ungeeignet, seine Funktion auszufüllen ${ }^{303}$. Dennoch blieb er bis 1958 im Justizministerium, wahrscheinlich weil ihn die sowjetische Geheimpolizei, für die er seit 1948 als Geheimer Mitarbeiter tätig war, halten wollte. Zunächst zur Aufklärung der ehemaligen SAP vorgesehen, wurde er von 1951 bis 1954 „zur Aufdeckung und Bearbeitung feindlicher Elemente unter den Angestellten der Justiz in der DDR eingesetzt“"304. Da seiner Hauptabteilung die Anleitung und Kontrolle der Rechtsprechung in der gesamten DDR oblag, besaß die sowjetische Geheimpolizei in Böhme eine wichtige Quelle, die sie nicht preisgeben wollte. Böhme unterstellt war seit Mitte 1952 ein Abteilungsleiter, der neben seinen Leitungsaufgaben für die Gerichtskontrolle bei zivilrechtlichen Prozessen zuständig war ${ }^{305}$. Besetzt war der Posten mit dem Volljuristen Rudolf Pätzold, der am 1. Februar 1950 als Hauptreferent im MdJ eingestellt worden war ${ }^{306}$. Seit 1932 KPD-Mitglied, war er 1943 der NSDAP beigetreten, was er nach dem Krieg verschwieg, um weiterhin im Justizdienst verbleiben zu können. Nach 1945 zunächst in der SPD und ab Mai 1946 in der SED, wurde er Amtsrichter in Bitterfeld (1946), Amtsgerichtsdirektor in Delitzsch (1947), und kam 1949 zum Justizministerium nach Halle. Als Hauptreferent im MdJ trat er in Verbindung zum Untersuchungsausschuß freiheitlicher Juristen (UfJ), dem er 1952 eine Reihe von Berichten lieferte und für den er Flugblätter verbreitete. Nachdem dies im Frühjahr 1953 aufgedeckt worden war, wurde er umgehend verhaftet und am 23. April 1953 vom Bezirksgericht Chemnitz zu lebenslänglicher Haft verurteilt ${ }^{307}$.

300 Zur SAP siehe Drechsler, Sozialistische Arbeiterpartei Deutschlands.

301 Lebenslauf Böhme, 25. 4. 1951, SAPMO, DY 30 IV 2/11/171, Bl. 256-259, hier 257.

$302 \mathrm{Zu}$ seiner Karriere ebenda und Lebenslauf Böhme, 13. 4. 1950, BStU, MfS AOP 23094/62, Bl. 25 f.

${ }^{303}$ Abschlußeinschätzung der SED-Sonderkommission, 25. 8. 1951, SAPMO, DY 30 IV 2/11/167, B1. 152.

304 Bericht betr. Böhme, 5. 1. 1959, übersetzt aus dem Russischen, Streng vertraulich, BStU, MfS AOP 23094/62, Bl. 131-135.

305 Vgl. Struktur- und Stellenplan des MdJ, 16. 2. 1953, BAB, DP1 VA Nr. 6176, Bl. 23.

306 Beurteilung über Pätzold, o.D., BAB, DP1 VA Nr. 6699.

307 Siehe seine unvollständige Personalakte in: BAB, DP1 SE Nr. 518, Bl. 272-275; ferner das Urteil in: BStU, MfS ASt I/1 325/53, Bl. 7-14, und den Schlußbericht in: BStU, Chemnitz ASt I/1 109/53, B1. 2-7. Pätzold wurde am 1.9.1964 aus der Haft entlassen. 
Nur der Leiter der Hauptabteilung III (Strafvollzug bzw. Justizhaftanstalten) blieb in Amt und Würden. Freilich wurde die Stellung von Gentz angesichts der Auseinandersetzungen um die Übertragung des Strafvollzugs auf das Innenministerium immer prekärer ${ }^{308}$. Hinzu kam, daß die SED-Sonderkommission aufdeckte, daß er 1919 fünf Monate lang der DNVP angehört hatte und ihm eine angeblich extreme Anpassungsfähigkeit vorwarf: Denn er sei „in der Monarchie, in der Weimarer Republik, im Hitlerreich und auch jetzt ununterbrochen in leitender Stellung tätig“ gewesen und besäße „keinerlei Verbundenheit zur Arbeiterklasse, geschweige denn zur Partei“. Am schwersten wog freilich seine Verbindung zu dem im Dezember 1950 in den Westen geflohenen thüringischen SEDJuristen Karl Schultes, der Gentz bei seinen Aufenthalten in Berlin oft besucht habe. Daß Gentz Schultes als „anständigen“ Menschen bezeichnete, den Namen der Familie, bei der er ihn kennengelernt hatte, nicht preisgeben wollte und leugnete, von dessen Fluchtplänen informiert worden zu sein, verstärkte den negativen Eindruck des SED-Sonderkommission ${ }^{309}$. Die bei diesen „Verfehlungen“ übliche Entscheidung, der Parteiausschluß, wurde zwar von der Kommission empfohlen, aber offensichtlich nicht getroffen ${ }^{310}$. Gentz blieb vielmehr noch ein knappes Jahr im MdJ und schied erst zum 15. Juli 1952 aus, als die Hauptabteilung III nach der endgültigen Übertragung aller Haftanstalten an das Innenministerium aufgelöst wurde 311 .

Auffällig beim Wechsel bzw. Ausscheiden der Hauptabteilungs- und Abteilungsleiter bis Mitte 1953 ist der relativ häufige Zusammenhang mit der Überprüfung durch eine SED-Sonderkommission im Frühjahr 1951. Vorausgegangen war am 27. Oktober 1950 ein Beschluß des ZK zur generellen Überprüfung der Parteimitglieder und zum Umtausch der Mitgliedsbücher ${ }^{312}$; für die SED-Genossen im Regierungsapparat wurden auf Anordnung des Politbüros gebildete Sonderkommissionen für zuständig erklärt ${ }^{313}$. Im Justizministerium entsprachen von den insgesamt sieben überprüften Hauptabteilungs- und Abteilungsleitern ${ }^{314}$ nur zwei den kaderpolitischen Vorstellungen, während fünf nach Auffassung der Sonderkommission auszuscheiden hatten. Die Reichweite dieser Beschlüsse war indes äußerst unterschiedlich: Nur der Parteiausschluß von Weiß führte zu seinem sofortigen Ausscheiden aus dem Justizministerium. Keine Folgen hatte die Empfehlung der Sonderkommission für Gentz, und Böhme konnte sich trotz massiver Kritik aufgrund mächtigerer Freunde halten. Bei Schoeps, Nathan und Nietham-

308 Siehe dazu Kap. B.V.4.

309 Protokoll der Sonderkommission, 25. 4. 1951, SAPMO, DY 30 IV 2/11/172, Bl. 245-248.

310 Siehe ebenda, Bl.247; vgl. auch Abschlußeinschätzung der Sonderkommission, 25.8. 1951, SAPMO, DY 30 IV 2/11/167, Bl. 80.

311 Siehe MdJ an MdI, 5. 7. 1952, Personalakte Gentz, BAB, DP1 VA Nr. 854, Bl. 19. Anschließend wurde er Vorsitzender einer Kommission des staatlichen Vertragsgerichts: Bericht, 19. 11. 1953, AdsD Ostbüro 0048a.

312 Der Beschluß in: Dokumente der SED, Bd. III, S. 239-242.

${ }^{313}$ Siehe Richtlinien über die organisatorische Durchführung der Überprüfung der Parteimitglieder und Kandidaten sowie den Umtausch der Parteimitgliedsbücher und Kandidatenkarten, SAPMO, DY 30 IV 2/11/160, Bl. 27-31.

${ }_{314}$ Als einziger Hauptreferent wurde Reinartz überprüft, der fälschlicherweise als Abteilungsleiter bezeichnet wurde: Protokoll der Sonderkommission, 27. 4. 1951, SAPMO, DY 30 IV 2/11/176, Bl. 208. 
mer zeitigte der entsprechende Beschluß der SED-Sonderkommission seine Folgen erst mit Zeitverzögerung; dies und die teilweise längere Vakanz bei der Besetzung der Führungspositionen im MdJ zeigen erneut, wie dünn die Personaldecke gerade bei den weiterhin benötigten Volljuristen war.

Dabei hatte man das „Volljuristenmonopol“ bereits erheblich gelockert. Von den hier vorgestellten 14 Hauptabteilungs- und Abteilungsleitern waren fünf Nicht-Akademiker. Bei den Hauptreferenten wurde sehr viel ungenierter auf Nicht-Juristen und Volksrichter zurückgegriffen, wenngleich hier sorgfältig zwischen den einzelnen Abteilungen unterschieden werden muß. So befand sich in der Personalabteilung nach Benjamins Weggang kein einziger Volljurist mehr. Die Abteilung Schulung wies mit Abteilungsleiter Schoeps und Hauptreferentin Carlota Schindowski, die am 31. Januar 1951 angeblich aus ,innerbetrieblichen Gründen" ausschied ${ }^{315}$, noch zwei akademische Juristen auf; mindestens drei der dort tätigen Hauptreferenten waren Volksrichter ${ }^{316}$. In der Hauptabteilung Gesetzgebung hingegen waren demgegenüber fast ausschließlich Volljuristen tätig317; dabei wurden, wie die parteilosen Wolfgang Koch ${ }^{318}$ und Wolfgang Vogel ${ }^{319}$ sowie Erich Liss (LDP) ${ }^{320}$ zeigen, sogar Abstriche vom Dogma der SED-Zugehörigkeit gemacht. In der Hauptabteilung Rechtsprechung waren wiederum unter den sieben Hauptreferenten mit Rudolf Pätzold und Heinrich Reuter nur zwei Volljuristen zu finden, während drei einen Volksrichterlehrgang absolviert hatten ${ }^{321}$, eine weitere (Ganske) nach langjähriger Praxis die Volksrichterprüfung abgelegt hatte, und ein letzter (Vössing) aus dem gehobenen Justizdienst stammte. Die Hauptreferenten der Hauptabteilung III schließlich hatten weder einen Volksrichterlehrgang noch eine Universität besucht, was jedoch angesichts ihres Aufgabenfeldes auch nicht erforderlich war. Die Tendenz der Jahre 1948/49, bei der Rekrutierung der leitenden Mitarbeiter des MdJ auch auf Nicht-Volljuristen zu setzen, hatte sich somit in den Abteilungen Personal, Schulung und Rechtsprechung weiter verstärkt.

Die relativ hohe Fluktuation unter dem Führungspersonal des MdJ in der Ära Fechner war - soweit Ursachen überhaupt feststellbar sind - vor allem auf vier Tatbestände zurückzuführen. Erstens mußte das Justizministerium im Zuge des Ausbaus des Justizwesens eine Reihe von geeigneten ,Kadern' abgeben: Neben Benjamin, Melsheimer und Heinze trifft dies auch auf Kurt Schmidt, der nach sei-

315 Siehe Beurteilung (Zeugnis) für Schindowski, 9. 10. 1951, BAB, DP1 SE Nr. 60; ein politischer Hintergrund ist nicht auszuschließen, denn ursprünglich sollte sie „mit Ablauf des 30.12.50 wegen personalpolitischer Maßnahmen" aus dem MdJ ausscheiden: siehe Karteikarte Schindowski, ebenda.

316 Gerda Grube, Wolfgang Mai und Kurt Schmidt.

317 Ausnahmen waren Herbert Burkhardt und Genrich, der nach seinem Ausscheiden aus der Personalabteilung im Februar 1952 bis zum 31.7. 1952 in der Hauptabteilung I blieb.

318 Koch hatte von Mai 1946 bis Sommer 1951 der LDP angehört; im MdJ war er seit dem 1.6. 1952: vgl. Kaderspiegel Kochs, BStU, MfS AP 11666/56, Bl. 89.

319 Vogel war seit dem 1. 8. 1952 im MdJ tätig; er gehörte von 1945 bis 1951 der LDP an; im März 1951 wollte er zur SED überzuwechseln, was allerdings so schnell nicht gelang: siehe Beurteilung über Vogel, 6. 1. 1954, Lebenslauf Vogels, o.D., BAB, DP1 SE Nr. 74. Vgl. auch Whitney, Advocatus Diaboli, S. 29.

320 Weitere Hauptreferenten in dieser Hauptabteilung waren Werner Artzt, Witold Deutsch, Rudolf Reinartz, Wolfgang Vogel, Gerhard Häusler, Kurt Görner und Gerhard Dillhöfer.

321 Dorothea (Belz-)Stolzenburg, Arthur Pannier und Erna Naumann. 
ner Tätigkeit in der Abteilung Schulung als stellvertretender Direktor an die Deutsche Hochschule der Justiz wechselte ${ }^{322}$, und auf Karl Kroll zu, der die Hauptabteilung III im März 1951 verließ, um Verwaltungsdirektor an der Zentralen Richterschule zu werden ${ }^{323}$. Zweitens mußten Abteilungsleiter Genrich sowie die Hauptreferentinnen Agnes Busch von der Personalabteilung ${ }^{324}$ und Dorothea Belz-Stolzenburg aus der Hauptabteilung $\mathrm{II}^{325}$ nachweislich aufgrund mangelnder fachlicher Eignung ausscheiden: Als Absolventen von Volksrichterschulen waren sie offensichtlich doch weniger qualifiziert als andere. Drei Volljuristen schieden - drittens - infolge von Flucht in die Bundesrepublik und nach WestBerlin aus: Neben Hans-Joachim Schoeps waren dies die Hauptreferenten Deutsch $^{326}$ und Liss $^{327}$ aus der Hauptabteilung I. Inwiefern genuin politische Gründe für ihre Flucht vorlagen, läßt sich nicht mehr feststellen. Die Karrieren von Helmut Brandt und Rudolf Pätzold schließlich endeten abrupt aufgrund von Prozessen vor DDR-Gerichten. Die häufigen Personalwechsel in den Führungsetagen des MdJ in der Ära Fechner stehen folglich in engem Zusammenhang mit der Aufbau- und Umbruchsituation dieser Jahre, in der zwar großer Bedarf an politisch und fachlich qualifizierten ,Kadern' herrschte, die neuen Kräfte jedoch teilweise ungeeignet waren und die alten sich entweder als politisch untragbar erwiesen oder die Chance zur Flucht in den Westen nutzten.

\section{Fechner als Justizminister und seine Personalpolitik im MdJ}

Obgleich er sich nicht besonders für seinen Posten eignete, blieb Fechner zwischen 1948 und 1953 in Amt und Würden. Gegen ihn sprachen seine mangelnde fachliche Kompetenz und seine Mißbilligung der rigorosen Strafpraxis, die in den fünfziger Jahren vor allem die politischen Strafverfahren der DDR prägte. So berief sich der Präsident des Oberlandesgerichts Dresden, Fritz Pogorschelsky, im September 1949 auf den DJV-Präsidenten, als er sich für die Aufhebung der Todesurteile im Glauchau-Meerane-Prozeß aussprach ${ }^{328}$. Auch bei einer Reihe von Urteilen in Verfahren nach Befehl Nr. 201 im Herbst 1949 war Fechner der Auffassung, daß die Justiz „über das zulässige Strafmaß hinausgegangen sei und man deshalb die Dinge noch einmal überprüfen müsse" ${ }^{329}$. Des weiteren kritisierte er

322 Schmidt war vom 1. 4. 1951 bis 29. 2. 1952 im MdJ: Beurteilung von Schmidt, 24. 11. 1952, BAB, DP1 SE Nr. 74.

${ }_{323}$ Siehe Protokoll der Sekretariatssitzung, 9. 3. 1951, SAPMO, DY 30 J IV 2/3/178, TOP 42.

324 Siehe Beurteilungen über Agnes Busch, 11. 7. 1952, 16. 4. 1953, BAB, DP1 SE Nr. 74. Busch war vom 1. 4. 1951 bis zum 25. 5. 1952 im MdJ tätig.

325 Siehe Böhme an Klühsendorf, 12. 3. 1953, BAB, DP1 SE Nr. 448; nach dem für sie ausgestellten Zeugnis vom 15. 4. 1953 schied sie „auf eigenen Wunsch“ aus, BAB, DP1 SE Nr. 74. Sie war vom 7.11. 1949 bis zum 30. 4. 1953 im MdJ tätig.

326 Mitteilung des MdJ an SKK, ZK, MdI und Herrn Böhm, 27. 12. 1951, BAB, DP1 VA Nr. 7621. Deutsch, seit dem 1.4. $1951 \mathrm{im}$ MdJ tätig, hatte sich am 27.11. 1951 nach West-Berlin begeben.

${ }^{327}$ Liss floh Ende April/Anfang Mai 1952: siehe Artzt an Fechner, 9. 5. 1952, Vermerk, 14. 5. 1952, in: Personalakte Liss, BAB, DP1 SE Nr. 90, Bl. 203 f., 220.

${ }^{328}$ Berger an Plenikowski, 17. 1. 1950, BStU, MfS AU 307/55, Bd. 5b, Bl. 61. Beim Prozeß von Glauchau-Meerane waren am 29.11. 1948 sechs der elf Angeklagten zum Tode verurteilt, aber auf Vorschlag des DDR-Justizministers am 19.11. 1949 zu lebenslanger Haft begnadigt worden: siehe Klawitter, Rolle der ZKK, S. 35 f.

${ }^{329}$ Aktenvermerk betr.: Justizminister Max Fechner, 19. 12. 1949, BStU, MfS AU 307/55, Bd. 7, Bl. 316. 
MdJ-intern im Februar 1951, daß bei der kurz zuvor erfolgten Verurteilung des Oberschülers Josef Flade ${ }^{330}$ aller Wahrscheinlichkeit nach „ein Druck auf das Gericht ausgeübt worden ist“; gleichzeitig wandte er sich gegen die Tendenz der Richter in der DDR, sich mit ihren Urteilen gegen die Zeugen Jehovas an den vom Obersten Gericht verhängten hohen Haftstrafen ${ }^{331}$ zu orientieren ${ }^{332}$. Darüber hinaus ist überliefert, daß er bei dem Prozeß gegen den Konsumverband Brandenburg im Frühsommer 1952 sogar versuchte, die Verteidigung der Angeklagten zu unterstützen ${ }^{333}$. Schließlich nutzte er einmal seine Position als Justizminister, um der Politisierung der Richter und Staatsanwälte in der Fortbildung entgegenzuarbeiten, indem er einen Dozenten im November 1951 mahnte: „Macht mir meine Richter nicht zu scharf.“ 334

Seinen mitunter kritischen Worten ließ er freilich keine Taten folgen. Eine wesentliche Ursache dafür waren die ihm mehrfach attestierten mangelhaften Fachkenntnisse ${ }^{335}$. Da er, wie er selbst zugab, nichts tat, um sich juristisch weiterzubilden ${ }^{366}$, war er seinen Mitarbeitern völlig ausgeliefert. Seine Reden und Referate wurden ihm von Scheele oder dem zuständigen Hauptabteilungsleiter - oftmals Böhme - ausgearbeitet; als er sie dann hielt, wurde den fachlich vorgebildeten $\mathrm{Zu}$ hörern klar, daß er nichts von dem verstand, was er sagte ${ }^{337}$. Der auch im Westen vorherrschende, durchaus zutreffende Eindruck, Fechner mache „zwar alles mit, was von ihm verlangt wird, ohne aber selbst Böses zu ersinnen" 338 , war des weiteren auf seine Eitelkeit und sein starkes Geltungsbedürfnis zurückzuführen. Dies äußerte sich zunächst in einem fast krankhaften Streben nach öffentlicher Anerkennung, das wohl einem Minderwertigkeitsgefühl gegenüber den SED-Juristen sowie den Benachteiligungen entsprang, denen er als ehemaliger Sozialdemokrat ausgesetzt war. Mehrfach versuchte er, von einer der juristischen Fakultäten die Ehrendoktorwürde verliehen zu bekommen, war dabei jedoch aufgrund von $\mathrm{W}_{1-}$ derständen in der SED-Führung nie erfolgreich ${ }^{339}$. Auch sein Vorhaben, die Zen-

330 Flade wurde am 10. 1. 1951 vom Landgericht Dresden zum Tode verurteilt; auf seine Revision hin wurde das Urteil in eine fünfzehnjährige Zuchthausstrafe umgewandelt: siehe Unrecht als System I, S. $58 \mathrm{f}$.

331 Am 4. 10. 1950 waren vom Obersten Gericht in einem Prozeß gegen neun Mitglieder der Zeugen Jehovas folgende Urteile verkündet worden: zweimal lebenslänglich, dreimal 15 Jahre, einmal 12 Jahre, zweimal zehn Jahre und einmal acht Jahre Zuchthaus. Vgl. Beckert, Instanz, S. 226.

332 Vermerk Böhmes für Kulaszewski, 24. 2. 1951, SAPMO, DY 30 IV 2/11/V1386, Bl. 49.

333 Vgl. Braun, Zentrale Kommission für Staatliche Kontrolle, S. 20.

334 Anonymes Dokument über Fechner, o.D., vermutlich von Gerda Grube, BStU, MfS AU 307/55, Bd. 7, Bl. 290.

335 Vgl. u.a. Aktenvermerk betr.: Rücksprache von Blumenstein mit Böhme und Grube, 28. 7. 1953, BStU, MfS AU 307/55 (EV), Bd. 1, Bl. $57 \mathrm{f}$.

336 Vernehmungsprotokoll, 30.7.1953, ebenda, Bl. 63.

337 Bericht, 19.11. 1953, AdsD, Ostbüro Nr. 0048a.

338 Vgl. SED-Juristen unter sich, in: Informationsbrief des UfJ, 1. 3. 1952, S. 199.

${ }^{339}$ Fechner strebte 1949 die Ehrendoktorwürde der Universität Halle an; nachdem das Politbüro davon erfahren hatte, gab Fechner vor, ihm sei "an der ganzen Sache gar nichts gelegen"; nach einer Unterredung mit Grotewohl lehnte er am 20. 5. $1949 \mathrm{ab}$ : Vermerk betr. Anruf von Benjamin, 3. 5. 1949, Kling an Dahlem, 3. 5. 1949, SAPMO, DY 30 IV 2/11/V1386, Bl. 126 f.; Protokoll der Politbürositzungen am 10. und 25. 5. 1949, SAPMO, DY $30 \mathrm{~J}$ IV 2/2/22 und 24, TOP 8, TOP 6; Fechner an Grotewohl, 20. 5. 1949, SAPMO, DY 30 IV 2/11/V1386, Bl. 123. Am 24. 2. 1950 lehnte das Sekretariat die Verleihung des Ehrendoktortitels an Fechner durch die Universität Jena ab, SAPMO, DY 30 J IV 2/3/87, TOP 17. Am 16. 7. 1951 erörterte das Sekretariat die Ernennung Fechners zum Ehrendoktor der Universität Berlin und entschied: „Fechner ist zu überzeugen, daß 
trale Richterschule mit seinem Namen zu versehen, scheiterte. Denn der angeblich auf die Schüler des Teillehrgangs Halle, tatsächlich aber auf Fechner zurückgehende Vorschlag wurde von der Abteilung Staatliche Verwaltung beim ZK in einem Telegramm zurückgewiesen, das den Justizminister während der Eröffnung der Richterschule am 5. Juni 1950 erreichte. Fechner fühlte sich zutiefst gekränkt und äußerte anschließend gegenüber Götz Berger, „daß eine derartige Maßnahme ihn als früheren Angehörigen der SPD getroffen habe" 340 . Sein Verweis auf Ulbricht als Namensgeber der „Deutschen Verwaltungsakademie“ zeigt, daß er dem anderen stellvertretenden SED-Vorsitzenden nicht nachstehen wollte. Er erreichte lediglich, daß die am 1. September 1951 eröffnete Zentrale Rechtspflegerschule in Halle (ab 1952 in Weimar-Ettersburg) seinen Namen trug 341 . Auch innerhalb des Ministerrats und in der Volkskammer wollte Fechner sich profilieren, da er "den allergrößten Wert darauf legte“, neue Justizgesetze, an deren Erarbeitung er keinerlei Anteil gehabt hatte, dort zu begründen ${ }^{342}$.

Seine mangelnde fachliche Qualifizierung und sein Geltungsbedürfnis prägten auch Fechners Verhalten im Justizministerium. Einerseits konnte er, da er die Arbeit des Ministeriums inhaltlich kaum zu beurteilen vermochte, keine fachliche Anleitung geben und überließ die Dinge „dem Selbstlauf“, was zu einer familiärgemütlichen, zum Schlendrian neigenden Arbeitsatmosphäre führte ${ }^{343}$. Andererseits beharrte er - wohl auch aufgrund seiner Unsicherheit - auf seiner formalen Autorität als Minister, etwa im Umgang mit der ZK-Abteilung oder mit dem Obersten Gericht, und bestand darauf, daß er für die Kontakte des Ministeriums ,nach außen' zuständig war ${ }^{344}$. Auch Fechners Engagement in Schulungsangelegenheiten diente insbesondere der Vermehrung seines Ansehens. Richterlehrgänge waren „sein großes Propagandaobjekt“, bei denen er mit Eröffnungs- oder Abschlußreden glänzen wollte und sich bei spektakulären Vorkommnissen einschaltete ${ }^{345}$. Angesichts der Schwierigkeiten Fechners in seinem Ministerium, der zahlreichen Düpierungen und seiner Benachteiligungen innerhalb der SED griff er zunehmend zur Flasche, und sein Alkoholkonsum wurde, insbesondere auf Abendveranstaltungen, zu einem Problem für die DDR-Führung 346 . Trotz Ausfällen bei solchen Gelegenheiten und deutlicher Kritik an der Arbeit des Justizministeriums Ende 1951/Anfang 1952 blieb Fechner im Amt und war, wie zwei aus-

er eine solche Ehrung erst zu seinem 60. Geburtstag entgegennimmt.“ Arbeitsprotokoll der Sekretariatssitzung, SAPMO, DY 30 J IV 2/3/A199, TOP 22.

${ }_{340}$ Siehe Bericht Paul Kienbergs betr. Fechner, 15. 6. 1950, BStU, MfS AU 307/55, Bd. 7, Bl. 311;

Notiz Bergers, 8. 6. 1950, SAPMO, DY 30 IV 2/11/V1386, Bl. 117.

${ }^{341}$ Siehe dazu Erinnerungen Max Fechners, 30. 1. 1965, SAPMO, SgY 30 1274, Bl. $55 \mathrm{f}$.

342 Anonymes Dokument über Fechner, o.D., vermutlich von Gerda Grube, BStU, MfS AU 307/55, Bd. 7, Bl. 288.

${ }^{343}$ Vernehmungsprotokoll, 30. 7. 1953, BStU, MfS AU 307/55 (EV), Bd. 1, Bl. 63; Betr. Fechner, o.D., BStU, MfS AU 307/55 (HA/GA), Bd. 1, Bl. 36. Vgl. Brentzel, Machtfrau, S. 245; Feth, Benjamin, S. 132.

${ }^{344}$ Siehe oben, S. 251 und Kap. B.VIII.3.

345 Anonymes Dokument über Fechner, o.D., vermutlich von Gerda Grube, BStU, MfS AU 307/55, Bd. 7, Bl. 287 f. Siehe Kap. B.IV.2.

${ }_{346}$ Fechner galt bereits vor 1949 als Trinker: vgl. Bouvier/Schulz, SPD, S. 79. Zur Zeit danach vgl. die Berichte von Hilde Neumann, 5. 9. 1951, von Willy Kulaszewski, 15. 12. 1950, SAPMO, DY 30 IV 2/11/V1386, Bl. 111, 112-115, und von Weiß, 29. 7. 1951, BStU, MfS AIM 6279/57 T.II, Bl. 13. 
gesprochen schmeichlerische Schreiben an Ulbricht aus dem Jahre 1951 zeigen $^{347}$, sehr darauf bedacht, es sich mit dem starken Mann in der SED-Führung nicht zu verderben, von dem sein politisches Überleben maßgeblich abhing. Mindestens genauso wichtig war ihm ein gutes Verhältnis zur SKK, das er, wie zwei Quellen unabhängig voneinander berichten, stets aufrechtzuerhalten trachtete. Ja, er setzte anscheinend auf die Unterstützung Semjonows und, ab April 1953, Pawel Judins, die ihm angeblich erklärten, daß ihm ,im Rahmen der Deutschlandpolitik große Aufgaben übertragen würden (vor allem Verbindung zur SPD und zu den Gewerkschaften) und daß bald der Zeitpunkt käme, in dem Benjamin abgesetzt würde“348. Inwiefern dies der Realität entspricht, muß offenbleiben; sicher scheint jedoch, daß Fechner gerade in der Krisensituation von 1953 mit den „Freunden“ rechnete.

Die Behauptung, Fechner sei „in seiner ganzen Denk- und Handlungsweise durch und durch Sozialdemokrat geblieben " 349 , läßt sich vor allem auf seine Personalpolitik im MdJ beziehen, die darauf hinauslief, ehemalige Sozialdemokraten $\mathrm{zu}$ fördern und $\mathrm{zu}$ beschützen ${ }^{350}$, Kommunisten hingegen $\mathrm{zu}$ behindern und, wenn möglich, zu verdrängen 351 . Die für Fechner ungünstige Ausgangssituation verbesserte sich schlagartig, als mit der Errichtung des Obersten Gerichts und der Obersten Staatsanwaltschaft Benjamin und Melsheimer ausschieden. Seit Herbst 1950 verließen dann nicht nur Heinze und Weiß das MdJ, sondern auch die eindeutig als Fechner-Gegner einzuschätzenden Erwin Reisler und Josef Streit ${ }^{352}$, so daß Anfang 1952 nur noch Nathan übrig blieb. Als auch dieser zum 30. März 1952 aus dem Justizministerium ausschied, war keiner der ursprünglichen Gegenspieler Fechners mehr im Amt ${ }^{353}$. Die Verbesserung seiner Position im MdJ durch die Heranziehung ihm ergebener Mitarbeiter gelang ihm jedoch nur teilweise. Eines seiner ersten Vorhaben, den ehemaligen Sozialdemokraten Kurt Richter zum Leiter der Personalabteilung zu befördern ${ }^{354}$, scheiterte, und er mußte den Kommunisten Franz Genrich akzeptieren. Demgegenüber konnte er durch die Heranziehung von Kurt Pauli zum Leiter der Verwaltungsabteilung und durch die Beförderung von Schoeps zum Leiter der Abteilung Schulung wenigstens zwei Posten in der Leitungsebene mit Männern seines Vertrauens besetzen ${ }^{355}$. Nach dem Ausscheiden Heinzes nutzte Fechner die Situation, um den ehemaligen Sozialdemokraten Fritz Böhme, der später zu seinen engen Vertrauten zählte, mit der Leitung

${ }^{347}$ Siehe Fechner an Ulbricht, 3.2., 3. 5. 1951, BAB, DP1 SE Nr. 3360, Bl. 573, DP1 VA Nr. 5806.

348 Vgl. Darlegungen Scheeles, BStU, MfS AU 307/55, Bd. 6, Bl. 173 f.; Bericht, 19. 11. 1953, AdsD, Ostbüro Nr. 0048a (dort das Zitat).

349 Ebenda.

350 Fechner bewahrte sogar einen ehemaligen Sozialdemokraten in seinem Ministerium, Kirchhoff, vor dem Parteiausschluß: Vernehmungsprotokoll Fechner, 10.8. 1953, BStU, MfS AU 307/55, Bd. 1, Bl. 97 f.; Vermerk für Pleni[kowski], 14. 11. 1951, ebenda, Bd. 5b, Bl. 142-146.

351 Vernehmungsprotokoll Brandt, 23. 6. 1952, BStU, MfS AU 449/54, Bd. 3, Bl. 270. Brandt zitiert Fechners Worte: „Die [Kommunisten] kriege ich schon raus."

352 Siche ebenda; Reisler wechselte zum Jahreswechsel 1950/51 zum ZK der SED, Streit am 30. 4.1951 zur Obersten Staatsanwaltschaft.

353 Vgl. die Auflistung im Bericht von Weiß über das Justizministerium, BStU, MfS AIM 6279/57 T.II, Bl. 9.

${ }^{354}$ Vernehmungsprotokoll Brandt, 23. 6. 1952, BStU, MfS AU 449/54, Bd. 3, Bl. 270; Bericht, 19. 11. 1953, AdsD, Ostbüro Nr. 0048a.

355 Vernehmungsprotokoll Brandt, 23. 6. 1952, BStU, MfS AU 449/54, Bd. 3, Bl. 270 f. 
der Hauptabteilung II zu betrauen ${ }^{356}$. Im Verlauf der Zeit vermochte er es zudem, auch andere, nicht-sozialdemokratisch vorgeprägte Personen sich zu verpflichten: $\mathrm{Zu}$ diesem Kreis zählten der 1951 noch als schwankend geltende Rudolf Reinartz $^{357}$, die ehrgeizige Julie Ganske und Heinrich Reuter (alle aus der Hauptabteilung II) sowie Gerhard Häusler aus der Hauptabteilung I358. Trotz des Ausbaus seiner Position bestand bis zum Ende von Fechners Amtszeit eine unter der Führung Gerda Grubes stehende gegnerische Gruppierung fort, die vor allem zum Sektor Justiz beim ZK sowie zu seiner Rivalin Hilde Benjamin enge Beziehungen unterhielt.

Das Ende der Ära Fechner wurde nach dem Aufstand vom 17. Juni 1953 durch ein Interview des Justizministers mit dem „Neuen Deutschland“ am 30. Juni eingeleitet, in dem er das Streikrecht als „verfassungsmäßig garantiert“ bezeichnete und den Streikführern Straffreiheit zusagte. Aufgrund dieser Äußerungen wurde er am 15. Juli verhaftet, seines Amtes enthoben und vom Obersten Gericht am 24. Mai $1955 \mathrm{zu}$ acht Jahren Zuchthaus verurteilt ${ }^{359}$. Die Spaltung des MdJ in zwei sich einander befehdende Gruppierungen hatte zur Folge, daß der Amtsantritt seiner Nachfolgerin Hilde Benjamin am 17. Juli von einem Teil der Mitarbeiter freudig begrüßt wurde, einem anderen Teil aber „die Schweißperlen auf der Stirn [standen]“ ${ }^{360}$. Dies war durchaus gerechtfertigt, denn Benjamin bereitete nicht nur dem Arbeitsstil der vergangenen Jahre ${ }^{361}$, sondern auch den von Fechner wesentlich mit herbeigeführten personellen Verhältnissen im Justizministerium ein rasches Ende. Daß sein persönlicher Referent Scheele, der ebenfalls verhaftet und vom MfS verhört wurde, das MdJ verlassen mußte, verstand sich von selbst ${ }^{362}$. Des weiteren standen der bei der Gruppenbildung im Ministerium nicht weiter aufgefallene Hauptabteilungsleiter Artzt sowie Reinartz auf der ,Abschußliste“ von Hilde Benjamin. Artzt entkam ihrer Verfolgung, da Grotewohl und dessen Staatssekretär Fritz Geyer ihn zum 30. September als Hauptabteilungsleiter in die Regierungskanzlei holten ${ }^{363}$. Reinartz, dem vorgeworfen wurde, zu Unrecht Honorare für den Abdruck von Referaten in der „Neuen Justiz“ kassiert zu haben,

356 Siehe ebenda und Aktenvermerk über Unterredung mit Klühsendorf, 26. 2. 1954, BStU, MfS AU 307/55, Bd. 2, Bl. 59. Böhme zählte somit zu den wenigen Personen, die zu Benjamin und zu Fechner gleichermaßen gute Beziehungen unterhielten.

357 Bericht von Weiß über Reinartz, 9. 11. 1951, BStU, MfS AIM 6279/57 T.II, Bl. $26 f$.

358 So die Auflistung von Klühsendorf, BStU, MfS AU 307/55, Bd. 2, Bl. 60. Zu Reuters Zugehörigkeit zur „Fechner-Gruppierung“ siehe Bericht, 19.11. 1953, AdsD, Ostbüro Nr. 0048a.

359 Vgl. dazu Amos, Justizverwaltung, S. 131-137, Beckert, Instanz, S. 153-175, und Suckut, Als wir in den Hof.

360 Benjamin an Titow, 22. 7. 1953, BAB, DP1 SE Nr. 1217; zur Nervosität Reuters und Emil Sommers siehe die Berichte Glücks, 16.7., 20. 7. 1953, BStU, MfS AIM 6725/89c, T.II, BI. 53 f., $58 \mathrm{f}$.

$361 \mathrm{Vgl}$. dazu u.a. Brentzel, Machtfrau, S. $245 \mathrm{f}$.; ein MdJ-Angestellter fühlte sich an den Ton „beim Kommiß" erinnert: Bericht Glücks, 17. 7. 1953, BStU, MfS AIM 6725/89c, T.II, BI. 39.

${ }^{362} \mathrm{Er}$ machte in seiner Haft ausführliche Angaben über Fechner und wurde am 7.8. 1953 entlassen: Marginal Mielkes auf dem MfS-Bericht über die Aufhebung der Internierung von Scheele, 3. 8. 1953, BStU, MfS AU 307/55, Bd. 6, Bl. 73. Anschließend war er als Dozent für Marxismus-Leninismus am Institut für Lehrerbildung in Köpenick, von 1955 bis 1970 als Direktor der Sektion für Marxismus-Leninismus an der PH Potsdam tätig: siehe SAPMO, SgY 30 1721, Bl. 36.

${ }^{363}$ Siehe Bericht, 19.11. 1953, AdsD, Ostbüro Nr. 0048a; Protokoll der Sekretariatssitzung, 16. 9. 1953, SAPMO, DY 30 J IV 2/3/399, TOP 15. Artzt ging von dort am 1.6. 1954 zur Deutschen Akademie für Staat und Recht, wo er am 1. 10. 1954 Direktor des Instituts für Zivilrecht wurde: siehe DASR an MdJ, 6. 7. 1954, BAB, DP1 SE Nr. 74, Breithaupt, Rechtswissenschaftliche Biographie, S. 178. 
entzog sich einer für den 26. Oktober angesetzten Parteileitungssitzung im MdJ, auf der sein Fall zur Sprache kommen sollte, durch Flucht nach West-Berlin in der Nacht vom 24. auf den 25. Oktober ${ }^{364}$. Auch die beiden Fechner-Anhänger unter den Hauptreferenten aus der Hauptabteilung Rechtsprechung mußten das MdJ verlassen. Während Ganske zum 12. August an das Bezirksgericht Halle versetzt wurde ${ }^{365}$, ging Reuter zum 12. Oktober an das Bezirksgericht Suhl. Wenngleich er sich dort als Oberrichter im Sinne des Regimes bewährte, verließ er - wohl aus privaten Gründen - Ende August 1954 die DDR in Richtung Westen ${ }^{366}$. Der Leiter der Personalabteilung, Klühsendorf, der nicht der Fechner-Gruppierung zugerechnet wurde, mußte dennoch zum 31. Dezember 1953 aus dem MdJ ausscheiden, da er angeblich „für die Leitung einer Personalabteilung in keiner Weise ausreichende Kenntnisse und Fähigkeiten" besaß, und ging als Bezirksstaatsanwalt nach Frankfurt an der Oder 367 . Benjamin, die seit ihrer Betätigung in der DJV hohe Ansprüche an die „Kaderpolitik“ stellte, wollte offensichtlich die in diesem Bereich unter Fechner eingerissenen Nachlässigkeiten beseitigen und hier eine Person ihres Vertrauens einsetzen. Die einzigen im MdJ verbleibenden Hauptabteilungs- und Abteilungsleiter waren Gerda Grube, Fritz Böhme und der erst im März 1953 ernannte Leiter der Abteilung Notariat und Rechtsanwaltschaft Rolf $\mathrm{Helm}^{368}$. Der CDU-Staatssekretär Heinrich Toeplitz, dem ein gutes Verhältnis zu Fechner nachgesagt wurde ${ }^{369}$, erwies sich als äußerst anpassungsfähig und konnte daher ebenfalls in seinem Amt bleiben.

Die Umwandlung der DJV zum MdJ bedurfte erheblicher Anstrengungen. Am Ende dieses Prozesses war die Struktur des MdJ gegenüber der auf das preußische Justizministerium zurückgehenden Organisation der DJV grundlegend verändert worden. Als Motor des strukturellen und personellen Wandels hatte zunächst die SED gedient, die ihre Ziele nur in enger Kooperation mit der SMAD-Rechtsabteilung erreichte. Während die Sowjetische Kontrollkommission mit ihrer Justizabteilung nach 1949 zwar weiterhin eingriffsberechtigt blieb, war ihre nachweisbare Einflußnahme insbesondere auf die Personalpolitik und den Strukturwandel im MdJ gering. Demgegenüber wurde die prinzipielle Überordnung des SED-Apparats über das MdJ - insbesondere im Hinblick auf die Zusammensetzung des Per-

364 Bericht über Reinartz, 7.10. [sic, wohl 11.] 1953, BStU, MfS AU 386/55, Bd. 1, Bl. 66 f.; vgl. Whitney, Advocatus Diaboli, S. 35, und Fricke/Engelmann, Konzentrierte Schläge, S. $149 \mathrm{f}$. Reinartz, der u.a. dem UfJ und dem SPD-Ostbüro Interna aus dem DDR-Justizwesen mitteilte, kehrte am 4. 2. 1955 nach Ost-Berlin zurück, da er im Westen nicht als politischer Flüchtling anerkannt wurde: Horst Schumann an Ulbricht, 12. 12. 1954, BStU, MfS AU 386/55, Bd. 1, Bl. 106. Er wurde umgehend verhaftet und am 22. 8. 1955 vom Bezirksgericht Rostock zu lebenslanger Haft verurteilt. Am 17. 9. 1965 freigekauft, begab er sich in die Bundesrepublik, wo er im Dezember 1972 Selbstmord beging: Fricke/Engelmann, Konzentrierte Schläge, S. 150, 157-159.

365 Benjamin an Ganske, 12. 8. 1953, Personalakte Ganske, BAB, DP1 SE Nr. 74.

366 Siehe Beurteilung von Reuter durch die Kaderabteilung der Justizverwaltungsstelle Suhl, 28.7. 1954; Reuter an MdJ, 3. 3. 1954, Antrag auf Abberufung Reuters, 26. 8. 1954, Personalakte Reuter, BAB, DP1 SE Nr. 169.

$367 \mathrm{MdJ}$ an Staatssekretariat für Innere Angelegenheiten, 1. 12. 1953, BAB, DP1 VA Nr. 5599; siehe auch MdJ-Kaderabteilung an Rechtsabteilung des Hohen Kommissars, 19.11. 1953, BAB, DP1 VA Nr. 7621; Hilde Benjamin, Arbeitsbericht für das Jahr 1953, BAB, DP1 SE Nr. 3145, Bl. 807; Aktenvermerk über Unterredung mit Klühsendorf, 26. 2. 1954, BStU, MfS AU 307/55, Bd.2, Bl. 57.

368 Siehe Helm, Anwalt des Volkes, S. 207.

369 Bericht Scheeles, BStU, MfS AU 307/55 Bd. 6, Bl. 174. 
sonals - festgeschrieben und formalisiert; von ihrer Kontroll- und Weisungsbefugnis machten SED-Führung und MdI indes nur selten Gebrauch, wenn man einmal von der allgemeinen Parteiüberprüfung und dem "Justizbeschluß" im Jahre 1951 absieht. Dies führte dazu, daß nach dem Übergang des - bereits kommunistisch dominierten - Führungspersonals der DJV zum MdJ die Stellenbesetzungen innerhalb des Ministeriums sehr viel mehr von Sachzwängen diktiert wurden als von SED- oder MdI-Entscheidungen und daß, solange er sich an die Vorgabe hielt, die leitenden Positionen fast ausschließlich mit SED-Genossen zu besetzen, Fechner ein gewisses Maß an Handlungsfreiheit besaß. Die Personalveränderungen in der Führungsebene von DJV und MdJ sind mithin nur in ihrer ersten Phase (1948/49) auf die Durchsetzung des kommunistischen Führungsanspruchs ausgerichtet. In der zweiten, in den Jahren 1949/50 verlaufenden Phase ging es um den personellen Aus- und Umbau im Zeichen der DDR-Gründung, während die dritte Phase des Personalaustauschs (1950-1952) sowohl unter dem Gesichtspunkt der Konsolidierung als auch unter dem Aspekt der persönlichen Einflußnahme Fechners zu sehen ist. 